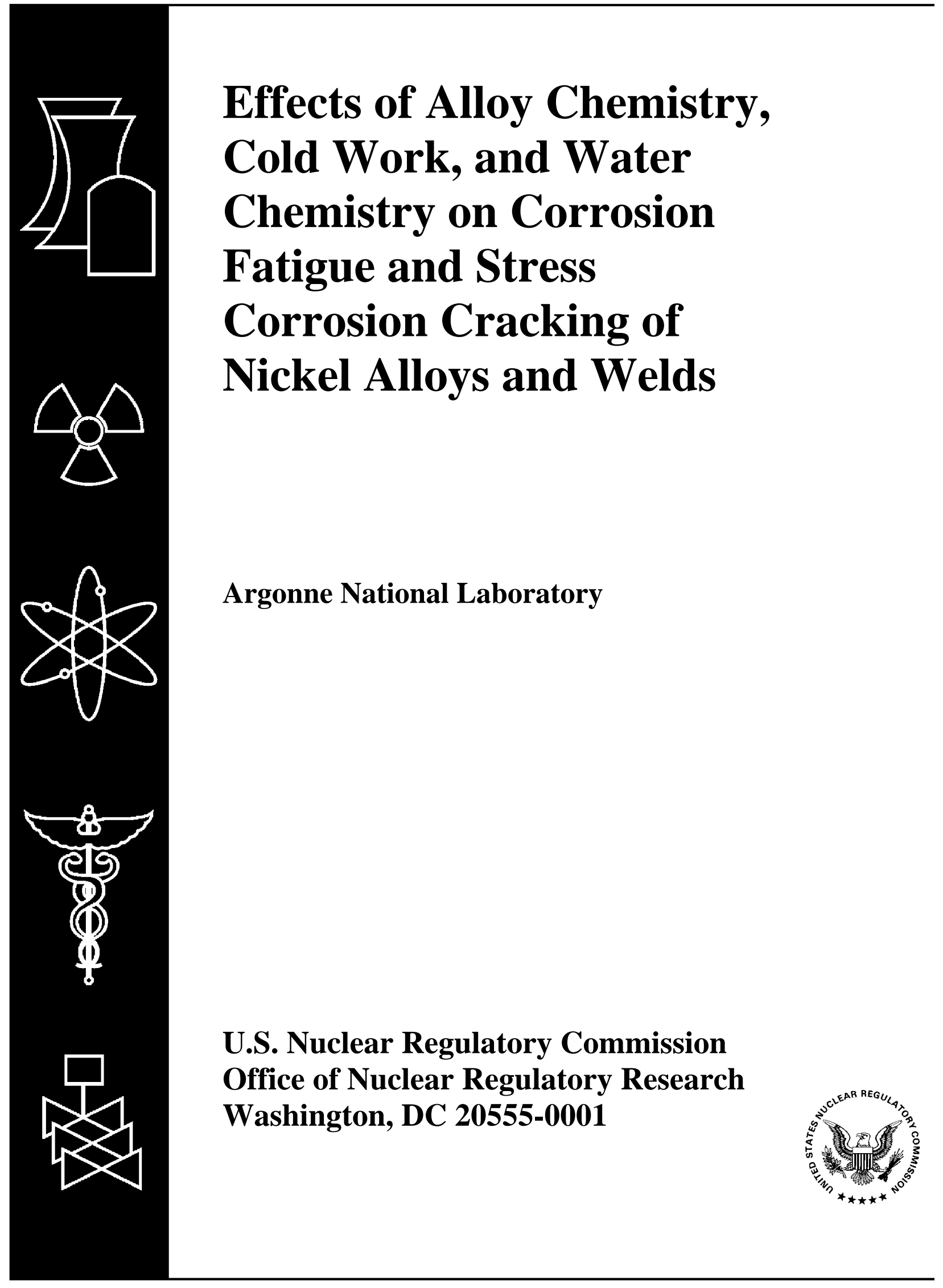


NUREG/CR-6721

ANL-01/07

\section{Effects of Alloy Chemistry, Cold Work, and Water Chemistry on Corrosion Fatigue and Stress Corrosion Cracking of Nickel Alloys and Welds}

Manuscript Completed: March 2001

Date Published: 2001

Prepared by

O. K. Chopra, W. K. Soppet, and W. J. Shack

Argonne National Laboratory

9700 South Cass Avenue

Argonne, IL 60439

M. B. McNeil, NRC Project Manager

Prepared for

Division of Engineering Technology

Office of Nuclear Regulatory Research

U.S. Nuclear Regulatory Commission

Washington, DC 20555-0001

NRC Job Code W6610 



\title{
Effects of Alloy Chemistry, Cold Work, and Water Chemistry on Corrosion Fatigue and Stress Corrosion Cracking of Nickel Alloys and Welds
}

by

\author{
O. K. Chopra, W. K. Soppet, and W. J. Shack
}

\begin{abstract}
Reactor vessel internal components made of nickel-base alloys are susceptible to environmentally assisted cracking (EAC). A better understanding of the causes and mechanisms of this cracking may permit less conservative estimates of damage accumulation and requirements on inspection intervals. The objective of this work is to evaluate and compare the resistance of Alloys 600 and 690 and their welds, such as Alloys 82, 182, 52, and 152 , to EAC in simulated light water reactor environments. The existing crack growth rate (CGR) data for these alloys under cyclic and constant loads have been evaluated to establish the effects of alloy chemistry, cold work, and water chemistry. The experimental fatigue CGRs are compared with CGRs that would be expected in air under the same mechanical loading conditions to obtain a qualitative understanding of the degree and range of conditions for significant environmental enhancement in growth rates. The existing stress corrosion cracking (SCC) data on Alloys 600 and 690 and Alloy 82, 182, and 52 welds have been compiled and analyzed to determine the influence of key parameters on growth rates in simulated PWR and BWR environments. The SCC data for these alloys have been evaluated with correlations developed by Scott and by Ford and Andresen.
\end{abstract}




\section{Contents}

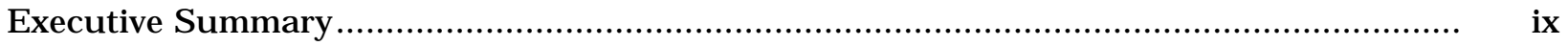

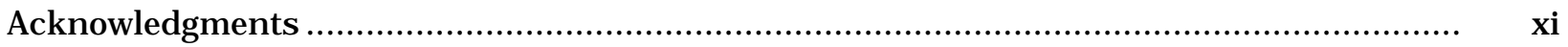

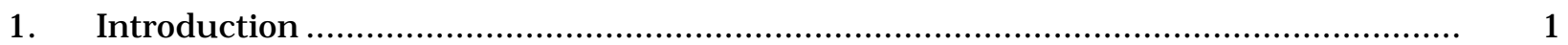

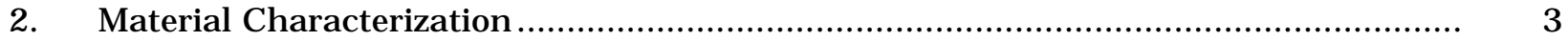

3. Fatigue Crack Growth Rates in Air............................................................... 5

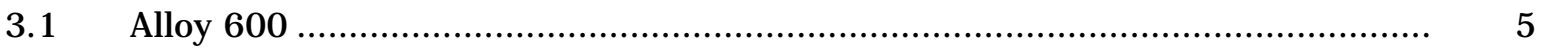

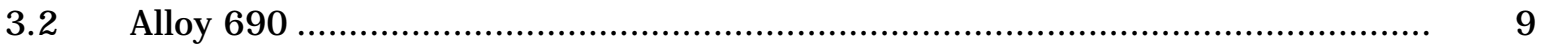

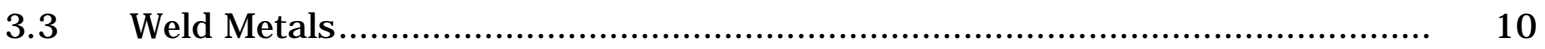

4. Fatigue Crack Growth in LWR Environments................................................... 13

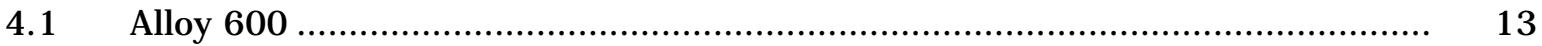

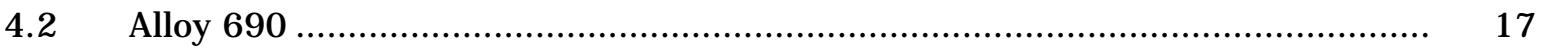

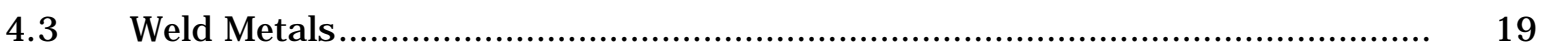

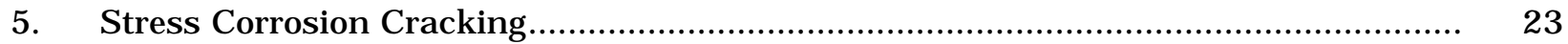

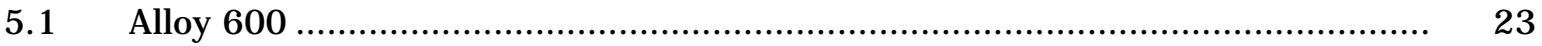

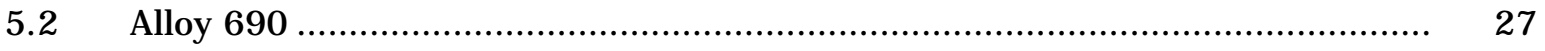

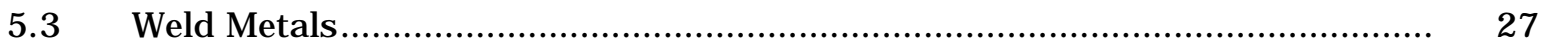

6. Crack Growth Rates Correlations................................................................. 35

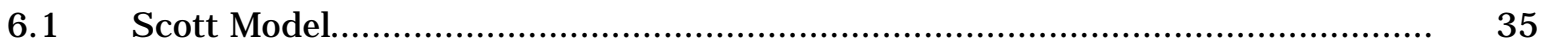

6.2 Film Rupture/Slip Oxidation Model......................................................... 35

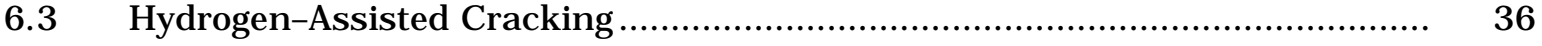

6.4 Comparisons with Experimental Data ................................................. 37

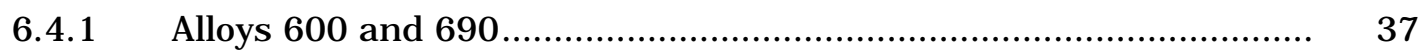

6.4.2 Ni Alloy Welds .................................................................. 40

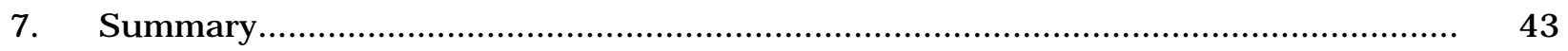

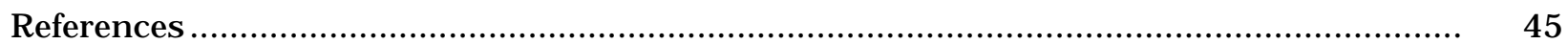




\section{Figures}

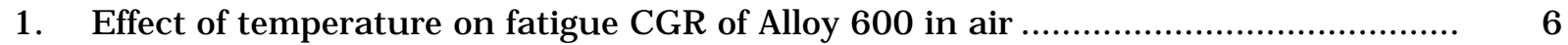

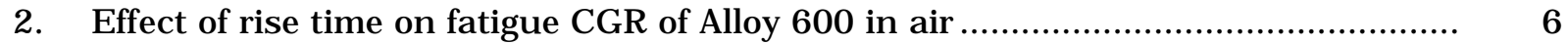

3. Variation of function C for Alloy 600 with temperature …................................. 7

4. Variation in product of functions $\mathrm{C}(\mathrm{T})$ and $\mathrm{S}(\mathrm{R})$ with load ration $\mathrm{R}$ at room temperature and 289 and $320^{\circ} \mathrm{C}$

5. Estimated-vs.-experimental values of fatigue crack growth rate of Alloy 600 in

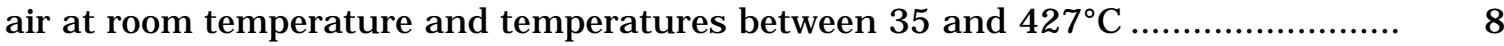

6. Variation of function $\mathrm{C}$ for Alloy 690 with temperature …................................... 9

7. Estimated-vs.-experimental values of fatigue crack growth rate of Alloy 690 in

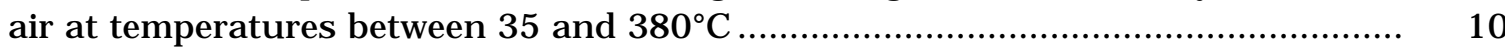

8. Experimental values of fatigue crack growth rate of Alloy 182 in air and those estimated for Alloy 600 under the same loading conditions ....

9. Corrosion fatigue data for Alloy 600 in high-purity water with $300 \mathrm{ppb} \mathrm{DO}$ at $289^{\circ} \mathrm{C},>6 \mathrm{ppm} \mathrm{DO}$ at $289^{\circ} \mathrm{C}$, and $>6 \mathrm{ppm} \mathrm{DO}$ at $320^{\circ} \mathrm{C}$.

10. Corrosion fatigue data for Alloy 600 in high-purity water with $<10 \mathrm{ppb}$ dissolved oxygen at 320,289 , and $240^{\circ} \mathrm{C}$

11. Dependence of CGRs of Alloy 600 at 289 and $320^{\circ} \mathrm{C}$ on concentration of dissolved hydrogen in simulated PWR water at load ratio of 0.8

12. Corrosion fatigue data for Alloy 690 in high-purity water with $\approx 6000$ or $300 \mathrm{ppb}$ dissolved oxygen at 320 and $289^{\circ} \mathrm{C}$.

13. Corrosion fatigue data for Alloy 690 in high-purity water with $<10 \mathrm{ppb}$ dissolved oxygen at 320,289 , and $240^{\circ} \mathrm{C}$

14. Corrosion fatigue data in simulated PWR water at $243-345^{\circ} \mathrm{C}$ for Alloys 182 , 82 , and 52

15. Corrosion fatigue data for Alloy 182 in high-DO water at $288^{\circ} \mathrm{C}$.

16. Effects of applied stress intensity and cold work on CGRs in Alloy 600 in simulated PWR water at $330^{\circ} \mathrm{C}$

17. Effect of temperature on CGRs of Alloy 600 in PWR environment

18. Effect of cold work on CGRs in Alloy 600 in simulated PWR water at 340 and $350^{\circ} \mathrm{C}$

19. Effects of applied stress intensity and sulfate additions on CGRs in Alloy 600 in BWR water with $\mathrm{NWC}$ at $288^{\circ} \mathrm{C}$ 
20. Effect of temperature on crack growth rates of Alloy 600 in high-dissolved oxygen high-purity water

21. Effect of applied stress intensity on crack growth rates in Alloy 690 in high-purity water at $290^{\circ} \mathrm{C}$.

22. Effects of crack orientation relative to the weld dendrites and stress relief on SCC CGRs in Alloy 182 welds in simulated PWR environment

23. Effect of crack orientation relative to weld dendrites on CGRs in Alloy 182 welds in BWR environment with normal water chemistry.

24. Effect of sulfate addition on CGRs in Alloy 182 welds in BWR environment.

25. Effect of sulfate-bearing NWC and HWC on CGRs in Alloy 182 welds

26. Effect of carbide stabilization parameter on CGRs in Alloy 182 welds in BWR environment with normal water chemistry

27. Effect of thermal treatment on SCC CGRs in Alloy 182 welds at $288^{\circ} \mathrm{C}$ in NWC and NWC with $0.1 \mathrm{ppm}$ sulfates.

28. Effect of thermal treatment on SCC CGRs in Alloy 182 welds at $275^{\circ} \mathrm{C}$ in NWC ......

29. SCC susceptibility of Alloy 82 welds in PWR environment at $360^{\circ} \mathrm{C}$ and BWR NWC with 170-550 ppb DO.

30. Effect of applied stress intensity on CGRs in Alloy 600 in simulated PWR or low-DO water at $290-360^{\circ} \mathrm{C}$.

31. Effect of applied stress intensity on CGRs in Alloy 600 in high-purity water with $\approx 300 \mathrm{ppb} \mathrm{DO}$ at 290 and $320^{\circ} \mathrm{C}$

32. Effect of applied stress intensity on CGRs in Alloy 182 weld in high-purity water with $50 \mathrm{ppb}$ or higher $\mathrm{DO}$ at $288^{\circ} \mathrm{C}$

33. Effect of applied stress intensity on CGRs in Alloy 182 weld in simulated PWR water at $290-345^{\circ} \mathrm{C}$ 


\section{Tables}

1. Nominal chemical composition (wt.\%) of various nickel alloys .............................. 3 


\section{Executive Summary}

Reactor vessel internal components made of Ni-base alloys are susceptible to environmentally assisted cracking (EAC). A better understanding of the causes and mechanisms of this cracking may permit less conservative estimates of damage accumulation and requirements on inspection intervals. The resistance of high-Ni alloys, e.g., Alloys 600 and 690 , as well as their welds, i.e., Alloys $82,182,52$, and 152, to EAC in simulated light water reactor (LWR) environments has been evaluated. Existing crack growth rate (CGR) data for these materials under cyclic and constant loads have been analyzed to establish the effects of alloy chemistry, cold work, and thermal treatment, temperature, water chemistry, load ratio, and applied stress intensity on CGRs.

The fatigue crack growth data in air have been analyzed to develop correlations for estimating the fatigue CGRs of Alloys 600 and 690 as a function of stress intensity factor range $\Delta \mathrm{K}$, load ratio $\mathrm{R}$, and temperature. The results indicate that in air, the CGRs of these materials are relatively insensitive to changes in frequency.

For cyclic loads, the experimental CGRs in high-temperature, high-purity water are compared with CGRs that would be expected in air under the same mechanical loading conditions to obtain a qualitative understanding of the degree and range of conditions for significant environmental enhancement in growth rates. The fatigue CGRs of Alloy 600 are enhanced in high-dissolved-oxygen (DO) water; the environmental enhancement of growth rates does not appear to depend on the material condition. In contrast, environmental enhancement of CGRs of Alloy 600 in low-DO water seems to depend on material conditions such as yield strength and grain boundary coverage of carbides. Material with high yield strength and/or low grain boundary coverage of carbides exhibit enhanced CGRs. Correlations have been developed for estimating the enhancement of CGRs in LWR environments relative to the CGRs in air under the same loading conditions.

For Alloy 690, the data suggest some enhancements of CGRs in boiling water reactor (BWR) water. Limited data indicate no environmental effects on CGRs in pressurized water reactor (PWR) water. However, the existing database for Alloy 690 is small and additional tests are needed to verify these results.

The enhancement of fatigue CGRs of high-Ni alloy welds in LWR environments has been determined relative to the CGRs that would be expected under the same loading conditions for Alloy 600 in air. Fatigue CGRs of Alloy 82 and 182 welds are enhanced in PWR and BWR environments with normal water chemistry (NWC). The results in PWR water show significant scatter, growth rates of welds may be up to a factor of 10 higher than the CGRs predicted for Alloy 600 in air. Hydrogen water chemistry has a beneficial effect on growth rates; CGRs are decreased by a factor of 5-10 when DO level is decreased from 200 to $10 \mathrm{ppb}$. The results in a NWC BWR environment show good agreement with the predicted curve for Alloy 600; the data in a PWR environment are higher.

The existing stress corrosion cracking (SCC) data on Ni alloys and welds have been reviewed to determine the effects of critical parameters such as stress intensity, temperature, material heat treatment, cold work, and water chemistry on CGRs. In general, the SCC susceptibility of Alloy 82 and 182 welds is greater than that of Alloy 600. Limited data suggest 
that the temperature dependence of growth rates is similar to that for Alloy 600; CGRs of Alloy 82 or 182 welds can be represented by an activation energy of $130 \mathrm{~kJ} / \mathrm{mole}$. The SCC data have been evaluated with the Scott or Ford/Andresen models. Although the conceptual bases underlying the two models differ significantly, by appropriately choosing the constants in the models, the predicted CGRs are reasonably consistent with the available data for SCC in LWR environments. 


\section{Acknowledgments}

This work is sponsored by the Office of Nuclear Regulatory Research, U.S. Nuclear Regulatory Commission, under Job Code W6610; Program Manager: M. B. McNeil. 


\section{Introduction}

High-Ni alloys have experienced general corrosion (tube wall thinning), localized intergranular attack (IGA), and stress corrosion cracking (SCC) in light water reactors (LWRs). Cracking has occurred in high-Ni alloys, e.g., Alloys 600 and X 750, as well as their welds, e.g., Alloys 82 and 182, that are used in applications such as instrument nozzles and heater thermal sleeves in the pressurizer ${ }^{1}$ and penetrations for control-rod drive mechanisms in the reactor vessel closure heads in the primary system of pressurized water reactors (PWRs), ${ }^{2}$ and in dissimilar-metal welds between stainless steel (SS) piping and low-alloy steel nozzles, in jet pump hold-down beams, ${ }^{3}$ and in shroud support access hole covers ${ }^{4}$ in boiling water reactors (BWRs). In pressurized water reactors (PWRs), cracks in Alloy 600 instrument nozzles and heater thermal sleeves have generally been axial, but circumferential cracks have also been reported in instrument nozzles at several foreign plants. ${ }^{2}$ In BWRs, cracking has occurred both in the base metal and welds, primarily in creviced regions, ${ }^{3,4}$ Primary-water SCC of Alloy 600 steam generator tubes in PWRs at roll transitions and U-bends and in tube plugs ${ }^{5}$ is a widespread problem that has been studied intensively. Secondary-side IGA $^{6}$ and axial and circumferential SCC $^{7}$ have occurred in Alloy 600 tubes at tube support plates in many steam generators. Alloy 690 with a higher $\mathrm{Cr}$ content and greater resistance to SCC has been proposed as an alternate to Alloy 600.

Alloys 600 and 690, in general, undergo differing thermomechanical processing for applications other than steam generator tubes. Because environmental degradation of the alloys in many cases is very sensitive to processing, further evaluation of SCC is needed. In addition, experience strongly suggests that materials that are susceptible to SCC are also susceptible to environmental degradation of fatigue life and fatigue-crack growth properties. A program is being conducted at Argonne National Laboratory (ANL) to evaluate the resistance of Alloys 600 and 690 and their welds to environmentally assisted cracking (EAC) in simulated LWR coolant environments. Fracture mechanics crack growth rate (CGR) tests are being conducted on compact-tension specimens of Alloys 600 and 690 in oxygenated and deaerated water that contained $\mathrm{B}, \mathrm{Li}$, and low concentrations of dissolved $\mathrm{H}$ at $289-380^{\circ} \mathrm{C}$. The experimental details and results from this study are presented elsewhere. ${ }^{8-12}$

The existing CGR data for Alloys 600 and 690 and their weld metals Alloys 82, 182, 52, and 152, under cyclic and constant loading conditions have been compiled and evaluated to establish the effects of alloy type, temperature, load ratio $\mathrm{R}$, stress intensity $\mathrm{K}$, and dissolved oxygen (DO) level. The experimental CGRs under cyclic loading have been compared with CGRs that would be expected in air under the same mechanical loading conditions to obtain a qualitative understanding of the degree and range of conditions that are necessary for significant environmental enhancement in growth rates. 


\section{Material Characterization}

The Ni-base Alloy 600 has been used as a construction material in BWRs and PWRs. Because of the susceptibility of Alloy 600 to SCC in both BWR and PWR environments, Alloy 690, with a higher Cr content, has been proposed as an alternate to Alloy 600. Alloys 82 and 182 are used as weld metals for Alloy-600 components; Alloy 82 is used in gas tungsten arc (GTA) welding and Alloy 182, in shielded metal arc (SMA) welding. Usually, GTA welding is used for the first one or two weld passes, and the weld is then completed with SMA welding. Alloy 182 is most commonly used as a filler metal and butter in dissimilar-metal welds between Alloy 600, austenitic SS, and low-alloy steel. Alloy 82, with higher $\mathrm{Cr}$ and lower C than Alloy 182, is considered more resistant to SCC. Alloys 52 and 152 are used for welding Alloy 690; Alloy 52 in GTA welding and Alloy 152 in SMA welding. The nominal chemical composition of the above-mentioned Ni alloys is given in Table 1 .

Table 1. Nominal chemical composition (wt.\%) of various nickel alloys

\begin{tabular}{lcccccccccccc}
\hline \multicolumn{1}{c}{ Alloy } & $\mathrm{C}$ & $\mathrm{Mn}$ & $\mathrm{Fe}$ & $\mathrm{P}$ & $\mathrm{S}$ & $\mathrm{Si}$ & $\mathrm{Cu}$ & $\mathrm{Ni}$ & $\mathrm{Ti}$ & $\mathrm{Cr}$ & $\mathrm{Nb}+\mathrm{Ta}$ \\
\hline Alloy 600 & 0.15 & $1.0 \mathrm{max}$ & $6-10$ & - & 0.015 & 0.50 & 0.50 & $72 \mathrm{~min}$ & - & $14-17$ & - \\
Alloy 690 & 0.05 & $0.5 \mathrm{max}$ & $7-11$ & - & 0.015 & 0.50 & 0.50 & $58 \mathrm{~min}$ & - & $27-31$ & - \\
Alloy 82 & 0.10 & $2.5-3.5$ & 3.0 & 0.03 & 0.015 & 0.50 & 0.50 & $67 \mathrm{~min}$ & 0.75 & $18-22$ & $2.0-3.0$ \\
Alloy 182 & 0.10 & $5.0-9.5$ & $6-10$ & 0.03 & 0.015 & 1.0 & 0.50 & $59 \mathrm{~min}$ & 1.00 & $13-17$ & $1.0-2.5$ \\
Alloy 52 & 0.03 & 0.25 & 9.0 & - & 0.001 & 0.15 & 0.05 & 73.2 & 0.35 & 28.6 & - \\
Alloy 152 & 0.03 & 3.90 & 10.2 & - & 0.003 & 0.50 & 0.01 & 54.2 & 0.08 & 28.6 & 1.93 \\
\hline
\end{tabular}

The microstructure of Alloys 600 and 690 typically consists of either a semicontinuous or continuous carbide precipitates at the grain boundaries and some intragranular carbides. ${ }^{8}$ The precipitate phases are $\mathrm{Cr}-$ rich $\mathrm{M}_{7} \mathrm{C}_{3}$ and $\mathrm{M}_{23} \mathrm{C}_{6}$ carbides and $\mathrm{Ti}(\mathrm{C}, \mathrm{N})$ carbonitrides. ${ }^{13}$ In general, the microstructures depend on the thermomechanical processing histories and $\mathrm{C}$ concentrations vis-à-vis the solubility of $\mathrm{C}$ in the material. ${ }^{14}$ Materials with greater grain boundary coverage of carbides are resistant to SCC in high-temperature high-purity water. Also, materials with $\mathrm{M}_{7} \mathrm{C}_{3}$ carbides are more resistant to SCC than those with $\mathrm{M}_{23} \mathrm{C}_{6}$ carbides. ${ }^{13}$ The favorable microstructure may be developed by thermal treatments that promote extensive precipitation of intergranular carbides. The resistance to SCC of this favorable microstructure does not seem to depend on Cr depletion that accompanies formation of Cr-rich carbides. The greater resistance of Alloy 690 to SCC than that of Alloy 600 is attributed to the differences in the $\mathrm{C}$ solubility and carbide precipitation kinetics of these alloys. ${ }^{14,15}$

The microstructures of Alloys 182 and 82 are similar to that of wrought Alloys 600 and 690. Under certain thermal treatments, $\mathrm{Cr}$-rich carbides can precipitate at both interdendrite and intradendrite grain boundaries. ${ }^{16}$ Chromium depletion also occurs at the boundaries that are covered with such carbides. The precipitate phases are predominantly $\mathrm{M}_{23} \mathrm{C}_{6}$ and Ti-rich $\mathrm{MC}$ carbide. During the welding process, only the $\mathrm{M}_{23} \mathrm{C}_{6}$ carbide precipitates because of the rapid cooling of the weld metal from fusion temperature. Nucleation of $\mathrm{M}_{7} \mathrm{C}_{3}$ carbides requires long periods at relatively high temperatures, whereas nucleation of $\mathrm{M}_{23} \mathrm{C}_{6}$ is quite rapid and cannot be avoided even during water quenching from solution treatment temperatures. The matrix also contains a uniform dispersion of spherical $\gamma$ phase $\left(\mathrm{Ni}_{3} \mathrm{Ti}\right)$. 
The greater susceptibility of Alloy 182 to SCC than Alloy 82 has been attributed to differences in $\mathrm{Cr}$ depletion observed in the two alloys because of differences in their composition. Alloy 182 contains higher concentrations of $\mathrm{C}$ and $\mathrm{Fe}$ and a lower concentration of $\mathrm{Cr}$, all of which enhance $\mathrm{Cr}$ depletion during carbide precipitation.

For Alloys 600 and 690, the critical compositional variables that may influence EAC of these alloys in LWR environments include the concentrations of $\mathrm{C}, \mathrm{P}$, and S. For Ni-alloy welds, the critical compositional variables include carbide stabilization parameter $\mathrm{N}$, and the concentrations of $\mathrm{P}$ and $\mathrm{S}$. The parameter $\mathrm{N}$ is defined as

$$
\mathrm{N}=0.13(\mathrm{Nb}+2 \mathrm{Ti}) / \mathrm{C}
$$

where $\mathrm{Nb}, \mathrm{Ti}$, and $\mathrm{C}$ are the concentrations of the respective elements in wt.\%. 


\section{Fatigue Crack Growth Rates in Air}

\subsection{Alloy 600}

The existing fatigue CGR $(\mathrm{da} / \mathrm{dN})$ data on Alloy 600 have been analyzed to establish the effects of temperature, load ratio, frequency, and stress intensity factor range $\Delta \mathrm{K}$ on CGRs in air. The fatigue CGR $(\mathrm{da} / \mathrm{dN})$ database on Alloy 600 is composed of results from 465 tests in air ${ }^{8-22}$ at temperatures up to $538^{\circ} \mathrm{C}$. The number of tests at various temperatures are as follows: 166 at room temperature, 13 at $35^{\circ} \mathrm{C}, 9$ at $130^{\circ} \mathrm{C}, 14$ at $289^{\circ} \mathrm{C}, 26$ at $316^{\circ} \mathrm{C}, 20$ at $320^{\circ} \mathrm{C}, 11$ at $380^{\circ} \mathrm{C}, 76$ at $427^{\circ} \mathrm{C}$, and 130 at $538^{\circ} \mathrm{C}$.

For austenitic SSs, temperature, stress ratio R, and cyclic frequency have a significant effect on CGRs. ${ }^{23}$ Growth rates can be represented by

$$
\mathrm{da} / \mathrm{dN}=\mathrm{C}(\mathrm{T}) \mathrm{F}(\mathrm{f}) \mathrm{S}(\mathrm{R})(\Delta \mathrm{K})^{\mathrm{n}}
$$

where the functions $\mathrm{C}, \mathrm{F}$, and $\mathrm{S}$ express the dependence of temperature, frequency, and stress ratio, and $\mathrm{n}$ is the exponent for the power-law dependence of growth rates on the stress intensity factor range $\Delta \mathrm{K}$.

The existing fatigue CGR data on Alloy 600 were analyzed by using Eq. 2 to establish the effects of temperature, stress ratio $\mathrm{R}$, cyclic frequency, and stress intensity factor range $\Delta \mathrm{K}$ on the CGRs in air. First, the exponent $\mathrm{n}$ was determined from individual data sets in which only $\Delta \mathrm{K}$ was varied and the temperature, frequency, and $\mathrm{R}$ were all constant. Plots of CGR vs. $\Delta \mathrm{K}$ from several data sets (Figs. 1 and 2) yield values of $n$ in the range of 3.5-5.5; a value of 4.1 was selected for further analysis.

The results also indicate that for the temperature range of interest, the frequency or rise time has little effect on CGRs, i.e., function $F=1$ in Eq. 2. Because the cyclic stress ratio $R$ has a significant influence on CGRs in association with $\mathrm{K}_{\max }$, differing forms of function $\mathrm{S}$ have been used by various investigators to treat stress-ratio effects on CGRs. For example, $\mathrm{S}$ has been expressed as $(a+b R)$ for various regions of $R<0.79$ and $0.70<R<1.0$ (James and Jones), ${ }^{23}(\mathrm{a}-\mathrm{R})^{\mathrm{p}}$ (Bamford et al.), ${ }^{24} 1 /(1-\mathrm{R})^{\mathrm{n} /(1-\mathrm{p})}$ (Walker), ${ }^{25,26}\left(1 /\left[1-0.05 \mathrm{R}^{2}\right]\right)^{4}$ (Bernard and Slama), ${ }^{27}$ and $(\mathrm{a}-\mathrm{R}) \mathrm{p}$ (Rabbe and Lieurade), ${ }^{28}$ where $\mathrm{a}, \mathrm{b}$, and $\mathrm{p}$ are constants. After some preliminary studies with various forms of function $\mathrm{S}$, the following form was chosen to fit to the experimental data in air:

$$
S(R)=(1-b R)^{-p},
$$

where $\mathrm{R}$ is the stress ratio and $\mathrm{b}$ and $\mathrm{p}$ are constants. Best fits to individual data sets at constant temperature yield values of 0.82 and -2.2 for constants $\mathrm{b}$ and $\mathrm{p}$, respectively. Finally, the temperature dependence of function $\mathrm{C}$ was determined from data sets that were normalized for the effects of load ratio $\mathrm{R}$ (Fig. 3). The results indicate significant variation in function $\mathrm{C}$ due to either heat-to-heat differences or differences in heat treatment, e.g., at room temperature, $\mathrm{C}$ varies by a factor of 2 for the various heats and heat treatment conditions (Fig. 3). Two forms of the temperature dependence of function $\mathrm{C}$, an exponential and a 

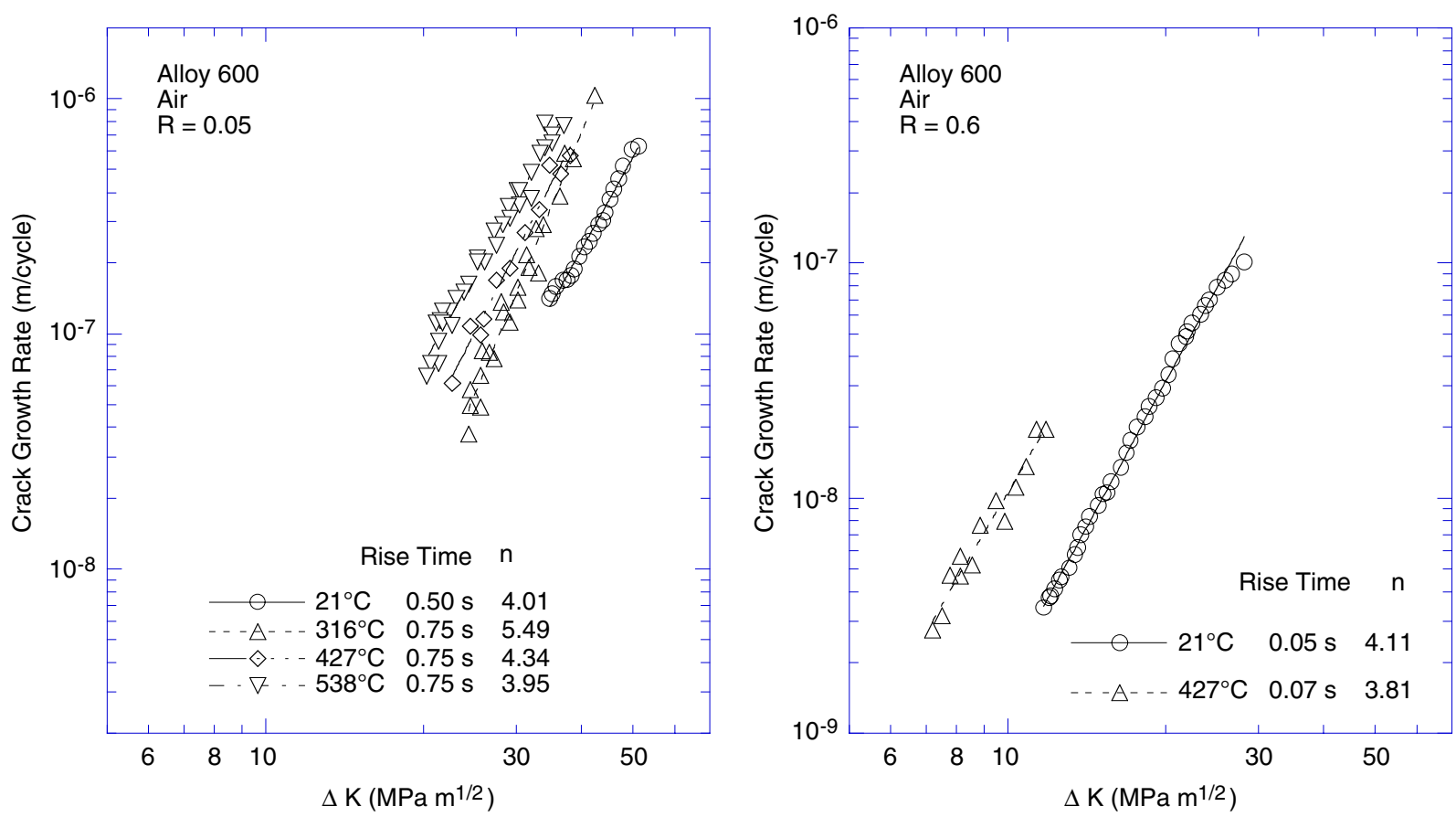

Figure 1. Effect of temperature on fatigue CGR of Alloy 600 in air. Data at $21^{\circ} \mathrm{C}$ from Ref. 22 (Was and Ballinger) and at higher temperatures from Ref. 18 (James).
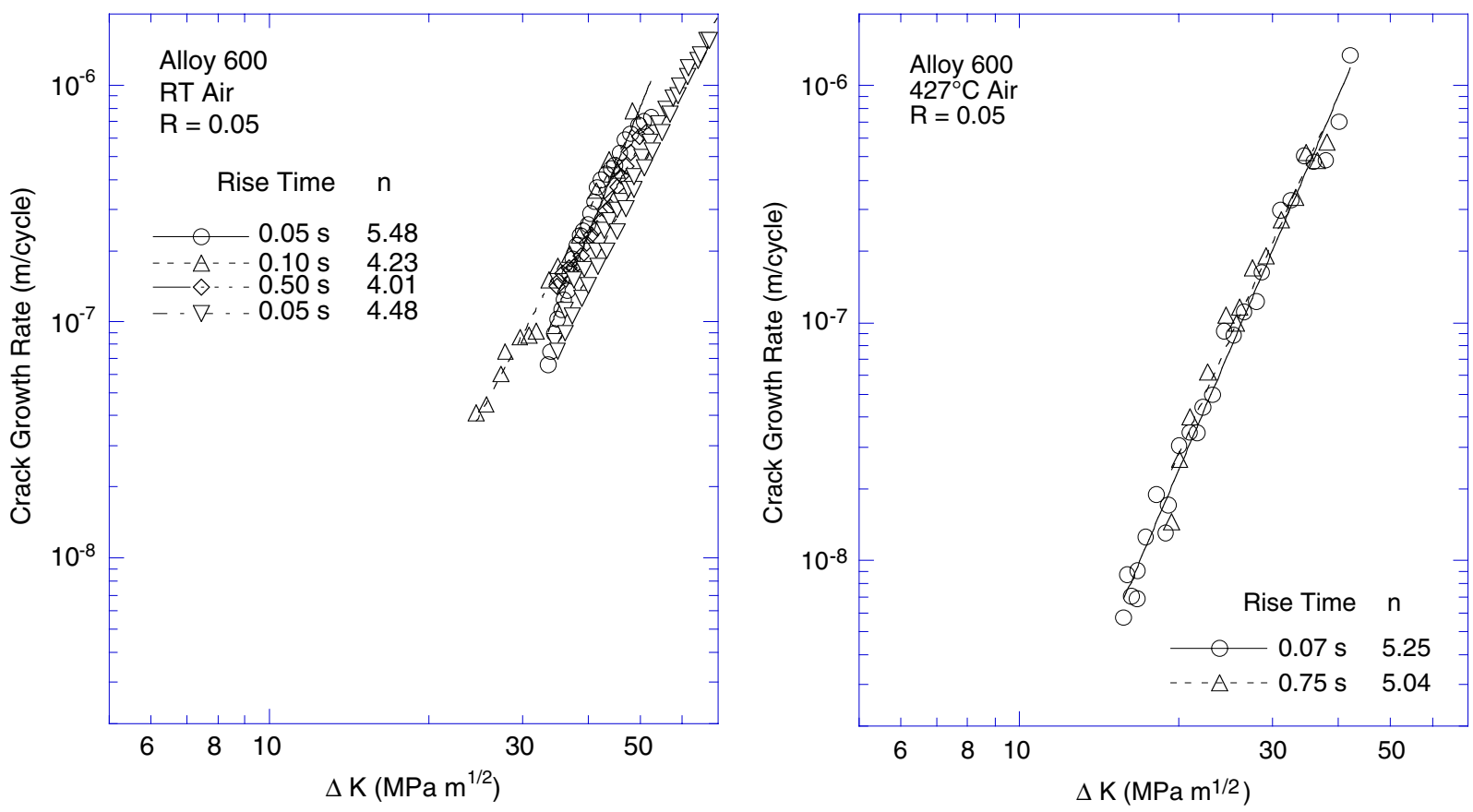

Figure 2. Effect of rise time on fatigue CGR of Alloy 600 in air. Data from Ref. 18 (James). 


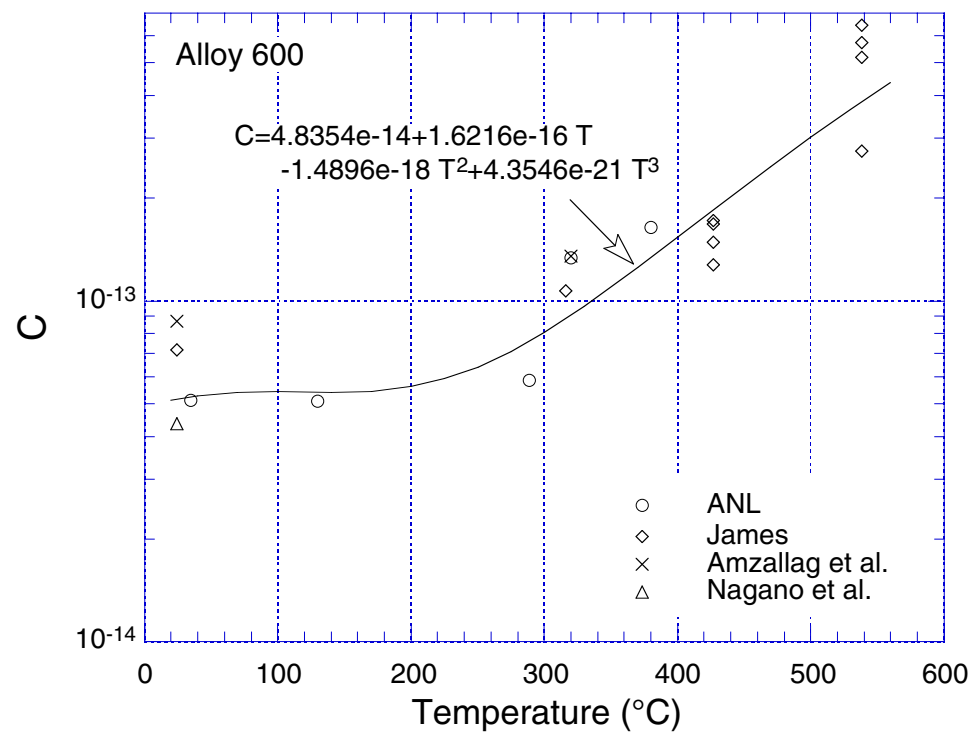

Figure 3. Variation of function $C$ for Alloy 600 with temperature. Data obtained at ANL (Refs. 8-12) and by James (Ref. 18), Amzallag et al. (Ref. 20), and Nagano et al. (Ref. 21).

third-order polynomial of temperature, were used to represent the experimental data; the latter gave a better fit of the data. Thus, the CGR (m/cycle) of Alloy 600 in air is expressed as

$$
\mathrm{da} / \mathrm{dN}=\mathrm{C}_{\mathrm{A} 600}(1-0.82 \mathrm{R})^{-2.2}(\Delta \mathrm{K})^{4.1}
$$

where $\Delta \mathrm{K}$ is in $\mathrm{MPa} \cdot \mathrm{m}^{1 / 2}$, and constant $\mathrm{C}_{\mathrm{A} 600}$ is given by a third-order polynomial of temperature $\mathrm{T}\left({ }^{\circ} \mathrm{C}\right)$ expressed as

$$
\mathrm{C}_{\mathrm{A} 600}=4.835 \times 10^{-14}+\left(1.622 \times 10^{-16}\right) \mathrm{T}-\left(1.490 \times 10^{-18}\right) \mathrm{T}^{2}+\left(4.355 \times 10^{-21}\right) \mathrm{T}^{3} .
$$

Most data subsets and plots did not show significant patterns, such as changing variance or a nonzero slope. In general, Eqs. 4 and 5 represent the existing CGR data very well; biases seem to be traceable to either heat-to-heat variation or changes in heat treatment condition. The experimental values of the term $\mathrm{C}(\mathrm{T}) \mathrm{S}(\mathrm{R})$ (i.e., the product of functions $\mathrm{C}$ and $\mathrm{S}$ ) are plotted as a function of load ratio $\mathrm{R}$ in Fig. 4 for three temperatures; the values estimated from Eqs. 4 and 5 are also shown in the figure. The results indicate that the form of function $\mathrm{S}$ expressed in Eq. 3 represents the experimental data very well.

The estimated-vs.-experimental CGRs for Alloy 600 at various temperatures are shown in Fig. 5. CGRs expressed as da/dt $(\mathrm{m} / \mathrm{s})$ were obtained from $\mathrm{da} / \mathrm{dt}=\left(1 / \mathrm{t}_{\mathrm{r}}\right) \mathrm{da} / \mathrm{dN}$, where $\mathrm{t}_{\mathrm{r}}$ is the rise time (s).

- In Eqs. 3 and 4 the units for $\mathrm{da} / \mathrm{dN}$ and $\Delta \mathrm{K}$ are $\mathrm{m} /$ cycle and $\mathrm{MPa} \cdot \mathrm{m}^{1 / 2}$, respectively. Divide da/dN in $\mathrm{m} / \mathrm{cycle}$ by 0.0254 to obtain $\mathrm{da} / \mathrm{dN}$ in in./cycle and multiply $\Delta \mathrm{K}$ in $\mathrm{MPa} \cdot \mathrm{m}^{1 / 2}$ by 0.91 to obtain $\Delta \mathrm{K}$ in ksi.in. ${ }^{1 / 2}$. 


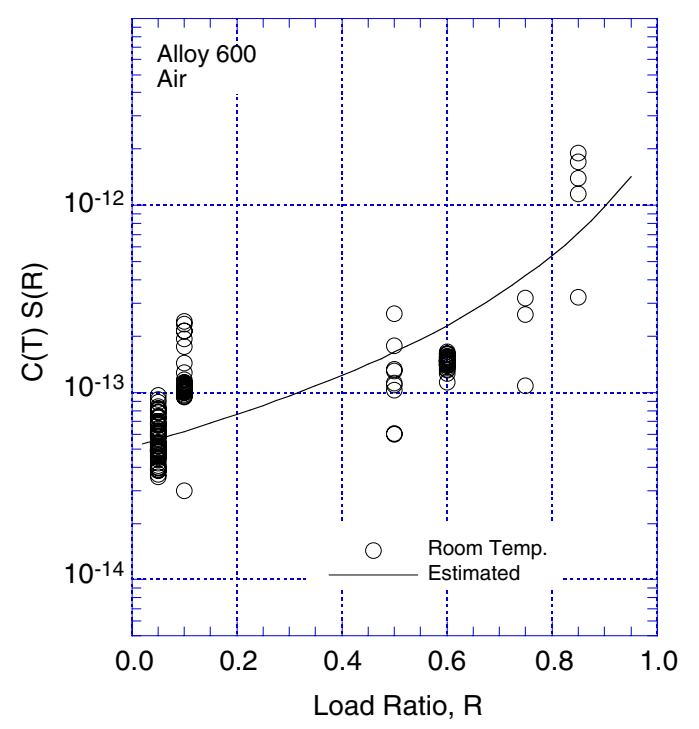

(a)

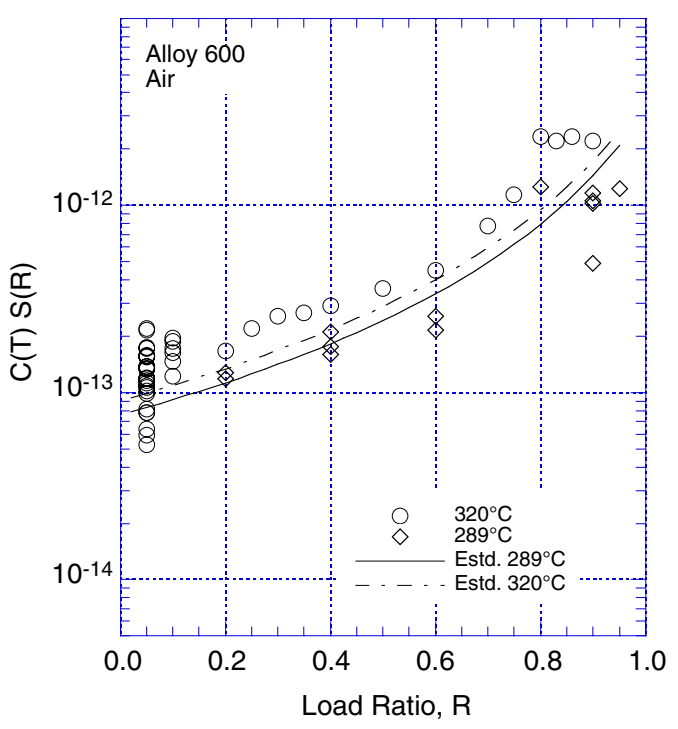

(b)

Figure 4. Variation in product of functions $C(T)$ and $S(R)$ with load ration $R$ at (a) room temperature and (b) 289 and $320^{\circ} \mathrm{C}$

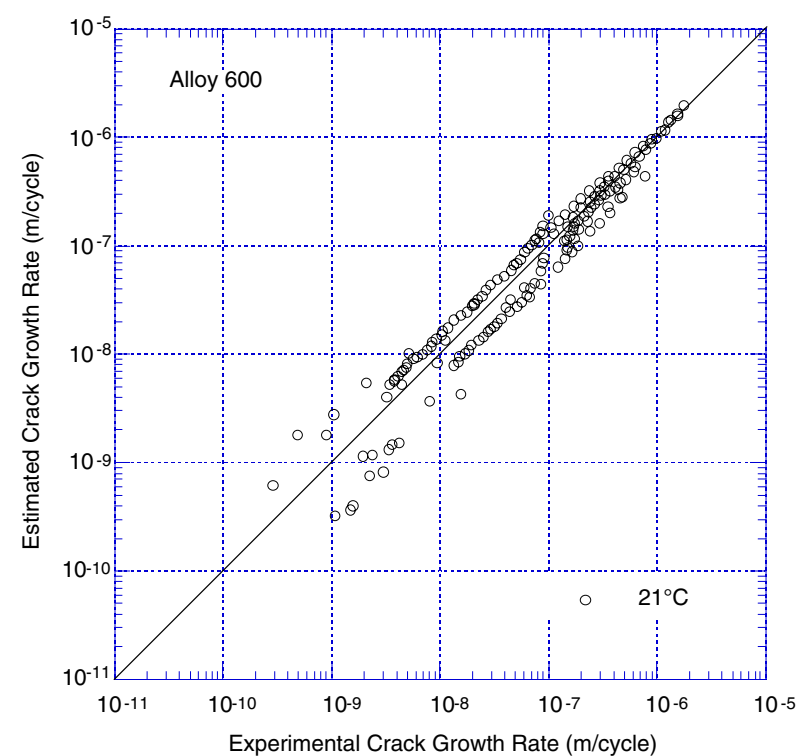

(a)

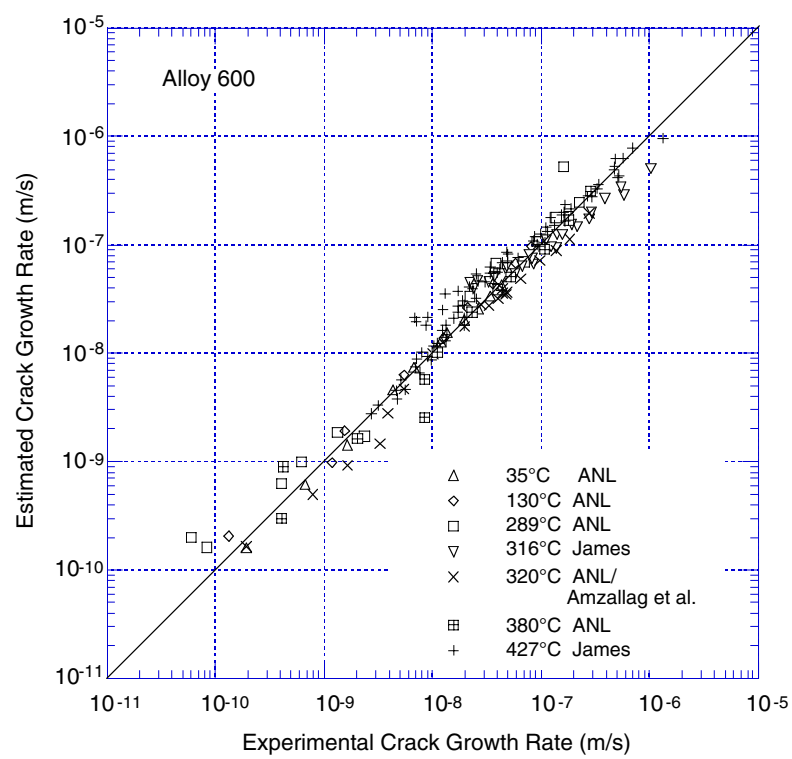

(b)

Figure 5. Estimated-vs.-experimental values of fatigue crack growth rate of Alloy 600 in air at (a) room temperature and (b) temperatures between 35 and $427^{\circ} \mathrm{C}$. Data obtained at ANL (Refs. 8-12) and by James (Ref. 18), EPRI (Ref. 19), and Amzallag et al. (Ref. 20). 


\subsection{Alloy 690}

The fatigue CGR (da/dN) data on Alloy 690 in air are very limited. ${ }^{8-12}$ The database is composed of results from $\approx 60$ tests at temperatures between 35 and $380^{\circ} \mathrm{C}$. The existing fatigue CGR data on Alloy 690 in air are inadequate to establish the effects of stress ratio R, cyclic frequency, and stress intensity factor range $\Delta \mathrm{K}$ on the CGRs in Eq. 2. The functional forms for functions $\mathrm{F}$ and $\mathrm{S}$ and the value of $\mathrm{n}$ in Eq. 2 were assumed to be the same as those for Alloy 600. The temperature dependence of function $\mathrm{C}$ was determined from data sets that were normalized for the effects of load ratio R (Fig. 6). Thus, the CGR (m/cycle) of Alloy 690 in air is expressed as

$$
\mathrm{da} / \mathrm{dN}=\mathrm{C}_{\mathrm{A} 690}(1-0.82 \mathrm{R})^{-2.2}(\Delta \mathrm{K})^{4.1}
$$

where $\Delta \mathrm{K}$ is in $\mathrm{MPa} \cdot \mathrm{m}^{1 / 2}$ and constant $\mathrm{C}_{\mathrm{A} 690}$ is given by a third-order polynomial of temperature $\mathrm{T}\left({ }^{\circ} \mathrm{C}\right)$ expressed as

$$
\mathrm{C}_{\mathrm{A} 690}=5.423 \times 10^{-14}+\left(1.83 \times 10^{-16}\right) \mathrm{T}-\left(1.725 \times 10^{-18}\right) \mathrm{T}^{2}+\left(5.490 \times 10^{-21}\right) \mathrm{T}^{3} .
$$

The estimated-vs.-experimental CGRs for Alloy 690 at various temperatures are shown in Fig. 7. The estimated values show good agreement with the experimental results. The estimated values show good agreement with the experimental results. Under similar loading conditions, the CGRs of Alloy 690 appear to be slightly higher than those of Alloy 600. This difference most likely is an artifact of a smaller database for Alloy 690.

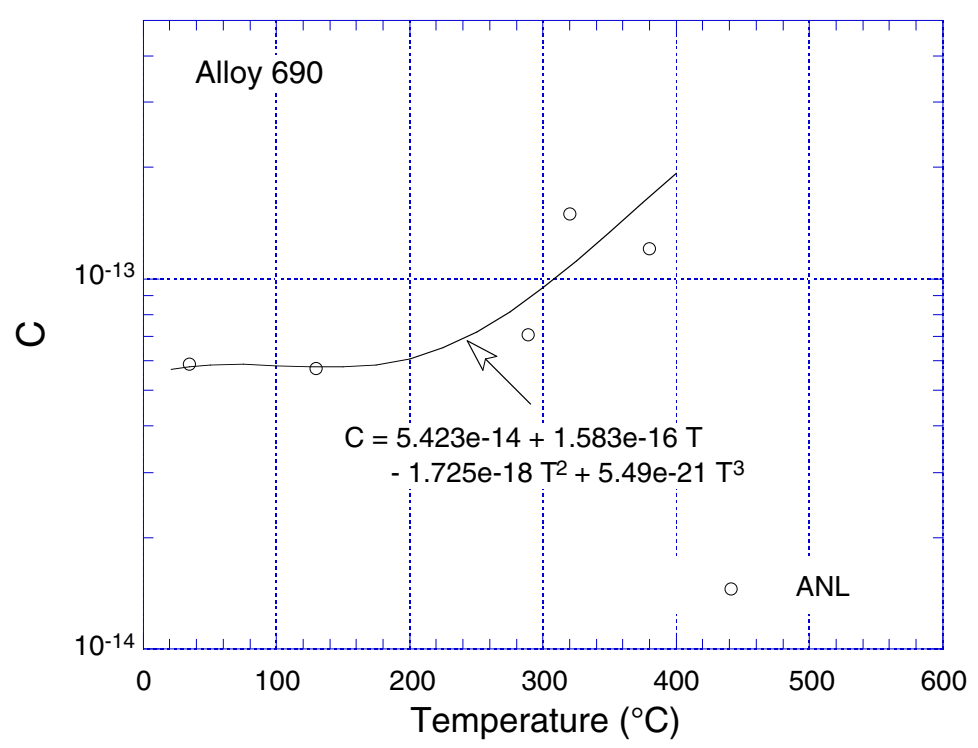

Figure 6. Variation of function C for Alloy 690 with temperature. Data obtained at ANL (Refs. 8-12). 


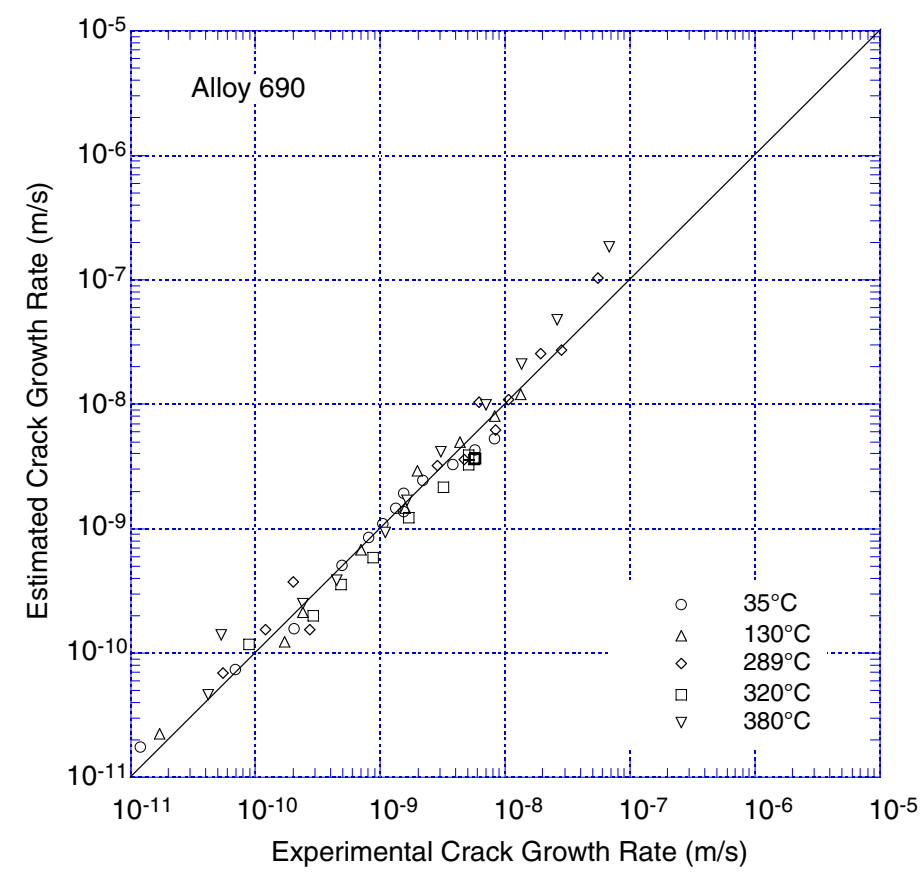

Figure 7. Estimated-vs.-experimental values of fatigue crack growth rate of Alloy 690 in air at temperatures between 35 and $380^{\circ} \mathrm{C}$. Data obtained at ANL (Refs. 8-12).

\subsection{Weld Metals}

For weld metals, the fatigue CGR $(\mathrm{da} / \mathrm{dN})$ database in air is composed of results from $\approx 35$ tests on as-welded Alloy 182 tested room temperature and $320^{\circ} \mathrm{C} .{ }^{20,29}$ The experimental CGRs for Alloy 182 and those estimated from Eqs. 4 and 5 for Alloy 600 for the same loading conditions, are plotted in Fig. 8 . The results indicate that under similar loading conditions, the fatigue CGRs of Alloy 182 are a factor of $\approx 2$ higher than those for Alloy 600 . The effect of temperature on growth rates is similar to that for Alloy 600. Fatigue crack growth data for Alloys 82, 52, and 152 in air are not available. 


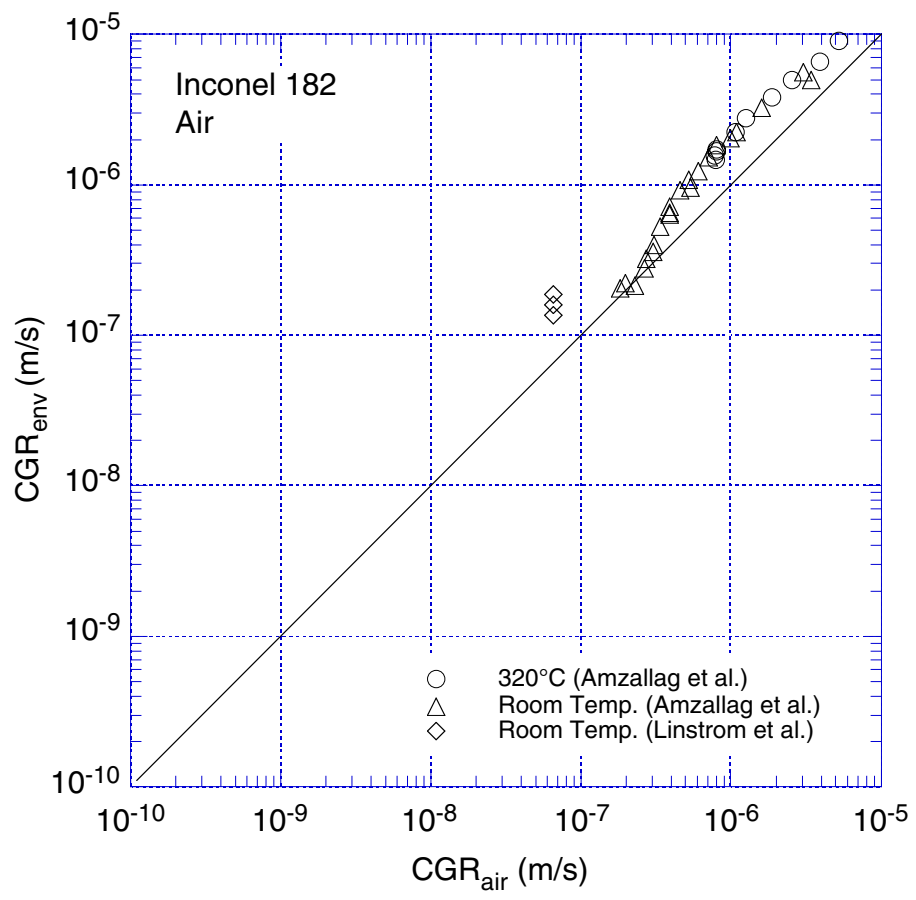

Figure 8. Experimental values of fatigue crack growth rate of Alloy 182 in air and those estimated for Alloy 600 under the same loading conditions. Data obtained by Amzallag et al. (Ref. 20) and Linstrom et al. (Ref. 29). 


\section{Fatigue Crack Growth in LWR Environments}

\subsection{Alloy 600}

Fatigue crack growth experiments have been performed on Alloy 600 to determine the effects of temperature, load ratio, stress intensity, material heat treatment, and water chemistry on CGR. The existing database ${ }^{8-11,19,20,30-36}$ consists of results of $\approx 800$ tests on several heats of Alloy 600 under various heat treatment conditions. The tests were conducted in high-purity water at temperatures between 240 and $325^{\circ} \mathrm{C} ; \approx 600$ tests have been conducted at $289^{\circ} \mathrm{C}$. The loading conditions include load ratio $\mathrm{R}=0.05-0.95$, maximum stress intensity $\mathrm{K}_{\max }=10-96 \mathrm{MPa} \cdot \mathrm{m}^{1 / 2}$, stress intensity factor range $\Delta \mathrm{K}=1.4-79 \mathrm{MPa} \cdot \mathrm{m}^{1 / 2}$, and rise time $\mathrm{t}_{\mathrm{r}}=0.05-800 \mathrm{~s}$. To obtain a qualitative understanding of the degree of enhancement and the range of conditions over which significant environmental enhancement is observed, it is helpful to plot the observed CGRs against the CGRs that would be expected in air under the same loading conditions, i.e., the same $\Delta \mathrm{K}, \mathrm{R}$, and $\mathrm{t}_{\mathrm{r}}$.

The experimental CGRs in high-DO ( $\geq 300 \mathrm{ppb}$ DO) water and those predicted by Eqs. 4 and 5 for the same mechanical loading conditions are plotted in Fig. 9.8,9,34,36 The significant results and influence of critical parameters on CGRs in high-DO water are summarized below.

Water Chemistry: The fatigue CGRs of Alloy 600 are enhanced in high-DO water; see Fig. 9. Growth rates increase slightly when DO level is increased from 300 to $6000 \mathrm{ppb}$ or when 15-100 ppb sulfates are added to the water. ${ }^{8}$

Material Condition: The environmental enhancement of growth rates does not appear to depend on either the $\mathrm{C}$ content or heat treatment of the material. For example, the CGRs of a low-C heat (NX9244G) are comparable to those of high-C heats (e.g., NX8197, NX8844J). The high-C heats contain continuous (NX8197) or semicontinuous (NX8844J, J422) carbide precipitation at the grain boundaries whereas, because of the low $\mathrm{C}$ content $(\approx 0.03 \%)$ and relatively high

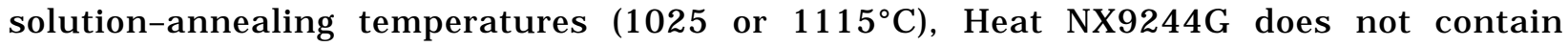
intergranular carbides. ${ }^{9}$ Also, thermal treatment for $24 \mathrm{~h}$ at $600^{\circ} \mathrm{C}$ has no effect on the CGRs in high-DO water; the growth rates of solution-annealed Heat NX9244G are approximately the same with or without thermal treatment; see Fig. 9a. ${ }^{9}$

Mechanical Loading: The results indicate that the effects of environment on growth rates in high-DO water are greater under loading conditions that correspond to $<1 \times 10^{-9} \mathrm{~m} / \mathrm{s}$ CGRs in air; under certain loading conditions the CGRs in high-DO water may be enhanced by nearly two orders of magnitude.

Temperature: Limited data suggest that in high-DO water, the growth rates at $320^{\circ} \mathrm{C}$ are comparable to those at $289^{\circ} \mathrm{C}$. However, nearly all of the fatigue crack growth data on Alloy 600 have been obtained at $289^{\circ} \mathrm{C}$, and additional tests at $320^{\circ} \mathrm{C}$ are needed to verify the temperature dependence of growth rates in high-DO water. 


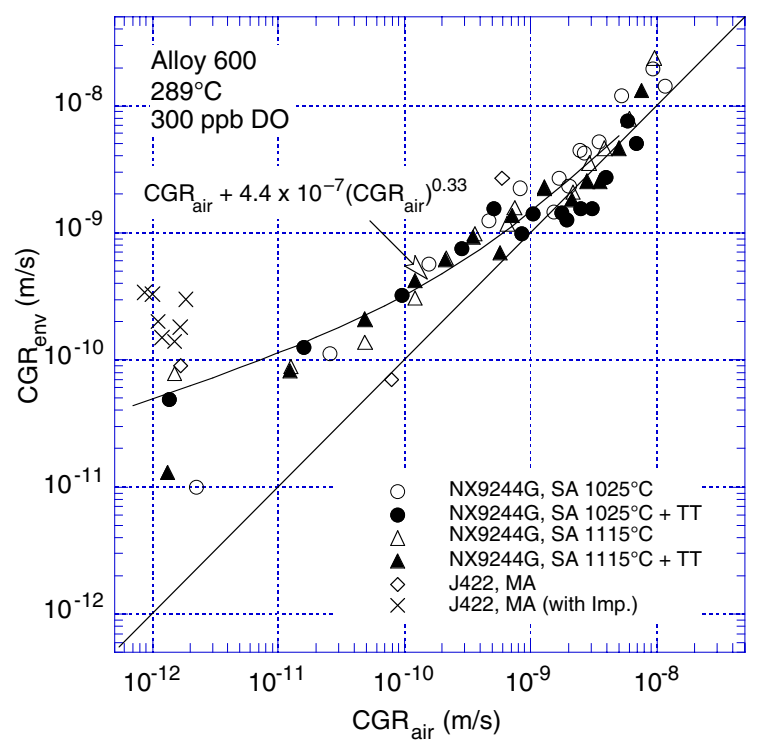

(a)

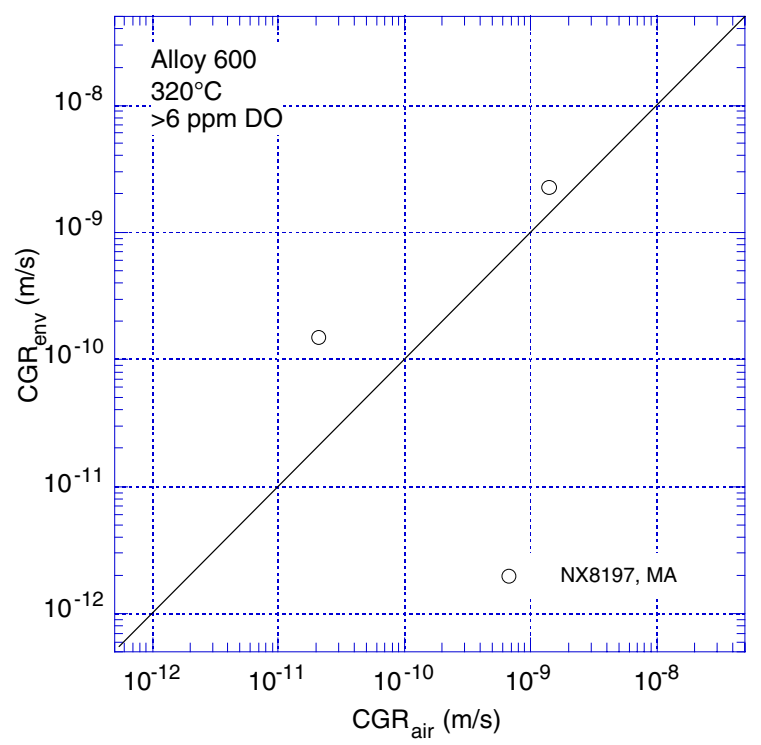

(c)

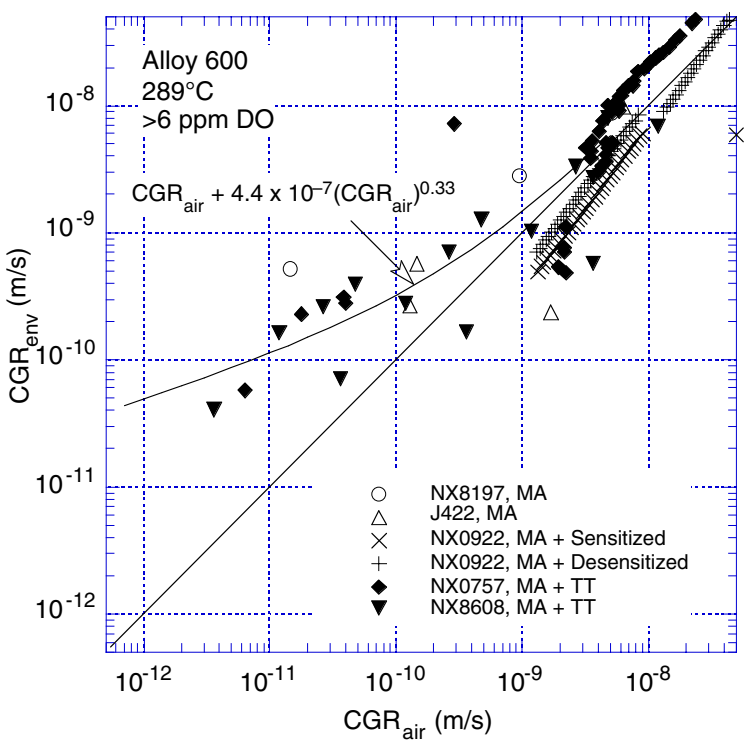

(b)

Figure 9.

Corrosion fatigue data for Alloy 600 in high-purity water with (a) $300 \mathrm{ppb} \mathrm{DO}$ at $289^{\circ} \mathrm{C}$, (b) $>6 \mathrm{ppm}$ $\mathrm{DO}$ at $289^{\circ} \mathrm{C}$, and (c) $>6 \mathrm{ppm} \mathrm{DO}$ at $320^{\circ} \mathrm{C}$. Data obtained at ANL (Refs. 8, 9), and by Andresen (Ref. 34) and Solomon (Ref. 36).

The experimental CGRs in simulated PWR or low-DO $(<10 \mathrm{ppb}$ DO) water and those predicted by Eqs. 4 and 5 for the same mechanical loading conditions are plotted in Figs. 10. In contrast to the behavior in high-DO water, where the CGRs of Alloy 600 are enhanced under nearly all material and loading conditions that have been investigated, only some conditions appear to enhance fatigue CGRs in low-DO water, Fig. 10.89,19,30 The significant results and influence of critical parameters on CGRs in simulated PWR water are summarized below.

Material Condition: The material yield strength and microstructure, such as grain boundary carbide distribution, and temperature appear to be important parameters that influence environmental enhancement of CGRs. In low-DO water, environmental enhancement of CGRs is observed for the solution-annealed (at $1025^{\circ} \mathrm{C}$ ) low-C Heat $\mathrm{NX} 9244 \mathrm{G}$ tested at $320^{\circ} \mathrm{C}$, and 
for the mill-annealed high-C Heat $\mathrm{J} 422$ tested at $289^{\circ} \mathrm{C}$, Figs. $10 \mathrm{a}$ and $\mathrm{b}$. However, the low-C Heat NX9244G, when solution annealed at $1115^{\circ} \mathrm{C}$ and tested under the same loading conditions, shows no effect of environment on growth rates, Fig. 10a. The two solution treatments exhibit similar grain boundary carbide distribution but the material that was solution annealed at $1025^{\circ} \mathrm{C}$ exhibits higher yield strength than that annealed at $1115^{\circ} \mathrm{C} .{ }^{9}$ Materials with poor grain boundary coverage of carbides and high yield strength are known to exhibit high susceptibility to SCC in low-DO PWR environments. ${ }^{37,38}$ At $289^{\circ} \mathrm{C}$, not all high-C heats show environmental enhancement of CGRs; Heats NX8197 and NX8844J show no effect of environment on growth rates. The enhanced growth rates of Heat J422 may be attributed to the higher yield strength of the material than that for Heats NX8197 or NX8844J. ${ }^{9}$

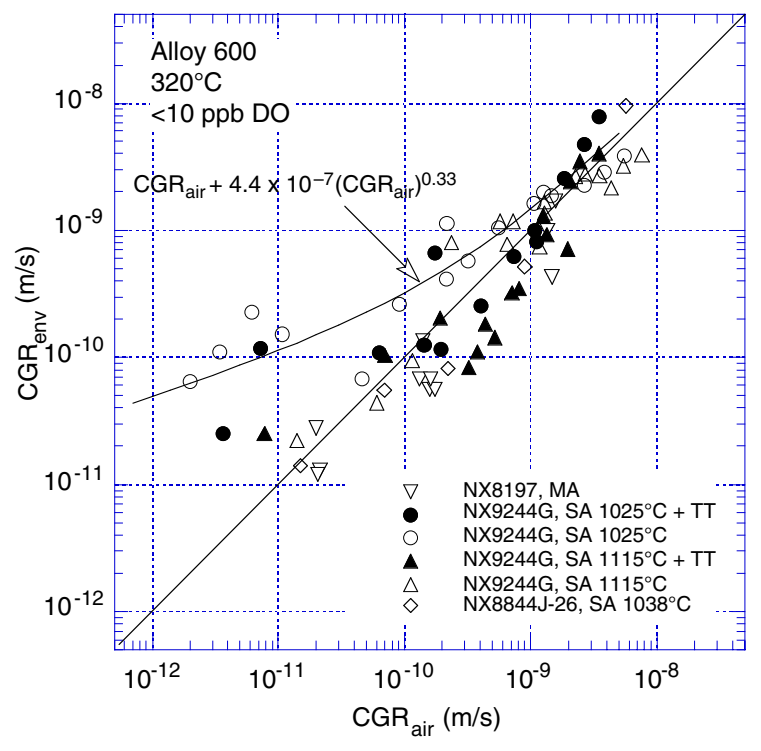

(a)

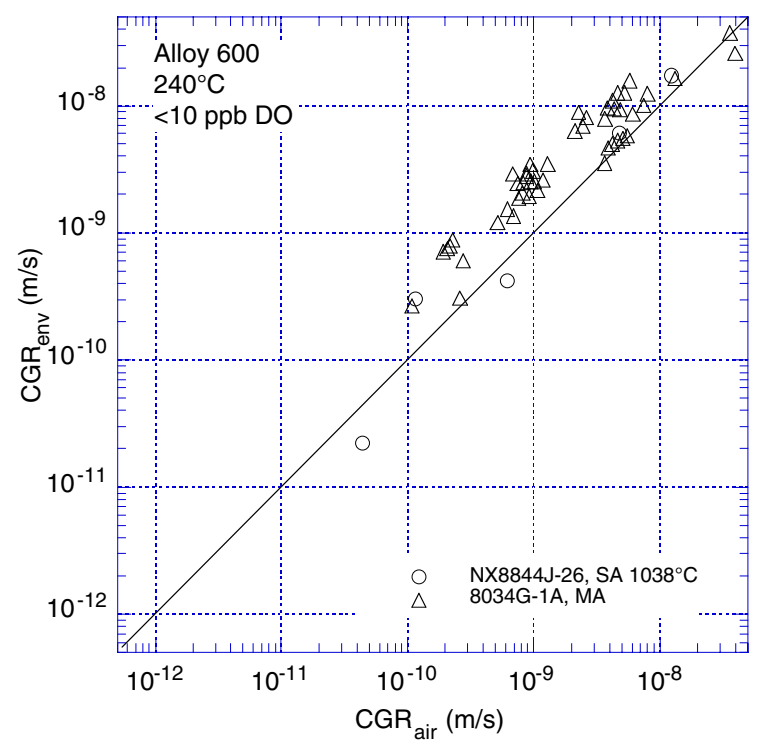

(c)

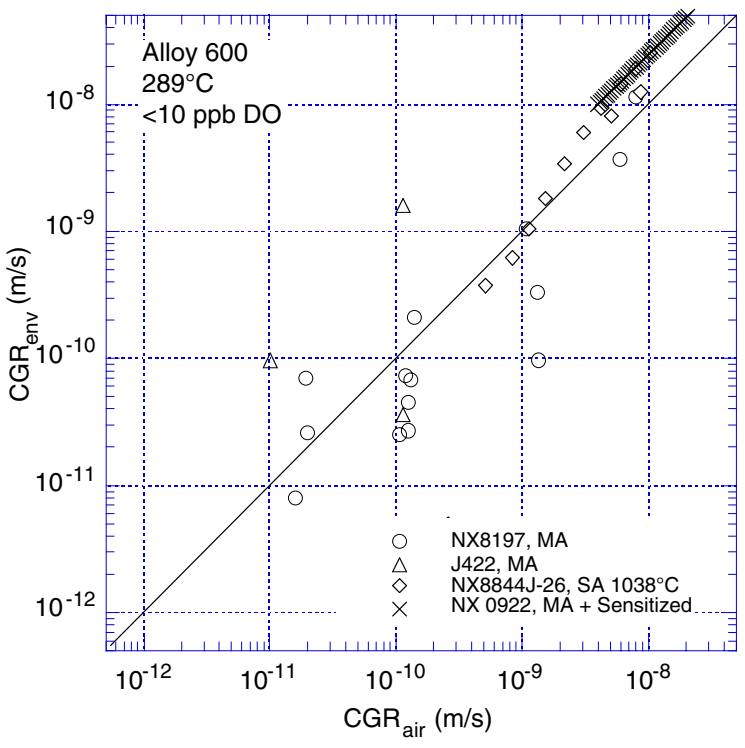

(b)

Figure 10

Corrosion fatigue data for Alloy 600 in high-purity water with $<10 \mathrm{ppb}$ dissolved oxygen at (a) 320, (b) 289 , and (c) $240^{\circ} \mathrm{C}$. Data obtained at ANL (Refs. 8, 9), and by Ballinger et al. (Ref. 19) and James and Mills (Ref. 30). 
Temperature: The fatigue CGR data in Fig. 10 suggest that environmental enhancement of CGR is greater at higher temperature. However, the existing data are inadequate to determine the effect of temperature on the fatigue CGR of Alloy 600 in low-DO water. For example, tests on susceptible heats of material have either not been conducted at low temperatures or the mechanical loading conditions are such that the contributions of environmental effects are moderate. At $\approx 240^{\circ} \mathrm{C}$, all of the tests have been conducted under loading conditions that correspond to growth rates $>1 \times 10^{-10} \mathrm{~m} / \mathrm{s}$ in air. 9,30 For these conditions, the growth rates of mill-annealed Heat $8034 \mathrm{G}$ are enhanced by a factor of $\approx 2$ in low-DO water. ${ }^{30}$

Dissolved Hydrogen: The dissolved H content in water can influence the nature of corrosion product films on $\mathrm{Ni}$ alloys, and thereby play a role in the crack growth process. A decrease in the bulk $\mathrm{H}$ content in water leads to an increase in the corrosion potential of the material and thus to increased oxidation of the material and higher CGRs. The effects of dissolved hydrogen in low-DO water on CGRs of Alloy 600 have been investigated.8,39 Studies on hot-worked and mill-annealed Alloy 600 tested in simulated PWR water ${ }^{39}$ indicate that the CGRs increase by a factor of 1.5 when dissolved $\mathrm{H}$ content in water is decreased from 25 to $0 \mathrm{~cm}^{3} / \mathrm{kg}$ of water. Similar results have also been observed in mill-annealed Alloy 600 (Heat NX8197) tested in simulated PWR water; 8 CGRs increase when dissolved $\mathrm{H}$ is decreased from 58 to $3 \mathrm{~cm}^{3} / \mathrm{kg}$ of water, Fig. 11. However, the significance of these results on enhanced CGRs in PWR environments is not clear; the results for Heat NX8197, shown in Fig. 10, show little or no effect of environment on CGRs at both 289 and $320^{\circ} \mathrm{C}$.

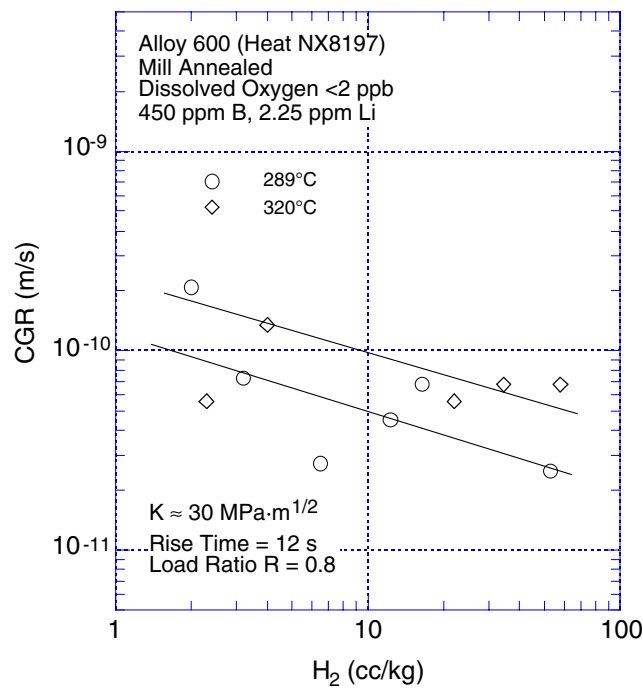

Figure 11.

Dependence of CGRs of Alloy 600 at 289 and $320^{\circ} \mathrm{C}$ on concentration of dissolved hydrogen in simulated PWR water at load ratio of 0.8 . Data obtained at ANL (Ref. 8).

Mechanical Loading. In PWR environments, high load ratios, e.g., 0.75 or higher, and low frequencies produce intergranular cracking, and low load ratios, e.g., 0.5 and lower, and high frequencies produce transgranular cracking. 39 The differing fracture morphology has been explained on the basis of the thermodynamic conditions at the crack tip, i.e., intergranular cracking is enhanced when the crack tip environment contains steam H bubbles.

The existing fatigue crack growth data have been analyzed to develop correlations for estimating the enhancement of CGRs in LWR environments relative to the CGRs in air. Ford and Andresen ${ }^{40,41}$ argue that there are fundamental reasons to expect that in LWR environments, the CGRs of austenitic SSs and Ni alloys should be of the form 


$$
\mathrm{CGR}_{\mathrm{env}}=\mathrm{CGR}_{\mathrm{air}}+\mathrm{A}\left(\dot{\varepsilon}_{C T}\right)^{\mathrm{m}}
$$

where $\mathrm{CGR}_{\mathrm{env}}$ is the CGR in the environment, CGR air is the CGR in air (a relatively inert environment), and $\dot{\varepsilon}_{C T}$ is the crack tip strain rate. The parameters $\mathrm{A}$ and $\mathrm{m}$ depend on the material and the environment. Shoji ${ }^{42}$ has argued that under cyclic loading, $\dot{\varepsilon}_{C T}$ is proportional to $\mathrm{CGR}_{\text {air. }}$. In this case, Eq. 8 can be written as

$$
\mathrm{CGR}_{\mathrm{env}}=\mathrm{CGR}_{\mathrm{air}}+\mathrm{A}\left(\mathrm{CGR}_{\mathrm{air}}\right)^{\mathrm{m}}
$$

which is a form convenient for comparisons with experimental data and which has been widely used to correlate CGR data. Fitting the fatigue crack growth data on Alloy 600 in high-purity water with $\approx 300 \mathrm{ppb}$ DO to Eq. 9 by minimizing the least-squares error between the experimental and predicted CGRs gives the values of $4.4 \times 10^{-7}$ and 0.33 for $\mathrm{A}$ and $\mathrm{m}$, respectively. ${ }^{10}$ The CGRs in the environment estimated from Eq. 9 and the best-fit values of constants $\mathrm{A}$ and $\mathrm{m}$ are plotted in Fig. 9. The same correlation may also be used to represent environmental enhancement of CGRs of the susceptible heats of Alloy 600 in low-DO water.

\subsection{Alloy 690}

The existing fatigue crack growth data on Alloy 690 in high-purity high-temperature water are very limited. The existing database ${ }^{8-11}$ consists of data from $\approx 110$ tests on three heats of Alloy 690, tested in high-purity water at temperatures between 240 and $320^{\circ} \mathrm{C}$; only 15 of these have been conducted in high-DO water, the remainder were conducted in either simulated PWR or $<10 \mathrm{ppb}$ DO water. The loading conditions include $\mathrm{R}=0.2-0.9, \mathrm{~K}_{\max }=$ 30-64 MPa $\cdot \mathrm{m}^{1 / 2}, \Delta \mathrm{K}=3-32 \mathrm{MPa} \cdot \mathrm{m}^{1 / 2}$, and a $12-\mathrm{s}$ rise time. To obtain a qualitative understanding of the degree of enhancement and the range of conditions over which significant environmental enhancement is observed, in Figs. 12 and 13, respectively, we plotted the

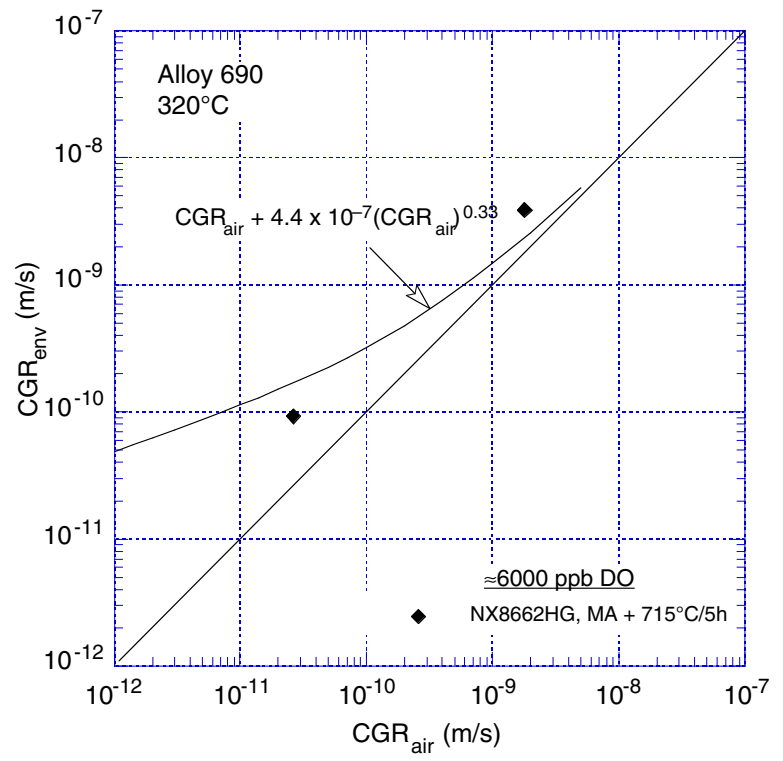

(a)

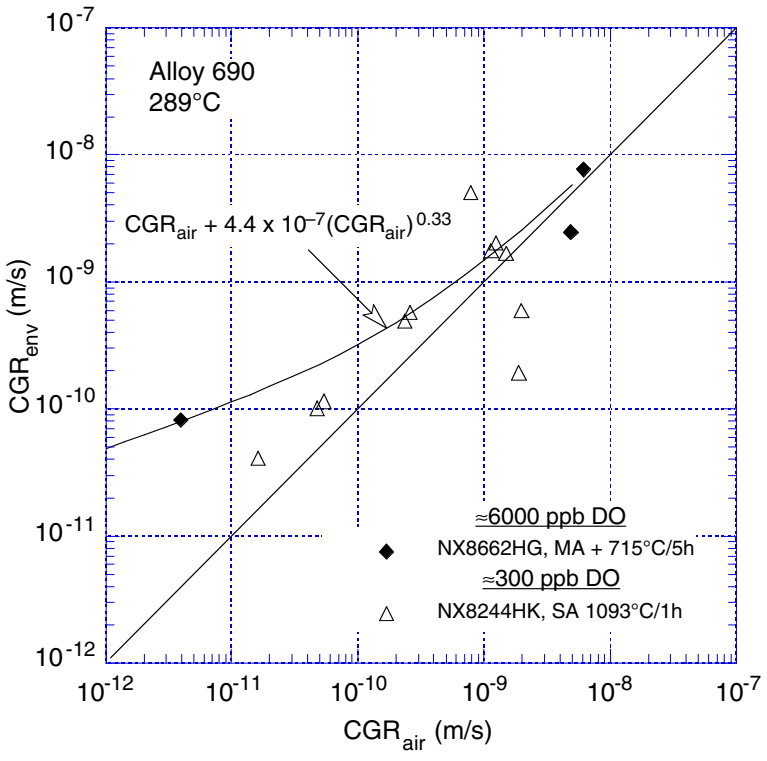

(b)

Figure 12. Corrosion fatigue data for Alloy 690 in high-purity water with $\approx 6000$ or 300 ppb dissolved oxygen at (a) 320 and (b) $289^{\circ} \mathrm{C}$. Data obtained at ANL (Refs. 8-11). 
experimental CGRs against those predicted by Eqs. 6 and 7 for the same mechanical loading conditions for high-DO ( $\geq 300 \mathrm{ppb}$ DO) water and simulated PWR or low-DO $(<10 \mathrm{ppb}$ DO) water.

Limited data indicate some enhancement of growth rates in high-DO (300 ppb or higher DO) water, Fig. 12. Results in high-DO water are bounded by the CGRs estimated from Eq. 9 for Alloy 600 in high-DO water. The results at $240-320^{\circ} \mathrm{C}$ indicate no environmental effects on the CGRs of Alloy 690 in low-DO $(<10$ ppb DO) water under the material and loading conditions investigated, Fig. 13. However, the existing database for Alloy 690 is small and additional tests are needed to verify these results.

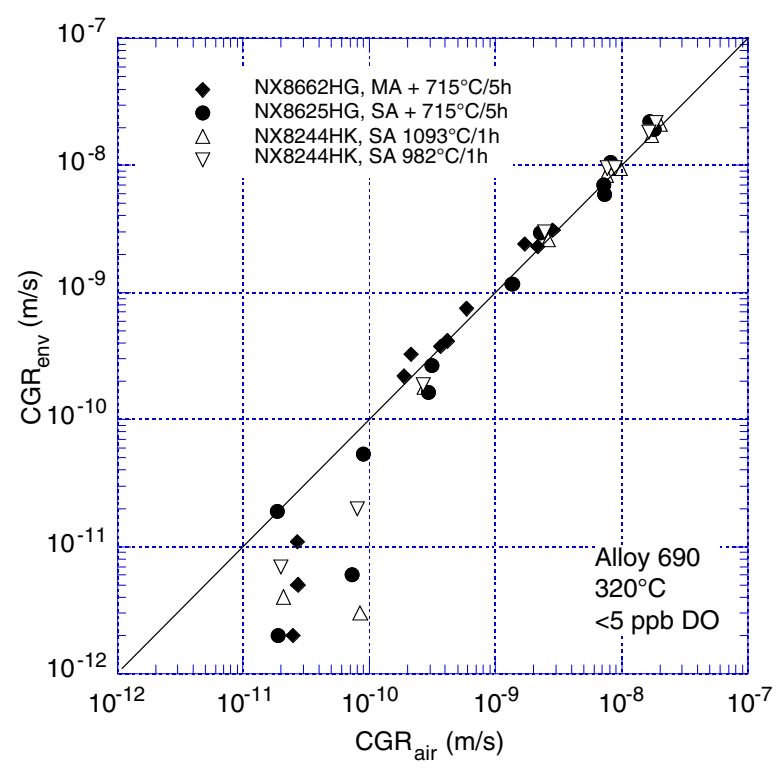

(a)

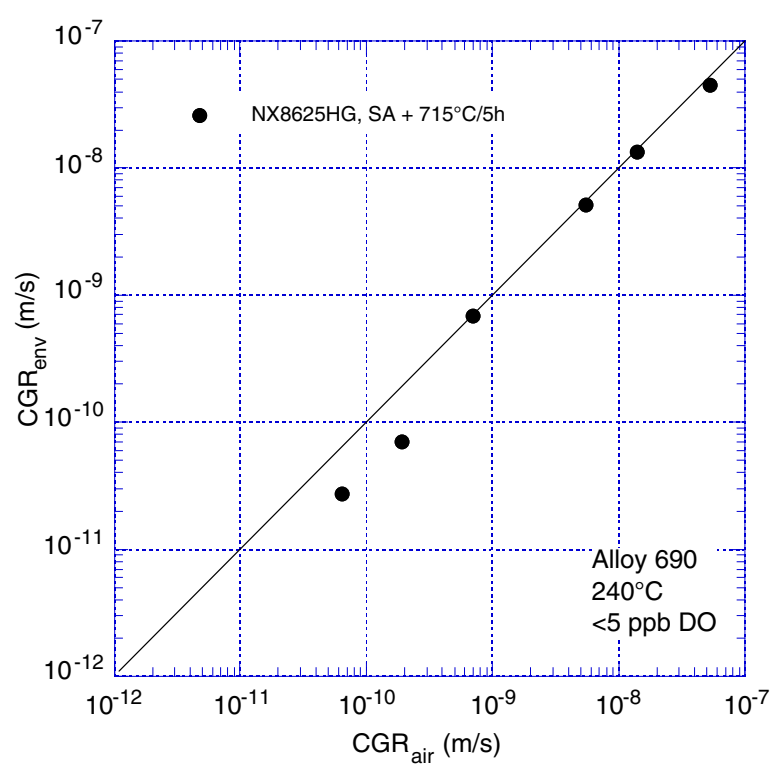

(c)

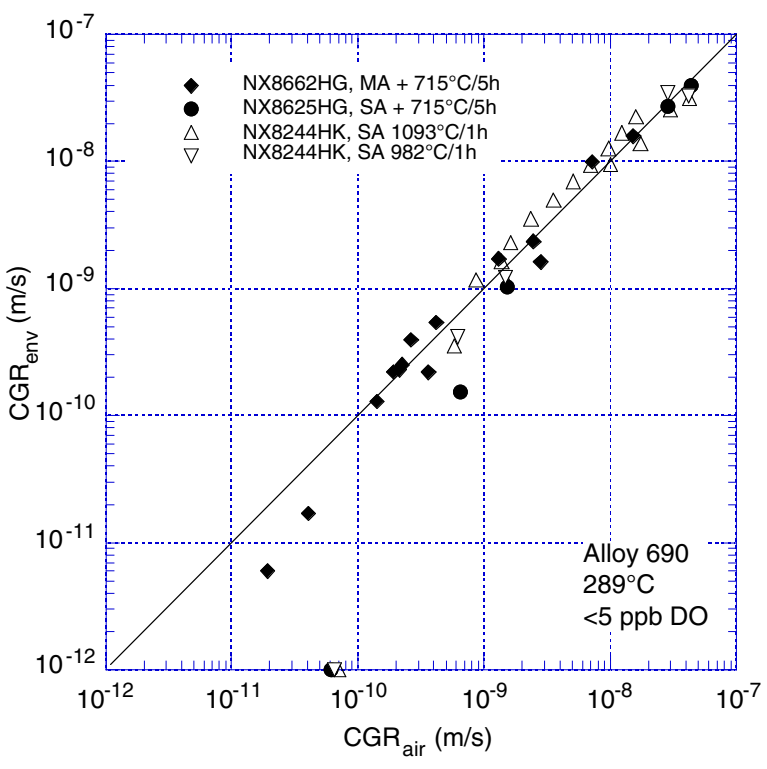

(b)

Figure 13.

Corrosion fatigue data for Alloy 690 in high-purity water with $<10 \mathrm{ppb}$ dissolved oxygen at (a) 320, (b) 289 , and (c) $240^{\circ} \mathrm{C}$. Data obtained at ANL (Refs. 8-11). 


\subsection{Weld Metals}

The fatigue crack growth data on Ni-alloy welds consists of results of $\approx 100$ tests in simulated PWR environments at temperatures between 243 and $345^{\circ} \mathrm{C}$, and $\approx 10$ tests in BWR environments at $288^{\circ} \mathrm{C}$. The data in PWR water have been obtained from 22 tests on Alloy 182, 74 tests on Alloy 82, and 4 tests on Alloy $52.20,29,30,43$ The loading conditions for these tests include $\mathrm{R}=0.1-0.75, \mathrm{~K}_{\max }=20-104 \mathrm{MPa} \cdot \mathrm{m}^{1 / 2}, \Delta \mathrm{K}=17-93 \mathrm{MPa} \cdot \mathrm{m}^{1 / 2}$, and rise time $=$ $0.5-5000 \mathrm{~s}$. The tests in BWR water were conducted on as-welded Alloy 182 at $\mathrm{R}=0.6-0.8$, $\mathrm{K}_{\max }=30 \mathrm{MPa} \cdot \mathrm{m}^{1 / 2}, \Delta \mathrm{K}=6-13 \mathrm{MPa} \cdot \mathrm{m}^{1 / 2}$, and rise times of 1800 and $4800 \mathrm{~s} .{ }^{44}$

To determine the enhancement of CGRs of the weld metals in simulated PWR environments relative to those of Alloy 600 in air, experimental CGRs for the weld metals in water and those predicted by Eqs. 4 and 5 for Alloy 600 in air under the same mechanical loading conditions are plotted in the Fig. 14. The CGRs estimated from Eq. 9 for Alloy 600 in high-temperature water are also shown in the figure. The significant results are summarized below.

Fatigue CGR data for Alloy 182 and Alloy 82 are shown in Figs. 14a and b. Most of the data for $\mathrm{Ni}$ alloy welds have been obtained under loading conditions that correspond to $>1 \times 10^{-9} \mathrm{~m} / \mathrm{s}$ CGRs in air. As discussed in Section 4.1, under these loading conditions, environmental enhancement of growth rates would be moderate even in materials that are susceptible to environmentally enhanced cracking. In PWR water at $\approx 320^{\circ} \mathrm{C}$ (Fig. 14a), the CGRs for Alloy 182 welds are up to a factor of 10 higher than the predicted fatigue CGRs of Alloy 600 in PWR environments. The enhanced growth rates under these loading conditions are unlikely to be primarily due to the effects of environment; in air, the fatigue CGRs of Alloy 182 weld are a factor of 2 greater than those of Alloy 600, see Fig. 8. The chloride content in water was not found to significantly influence the CGRs of Alloy 182 in PWR water, e.g., comparable CGRs were obtained when the chloride content was increased from 0.15 to $0.5 \mathrm{ppm} .{ }^{20}$

In PWR water at $\approx 320^{\circ} \mathrm{C}$ (Fig. 14b), the CGRs of Alloy 82 welds are generally a factor of $\approx 4$ higher than the predicted fatigue CGRs of Alloy 600 in PWR environments; some values are up to a factor of $\approx 8$ higher. ${ }^{20}$ The large scatter in growth rates has been attributed to variations in the weld structure. Fatigue crack growth data for Alloy 82 welds in air are not available to determine whether these enhanced rates are due to the environment alone. Changes in frequency from 1 to $0.00018 \mathrm{~Hz}$ did not substantially change the CGRs of Alloy 82 welds. ${ }^{43}$ The lack of frequency dependence suggests that under the loading conditions that have been investigated, environment exhibits a minor influence on CGRs of Alloy 82 welds, but as noted previously, most of the data have been obtained under loading conditions that correspond to $>1 \times 10^{-9} \mathrm{~m} / \mathrm{s}$ CGRs in air, in which case environmental effects are unlikely to be significant.

Enhancement of growth rates of up to a factor of $\approx 8$ are also observed for Alloy 182 welds at $243^{\circ} \mathrm{C} .{ }^{30}$ At $243^{\circ} \mathrm{C}$, growth rates do not appear to be influenced by the orientation of the crack plane relative to the weld dendrite, e.g., comparable CGRs are observed for specimens oriented parallel or perpendicular to the weld dendrites. These results are in contrast to the strong influence of crack orientation observed in SCC growth rates of Ni alloy welds in PWR environments; as discussed later in Section 5.3, SCC CGRs are significantly greater in a direction parallel to the weld dendrites than in a perpendicular direction. 


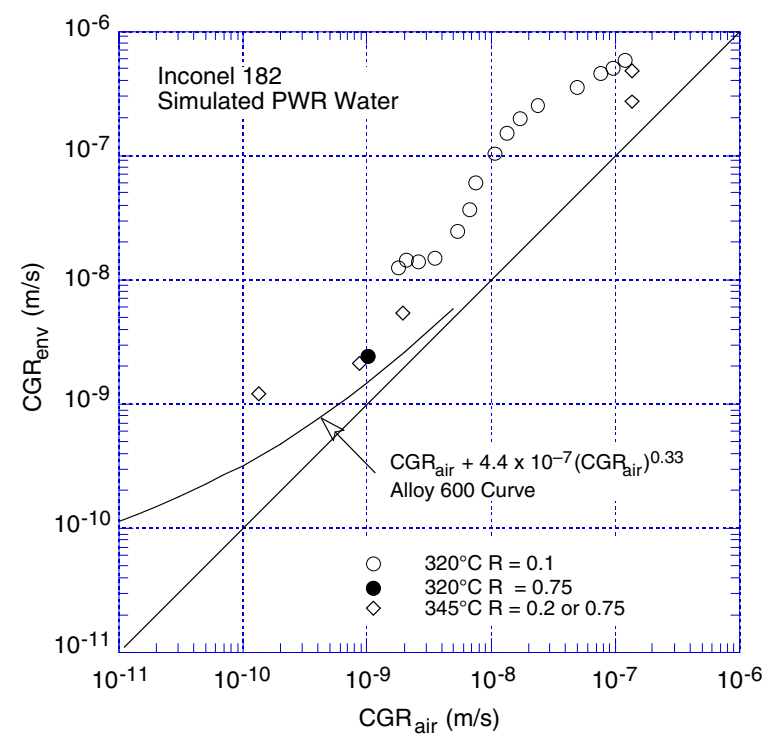

(a)

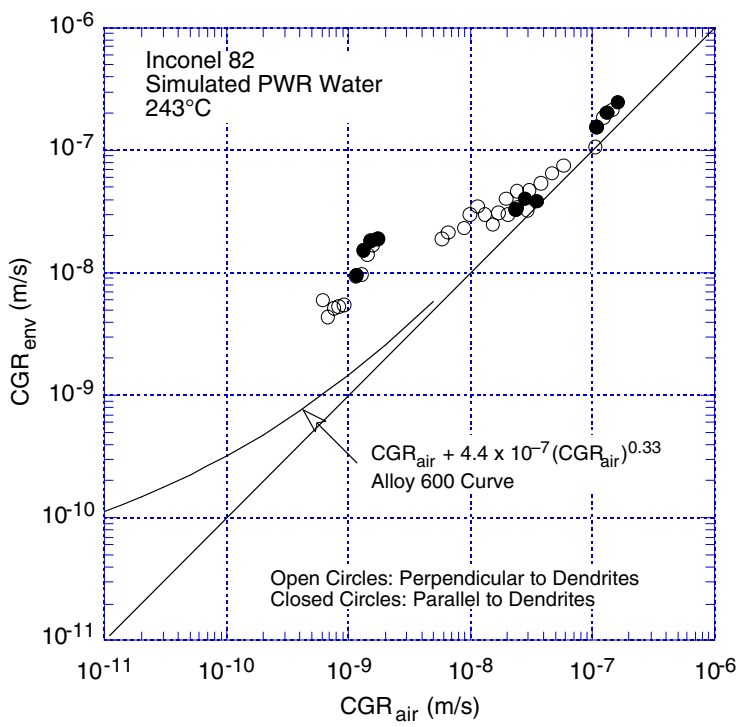

(c)

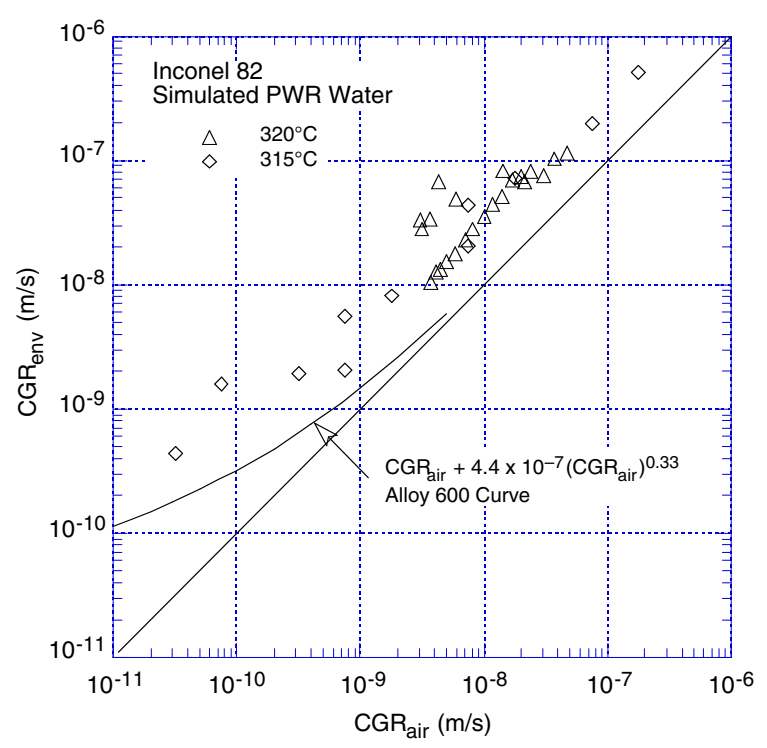

(b)

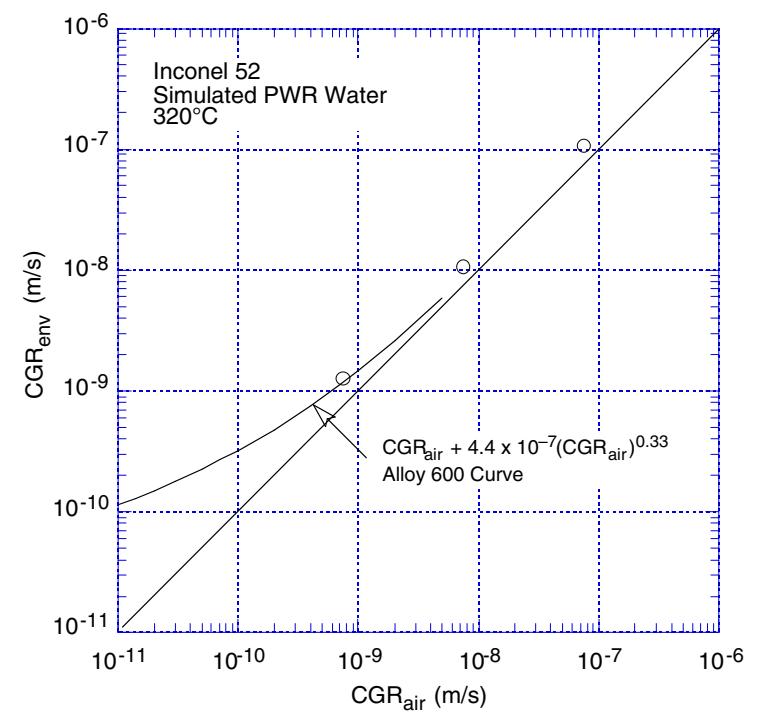

(d)

Figure 14. Corrosion fatigue data in simulated PWR water at $243-345^{\circ} \mathrm{C}$ for (a) Alloy 182 , (b) and (c) Alloy 82, and (d) Alloy 52. Data obtained by Amzallag et al. (Ref. 20), Lindstrom et al. (Ref. 29), James and Mills (Ref. 30), and Dombrowski et al. (Ref. 43).

Little or no enhancement of CGRs in PWR water is observed in the existing fatigue CGR data for Alloy 52 welds (Fig. 14d). However, most of the tests have been conducted under loading conditions that correspond to $>1 \times 10^{-9} \mathrm{~m} / \mathrm{s}$ CGRs in air, for which case environmental effects are not expected to be significant.

The environmental enhancement of CGRs of Alloy 82 and 182 welds observed in Fig. 14 is quite different from that observed typically for Alloys 600 and 690 and austenitic SSs. For the latter, environmental effects on CGRs are generally not significant under loading conditions that produce $>1 \times 10^{-9} \mathrm{~m} / \mathrm{s}$ CGRs in air. Additional tests are needed to confirm these results. 
The experimental CGRs of Alloy 182 welds in a BWR environment and those predicted by Eqs. 4 and 5 for Alloy 600 in air under the same mechanical loading conditions are plotted in Fig. 15. The results indicate enhancement of CGRs in Alloy 182 welds in a normal water chemistry (NWC) BWR environment. The CGRs estimated from Eq. 9 for Alloy 600 in high-temperature water are also shown in the figure. The results for Alloy 182 welds in NWC BWR water show good agreement with the predicted curve for Alloy 600. The CGRs of Alloy 182 are greatly decreased at very low levels of DO in water. For example, the CGRs decreased by a factor of 5-10 when DO level was decreased from 200 to $10 \mathrm{ppb}$. ${ }^{44}$, The crack growth, however, does not cease at the low DO levels. A similar benefit was observed when DO level was decreased from 700 to $200 \mathrm{ppb}$.
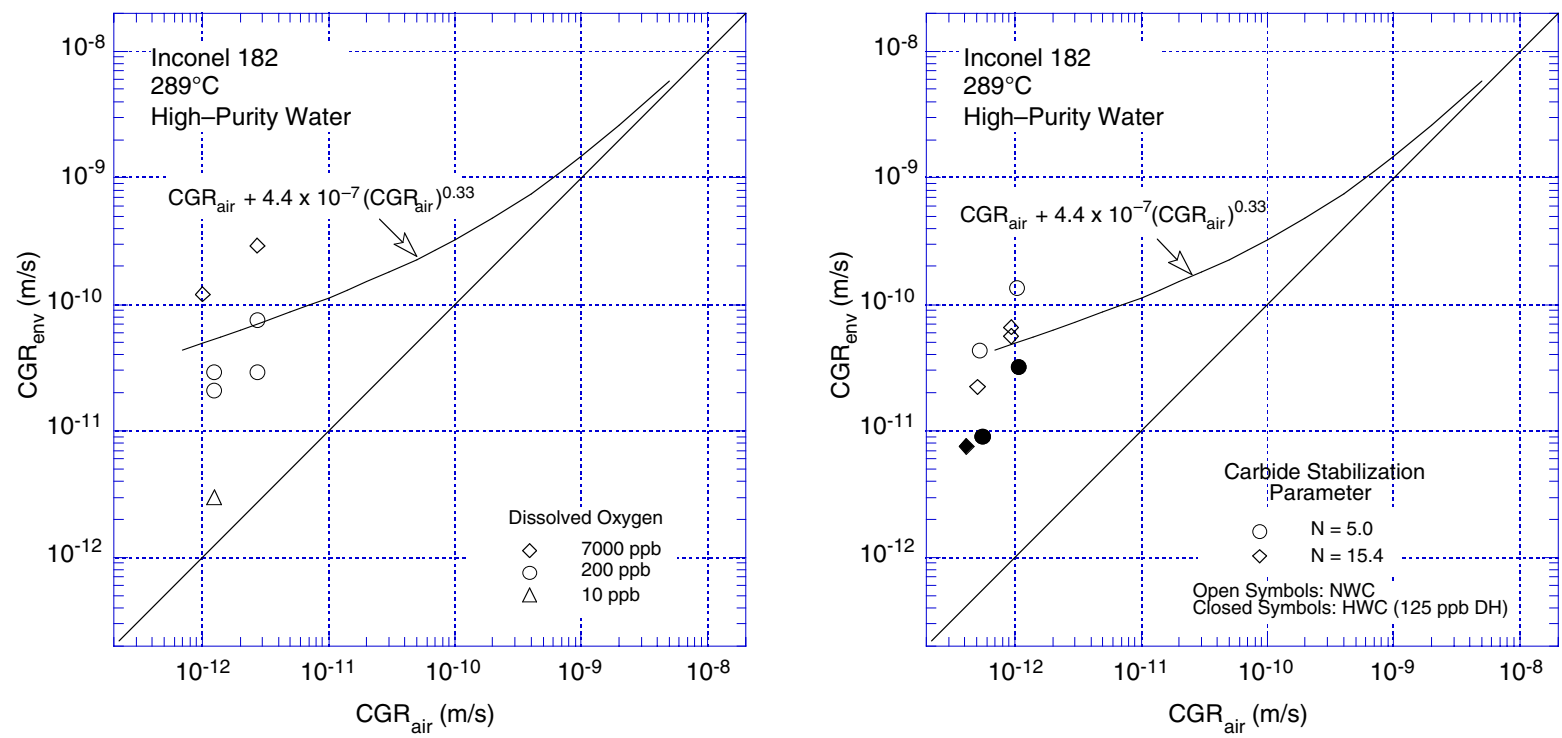

Figure 15. Corrosion fatigue data for Alloy 182 in high-DO water at $288^{\circ} \mathrm{C}$. Data obtained by Andresen (Ref. 44). 


\section{Stress Corrosion Cracking}

\subsection{Alloy 600}

Stress corrosion cracking data on Alloy 600 have been obtained on circumferentially cracked tube specimens, ${ }^{45}$ notched plate specimens made from flattened tubing, ${ }^{46}$ double notched tubular specimens, ${ }^{47}$ constant displacement specimens such as wedge-open-loaded or double cantilever beam, ${ }^{37,48,49}$ and compact tension specimens. ${ }^{11,38,49,50}$ Tests have been conducted on several heats of Alloy 600 in simulated PWR environments with $<10 \mathrm{ppb}$ DO or in high-purity water with $200-300 \mathrm{ppb}$ DO under several heat treatment conditions. Test temperatures ranged from 290 to $360^{\circ} \mathrm{C}$ for low-DO water and 200 to $320^{\circ} \mathrm{C}$ for high-DO water.

The results indicate that Alloy 600 is susceptible to SCC in simulated PWR environments. Under most of the loading and environmental conditions that have been investigated, the crack growth from SCC is predominantly intergranular. The significant results and influence of critical parameters on growth rates in simulated PWR water or low-DO water are summarized below.

Stress Intensity: The results indicate a strong dependence of stress intensity on CGRs up to $\approx 25 \mathrm{MPa} \cdot \mathrm{m}^{1 / 2}$; by increasing the stress intensity from $\approx 5$ to $\approx 25 \mathrm{MPa} \cdot \mathrm{m}^{1 / 2}$, the growth rates can increase from $1 \times 10^{-11}$ to $1 \times 10^{-9} \mathrm{~m} / \mathrm{s}$. The CGRs are relatively insensitive to stress intensity at values $>25 \mathrm{MPa} \cdot \mathrm{m}^{1 / 2}$; see Fig. 16 . The threshold value of stress intensity for SCC in low-DO water may be in the range of $5-10 \mathrm{MPa} \cdot \mathrm{m}^{1 / 2} .46$

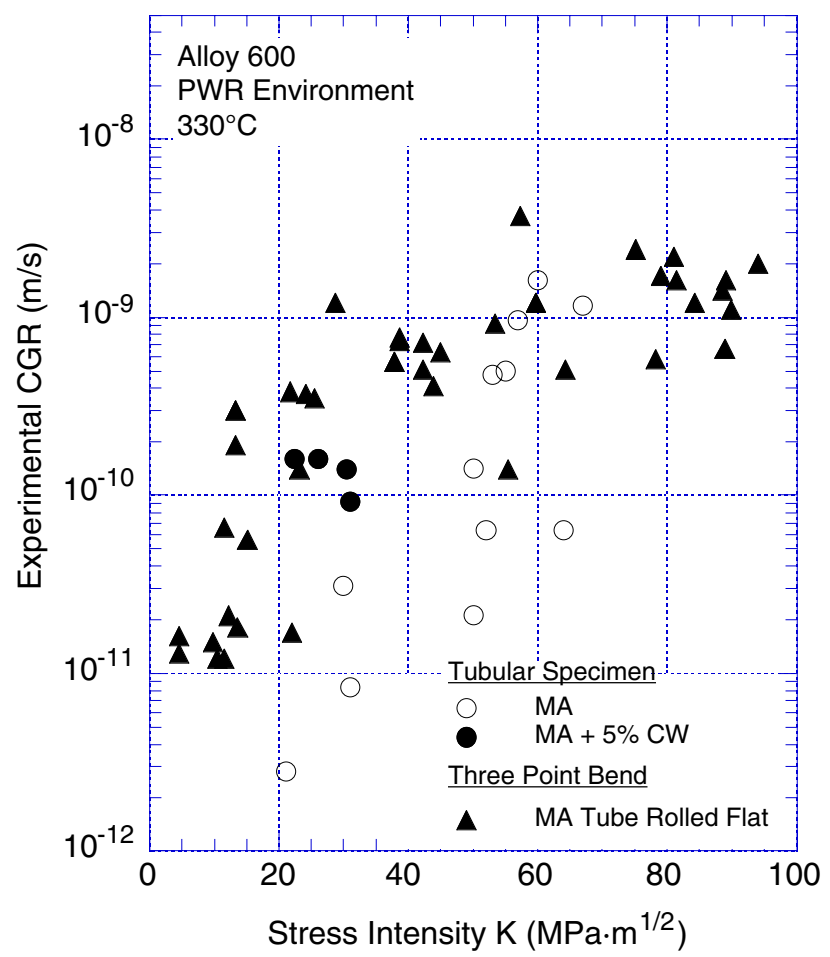

Figure 16.

Effects of applied stress intensity and cold work on CGRs in Alloy 600 in simulated PWR water at $330^{\circ} \mathrm{C}$. Data obtained by Cassagne and Gelpi (Ref. 47), Lott et al. (Ref. 45), and Rebak et al. (Ref. 46). 
Temperature: CGRs increase with temperature between 290 and $360^{\circ} \mathrm{C}$. The effects of temperature on SCC growth rates are best characterized by an activation energy of $130 \mathrm{~kJ} / \mathrm{mole}$; actual values for individual data sets range from 100 to $180 \mathrm{~kJ} / \mathrm{mole} \cdot{ }^{37,38,47,49}$ Cold work does not seem to influence the activation energy for SCC growth rates, at least in the temperature range of $290-360^{\circ} \mathrm{C}$; see Fig. $17.37,47,49$

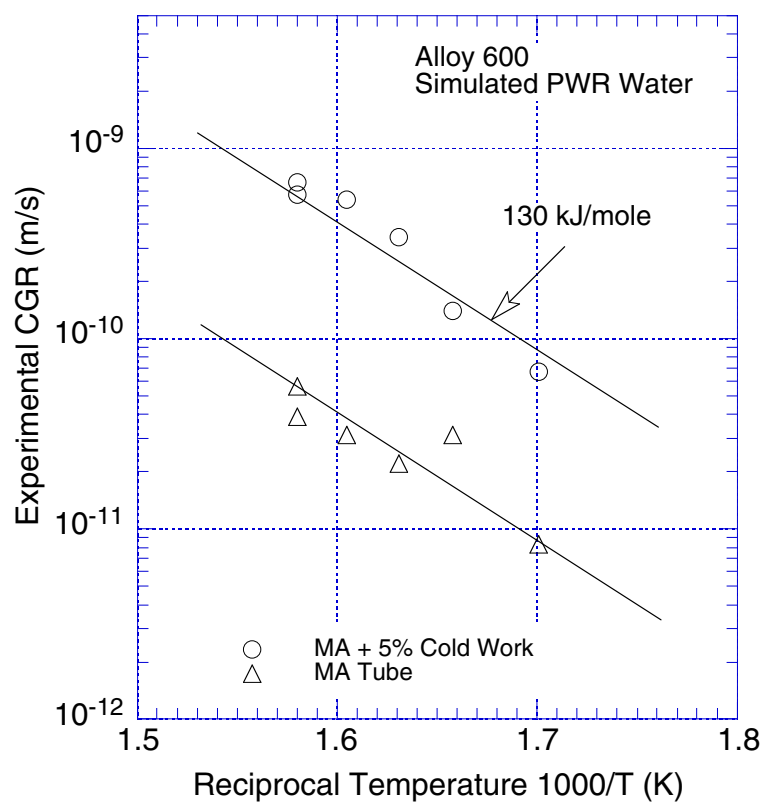

Figure 17.

Effect of temperature on CGRs of Alloy 600 in PWR environment. Data obtained by Cassagne and Gelpi (Ref. 47).

Cold Work: Several studies have established the effect of cold work on the susceptibility of Alloy 600 to intergranular SCC in low-DO PWR environments. $37,46,47,49$ Moderate amounts of cold work are more detrimental than severe amounts of cold work. For example, CGRs are enhanced by one order of magnitude from only 5\% cold work, Fig. 18; further amounts of cold work lead to only moderate enhancement in CGR. Because cold work increases the yield strength of the material, an effect similar to that of cold work on CGRs is also observed for yield strength on CGRs; ${ }^{37,49}$ CGRs are increased with an increase in yield stress. However, the individual effect of an increase in yield stress due to microstructural changes or from cold work, on the growth rates is not well established.

The influence of cold work on SCC growth rates is attributable to its effect on dislocation density and the deformation behavior ahead of the crack tip. The SCC susceptibility of $\mathrm{Fe}-\mathrm{Cr}-\mathrm{Ni}$ alloys has been correlated with the dislocation arrangements in the material. ${ }^{51}$ For example, planar dislocation structures lead to transgranular SCC, whereas intergranular SCC is observed in materials with high stacking fault energy, e.g., Ni-base alloys. Bruemmer showed that a mill-annealed and 5\% cold-worked Alloy 600 contained higher dislocation density near the grain boundary than in the grains. ${ }^{52}$ The greater susceptibility of the cold-worked Alloy 600 has been explained by localized plastic deformation at the grain boundaries, preventing relaxation at the crack tip.

Microstructure: The effects of the various metallurgical parameters on the SCC of Alloy 600 are not well known because these parameters are not independent. ${ }^{53}$ In general, materials with extensive grain boundary coverage with fine carbides and a low yield strength exhibit low 


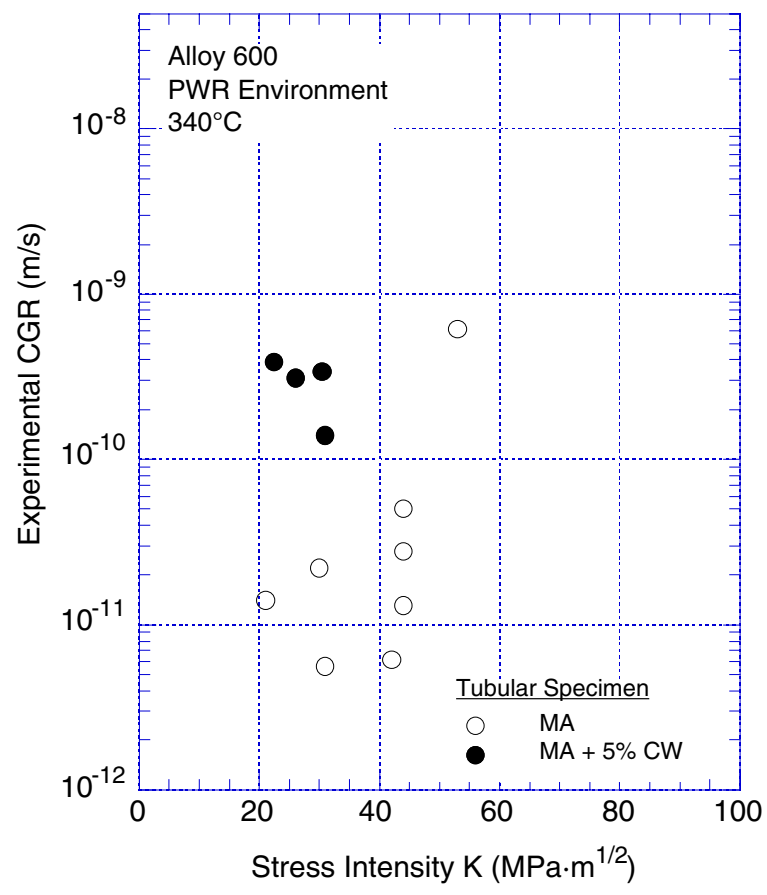

(a)

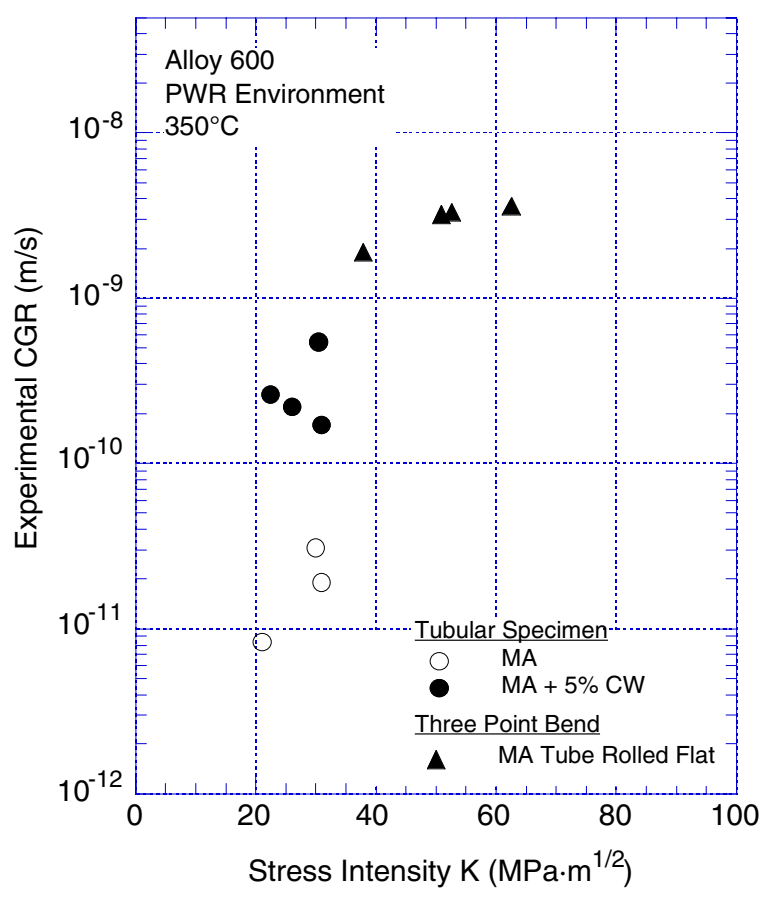

(b)

Figure 18. Effect of cold work on CGRs in Alloy 600 in simulated PWR water at (a) 340 and (b) $350^{\circ} \mathrm{C}$. Data obtained by Cassagne and Gelpi (Ref. 47) and Rebak et al. (Ref. 46).

susceptibility to SCC. ${ }^{37,38}$ A low grain boundary coverage and a high intragranular carbide density, along with a high yield strength, lead to high SCC susceptibility.

Water Chemistry: The effects of water chemistry on the SCC in Alloy 600 in simulated PWR environments are not well established. Rebak et al. ${ }^{46}$ have shown an effect of water chemistry that was caused by the solution $\mathrm{pH}$ rather than by the presence of $\mathrm{B}$ or $\mathrm{Li}$ in the solution. Their results also indicate that the CGRs of Alloy 600 do not change significantly over the $\mathrm{pH}$ range typical for PWRs, i.e., 6.9-7.4. Contrary to this, Lott et al. ${ }^{45}$ have shown effects of $\mathrm{B}$ or $\mathrm{Li}$ content on SCC in Alloy 600. For example, their results indicate that at a given pH, the CGRs can be significantly changed by independently changing either the B or Li content in the water.

Hydrogen: Most of the studies on the influence of H on the SCC susceptibility of Alloy 600 have been carried out with slow strain rate tests that include both crack initiation and propagation. CGR measurements on Alloy 600 tubing at $360^{\circ} \mathrm{C}$ in hydrogenated water with all-volatile treatment ${ }^{47}$ indicate that the CGRs increased as $\mathrm{H}$ partial pressure was decreased from 0.15 to 0.02-0.03 $\mathrm{MPa}$, and the CGRs then decreased with further decrease in $\mathrm{H}$ partial pressure, until the cracks essentially stopped growing. A similar behavior has been observed for Alloy 600 in $400^{\circ} \mathrm{C}$ steam. ${ }^{54}$

Cyclic Loading: The effects of periodic cyclic loading during a constant load SCC test have also been investigated. 49 The results indicate that at $290^{\circ} \mathrm{C}$, cyclic loading increased the CGRs and induced transgranular cracks in Alloy 600. 
The results indicate a dependence of stress intensity on CGR in high-DO water similar to that observed for Alloy 600 in simulated PWR or low-DO water. Sulfate addition to the water, enhanced CGRs of Alloy 600; see Fig. 19. ${ }^{11,50}$ Also, limited data suggest that moderate amounts of cold work enhance CGRs. However, because all of the tests in high-DO water have been obtained at $320^{\circ} \mathrm{C}$ or lower, the CGRs in high-DO water show little or no effect of temperature in the range of $200-320^{\circ} \mathrm{C}$, Fig. 20. ${ }^{11}$ SCC studies on Alloy 600 in simulated BWR environments ${ }^{50}$ indicate that in $\mathrm{NWC}$, cracking is enhanced in high-C alloys by heat treatments that lead to the formation of $\mathrm{Cr}$ carbides at the grain boundaries, or in alloys that
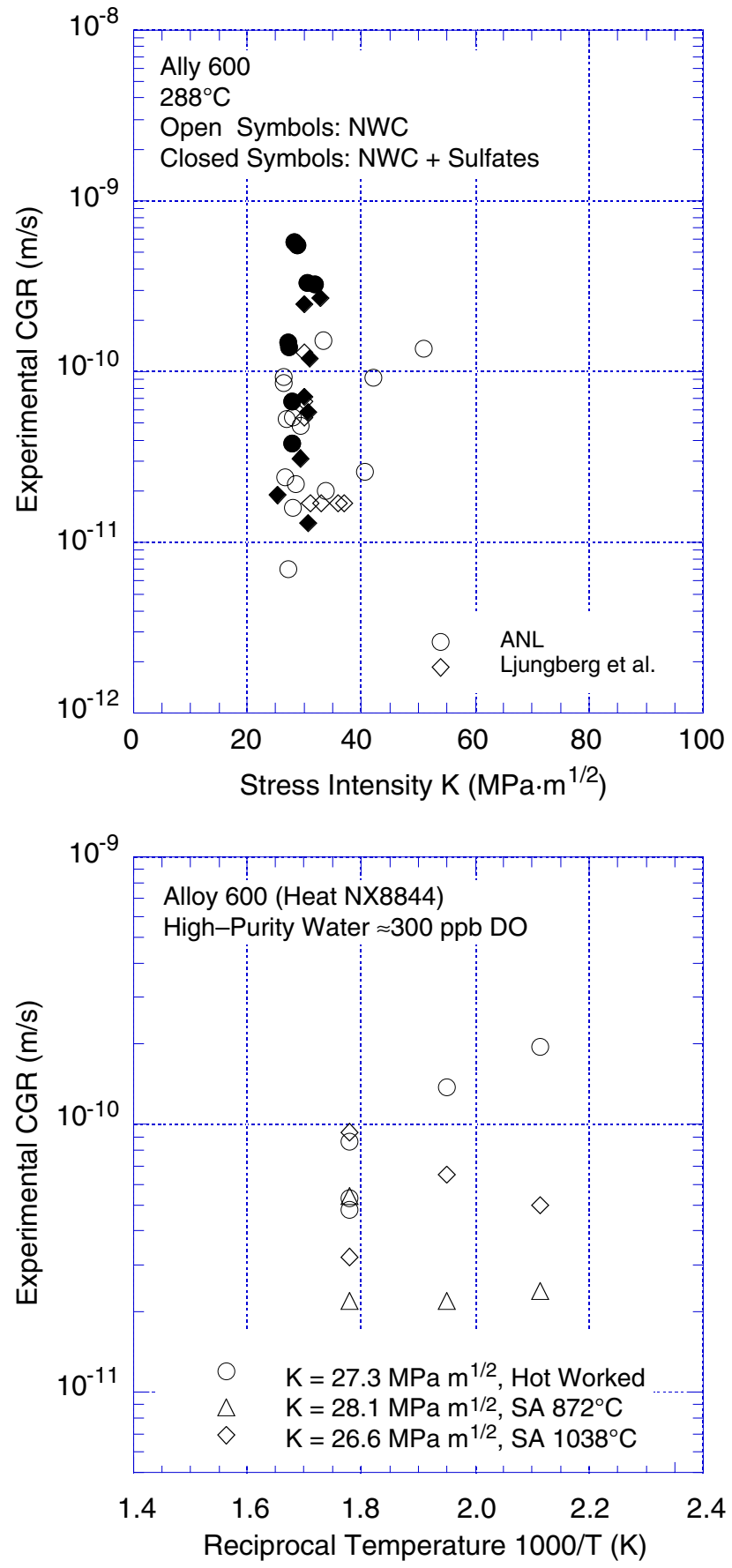

Figure 19.

Effects of applied stress intensity and sulfate additions on CGRs in Alloy 600 in BWR water with NWC at $288^{\circ} \mathrm{C}$. Data obtained at ANL (Ref. 11) and by Ljungberg et al. (Ref. 50).

Figure 20.

Effect of temperature on crack growth rates of Alloy 600 in high-dissolved oxygen high-purity water. Data obtained at ANL (Ref. 11). 
contain high concentrations of $\mathrm{P}$ and $\mathrm{S}$. Hydrogen water chemistry decreased CGRs in Alloy 600, particularly in materials low in P and S. ${ }^{50}$

\subsection{Alloy 690}

The relevant SCC crack growth data on Alloy 690 are very limited. ${ }^{11}$ The results shown in Fig. 21 for simulated BWR environments indicate little dependence of stress intensity on CGRs; the rates range between $\approx 2 \times 10^{-12}$ and $6 \times 10^{-12} \mathrm{~m} / \mathrm{s}$. Also, the addition of sulfates exerted no effect on the growth rates of Alloy 690. ${ }^{11}$ However, these values may be below the sensitivity of the crack length monitoring system.

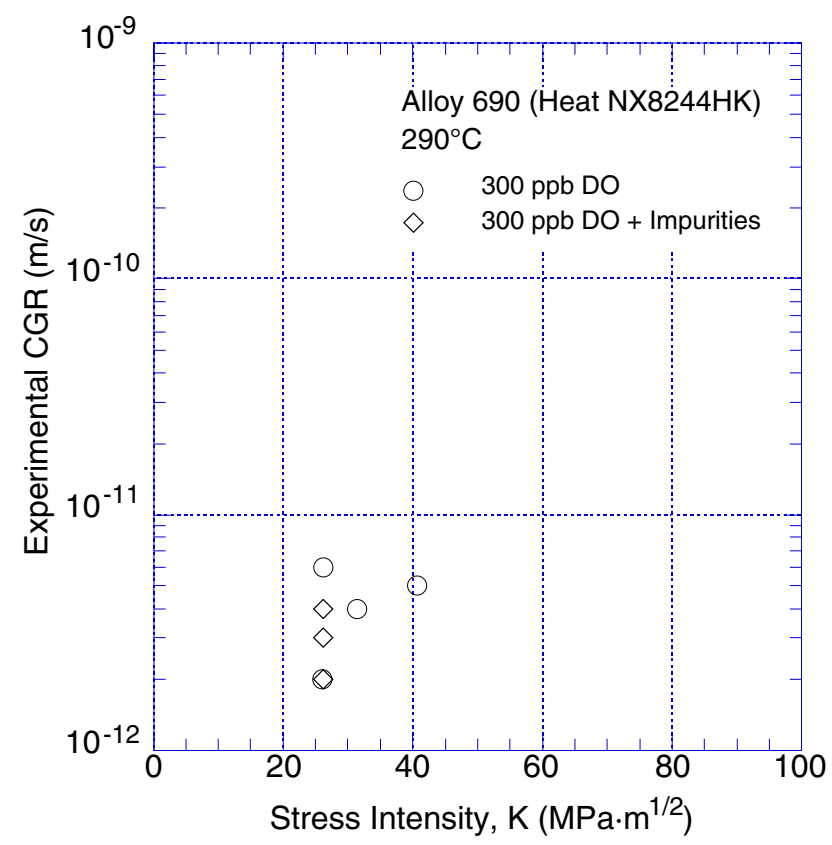

Figure 21.

Effect of applied stress intensity on crack growth rates in Alloy 690 in high-purity water at $290^{\circ} \mathrm{C}$. Data obtained at ANL (Ref. 11).

The fracture resistance of $\mathrm{Ni}$ alloys and their welds has been investigated by conducting fracture toughness $\mathrm{J}-\mathrm{R}$ curve tests at $24-338^{\circ} \mathrm{C}$ in deionized water with $<20 \mathrm{ppb}$ DO and dissolved $\mathrm{H}$ levels of $125-200 \mathrm{~cm}^{3} / \mathrm{kg}$ of water. ${ }^{55,56}$ The results indicate that Alloy 690 exhibits excellent fracture toughness in air and high-temperature water $\left(>93^{\circ} \mathrm{C}\right)$. However, the apparent fracture toughness of Alloy 690 is dramatically reduced in $54^{\circ} \mathrm{C}$ water under slow rising loads; the fracture toughness $\mathrm{J}_{\mathrm{IC}}$ and tearing modulus are reduced by one to two orders of magnitude. The reductions have been attributed to a $\mathrm{H}$-induced intergranular cracking mechanism. Hydrogen from the water reduces grain boundary cohesive strength and promotes planar slip, which localizes strain concentrations along the grain boundaries. In other systems, such decreases in apparent fracture toughness in slow rising load tests have been associated with susceptibility to SCC.

\subsection{Weld Metals}

The SCC database on Alloy 82 and 182 welds reviewed in this paper consists of results of $\approx 250$ tests on Alloy 182 and $\approx 12$ tests on Alloy 82 in simulated PWR and BWR environments. Approximately one-fifth of the data on Alloy 182 have been obtained in simulated PWR water; ${ }^{29,38,57}$ the remainder, in simulated BWR water. ${ }^{44,50,58-62}$ The data in simulated PWR 
water have been obtained primarily on as-welded material tested at $290-345^{\circ} \mathrm{C}$ and maximum stress intensity $\mathrm{K}_{\max }$ in the range of $13-49 \mathrm{MPa} \cdot \mathrm{m}^{1 / 2}$. In these tests, the crack orientation was generally parallel to the weld dendrites. The data in simulated BWR water have been obtained on both as-welded material and material with differing thermal treatments, tested at $288^{\circ} \mathrm{C}$ and maximum stress intensity $\mathrm{K}_{\max }$ in the range of $12-67 \mathrm{MPa} \cdot \mathrm{m}^{1 / 2}$. The data on Alloy 82 in this review have been obtained on as-welded material; four tests were performed at $275^{\circ} \mathrm{C}$ in BWR water with $\mathrm{NWC},{ }^{58}$ and eight at $360^{\circ} \mathrm{C}$ in low-DO water with $150 \mathrm{~cm}^{3} \mathrm{H} / \mathrm{kg}$ of water. ${ }^{55}$

The results indicate that Alloy 182 welds are susceptible to SCC in simulated PWR environments. The data exhibit significant scatter, which is probably associated with the irregular crack fronts that are often observed on Alloy 182 welds. The CGRs reported in all of the studies represent the maximum values obtained from the maximum crack length measured anywhere along the crack front. The average CGRs are a factor of $\approx 2$ lower than the maximum values. ${ }^{57}$ The significant results and influence of critical parameters on growth rates of Alloy 182 welds in simulated PWR water are summarized below.

Material Condition: The results indicate a significant effect of crack orientation on CGRs. Crack growth along the weld dendrites occurs at a rate $\approx 5$ times faster than the rate obtained when the crack is growing across the dendrites; see Fig, 22. ${ }^{57}$ In these tests in a PWR environment, a stress relief heat treatment at $610^{\circ} \mathrm{C}$ for $6 \mathrm{~h}$ appears to have a beneficial effect on CGRs in low-C welds, most likely because the stress relief treatment increases the grain boundary coverage of carbides in low-C welds. ${ }^{38}$

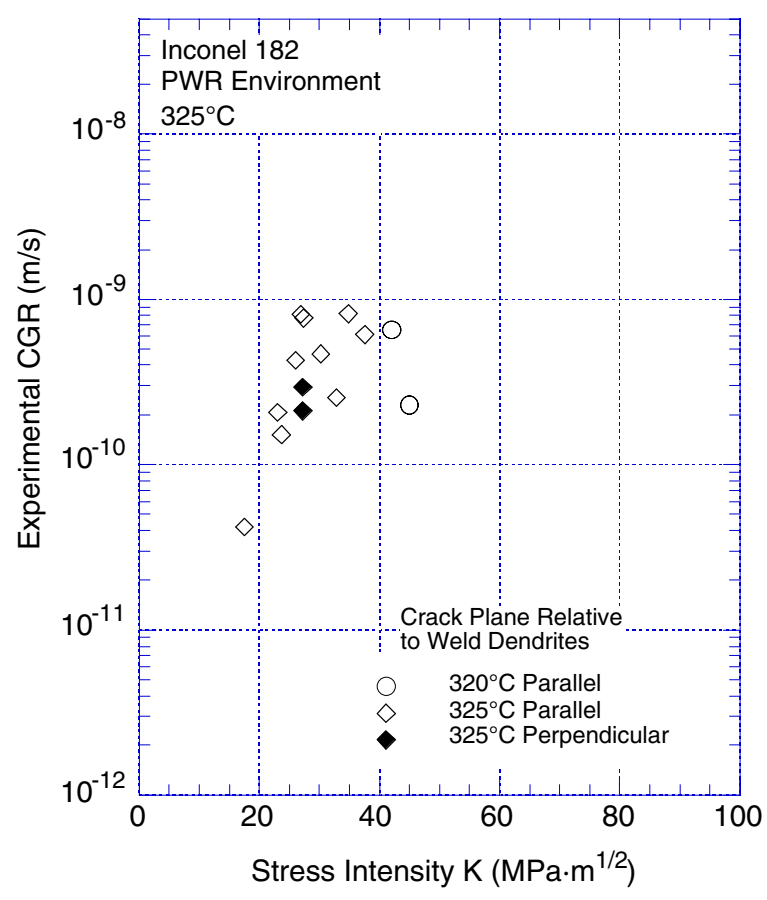

(a)

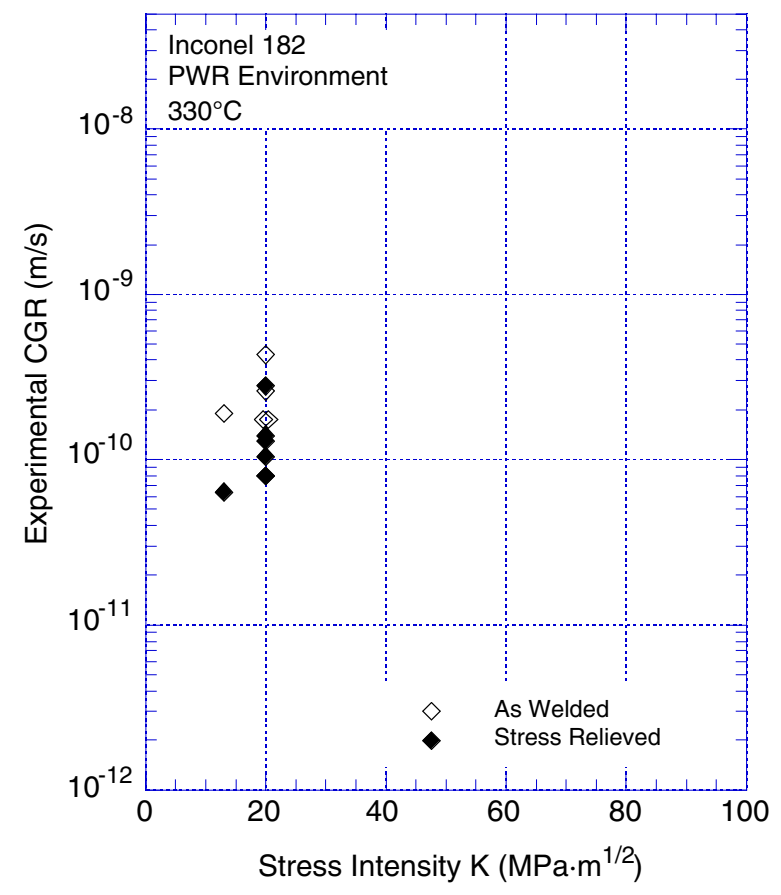

(b)

Figure 22. Effects of (a) crack orientation relative to the weld dendrites and (b) stress relief on SCC CGRs in Alloy 182 welds in simulated PWR environment. Data obtained by Bamford et al. (Ref. 57) and Cassagne et al. (Ref. 38). 
Mechanical Loading: The effects of applied maximum stress intensity on CGRs in Alloy 182 in a PWR environment follow the trends observed for Alloy 600. However, the existing database for Alloy 182 is very small and additional tests on various material conditions and a wide range of applied stress intensities are needed to verify these results. ${ }^{57}$

Temperature: The limited data suggest that the temperature dependence of growth rates is similar to that observed for Alloy 600; the variation in CGRs of Alloy 182 welds with temperature can be represented by an activation energy of $130 \mathrm{~kJ} /$ mole. $^{38,57}$

Alloy 182 welds are also susceptible to SCC in BWR environments with NWC (typically $\approx 200 \mathrm{ppb}$ DO and $<10 \mathrm{ppb}$ dissolved H). In general, the SCC susceptibility of Alloy 182 welds is greater than that of Alloy 600.44,50,58-62 The significant results and influence of critical parameters on growth rates of Alloy 182 welds in simulated BWR water are summarized below.

Crack Orientation: Similar to the behavior in low-DO PWR environments, cracking in high-DO BWR environments is also much faster parallel to the weld dendrites than in a direction perpendicular to the dendrites, see Fig. 23. The large difference in CGRs between the two directions in the weld metal has been attributed to the difference in segregation of $\mathrm{P}$ and $\mathrm{S}$ during cooling from the fusion temperature; the carbide precipitation is expected to be similar on both dendrite boundaries and intradendrite grain boundaries.

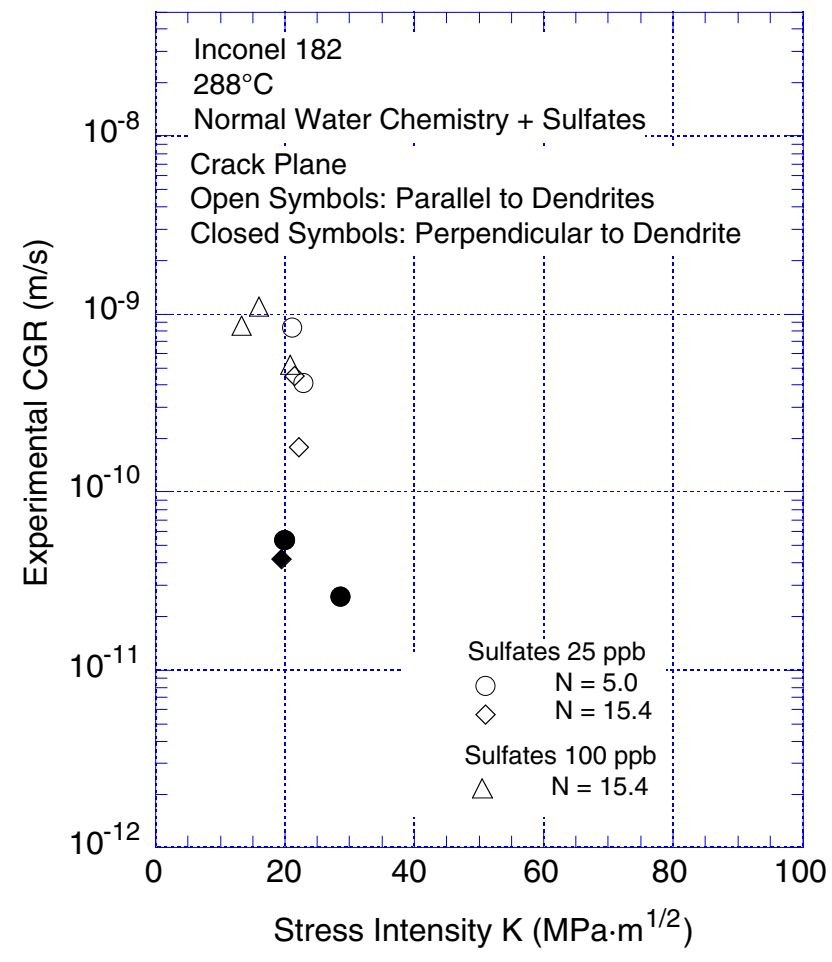

Figure 23.

Effect of crack orientation relative to weld dendrites on CGRs in Alloy 182 welds in BWR environment with normal water chemistry. Data obtained by Ljungberg et al. (Ref. 50).

Water Chemistry: Sulfate addtions in oxygenated environments enhanced CGRs of Alloy 182 welds. For example, addition of $100 \mathrm{ppb}$ sulfate to NWC increased the CGRs of Alloy 182 welds by one order of magnitude; see Fig. 24. Hydrogen water chemistry (HWC) (typically $<5$ ppb DO and $\approx 125 \mathrm{ppb}$ dissolved $\mathrm{H}$ ) decreased the CGRs of Alloy 182 welds; the measured CGRs in Alloy 182 welds were $1 \times 10^{-12} \mathrm{~m} / \mathrm{s} .{ }^{50}$ The beneficial effect of HWC was larger for welds with low $\mathrm{P}$ 
and S content. Also, the beneficial effect of reduced O levels was not observed in high sulfate environments; see Fig. 25.
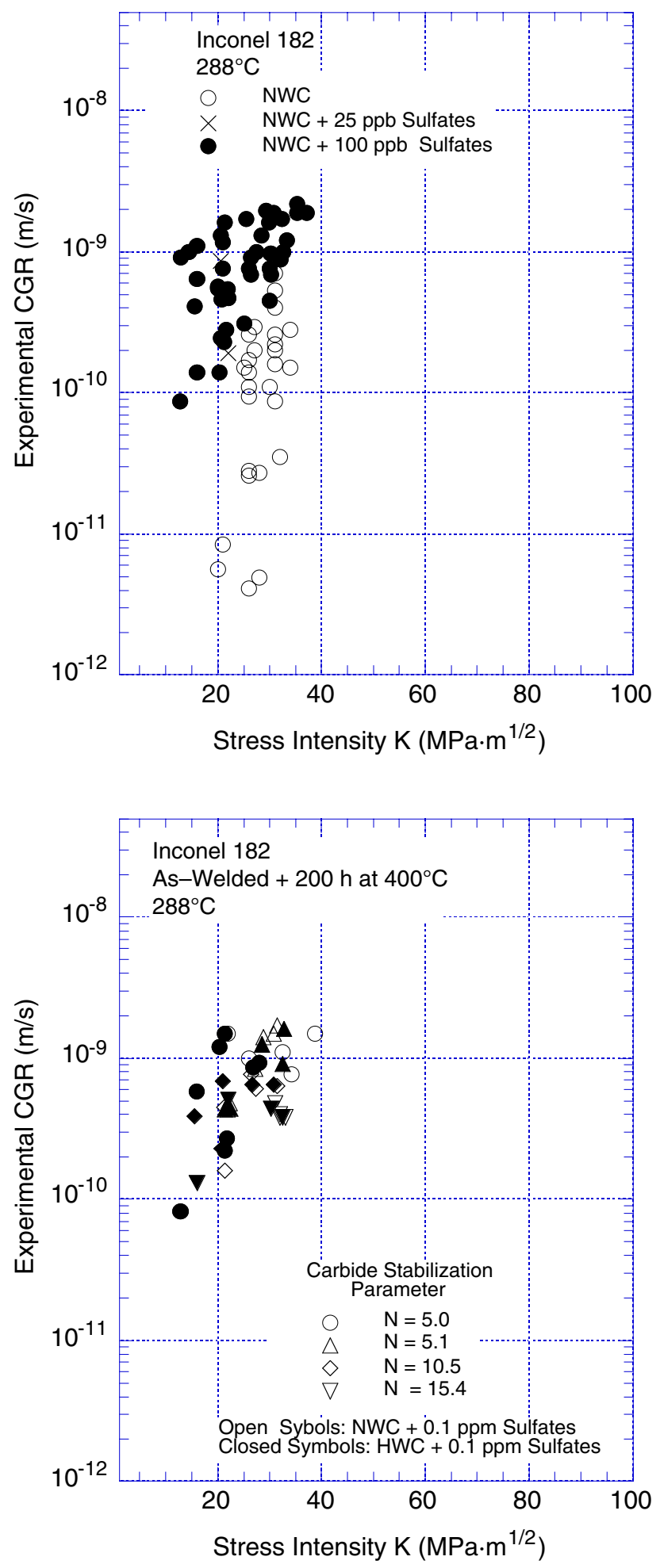

Figure 24.

Effect of sulfate addition on CGRs in Alloy 182 welds in BWR environment. Data obtained by Ljungberg et al. (Ref. 50).
Figure 25.

Effect of sulfate-bearing NWC and HWC on CGRs in Alloy 182 welds. Data obtained by Ljungberg et al. (Ref. 50). 
Material Condition: In BWR environments with NWC, CGRs on Alloy 182 welds are enhanced by high concentrations of $\mathrm{P}$ and $\mathrm{S}$ in the welds; the difference in CGRs is not observed in sulfate-bearing NWC environments. ${ }^{50}$ The carbide stabilization parameter $\mathrm{N}$ has little or no influence on susceptibility of Alloy 182 welds to SCC in BWR environments. ${ }^{50,58}$ Welds with N parameters in the range of 5-15 exhibit comparable CGRs in NWC BWR environments, see Fig. 26. The results suggest a weak dependence of growth rates on N; low degree of carbide stabilization enhances cracking. The differences among CGRs in Fig. 26 have been attributed to differing concentrations of $\mathrm{P}$ and $\mathrm{S}$ in the weld metal rather than to parameter $\mathrm{N}$.

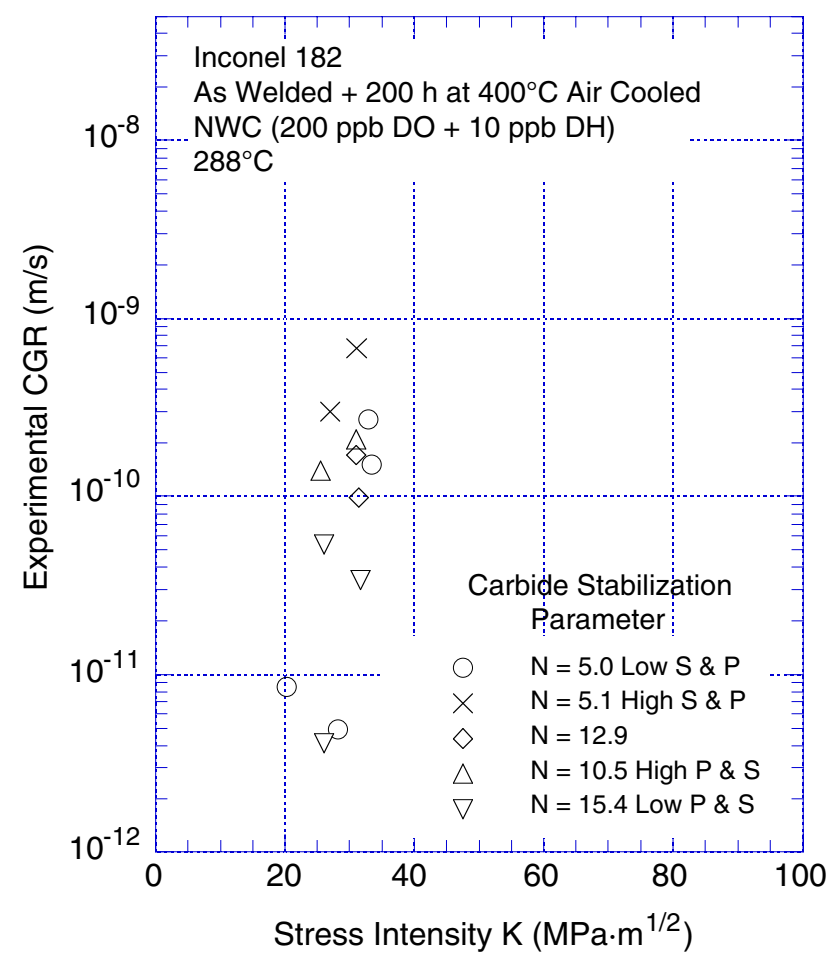

Figure 26.

Effect of carbide stabilization parameter on CGRs in Alloy 182 welds in BWR environment with normal water chemistry. Data obtained by Ljungberg et al. (Ref. 50).

The effect of thermal treatment on SCC susceptibility of Alloy 182 welds is not well known. Ljungberg et al. ${ }^{50}$ observed little or no effect of thermal treatment on SCC CGRs of as-welded Alloy 182; see Fig. 27. They investigated the effects of severe weld sensitization, i. e., $24 \mathrm{~h}$ at $600^{\circ} \mathrm{C}$ and air cooled; low-temperature sensitization, i. e., $200 \mathrm{~h}$ at $400^{\circ} \mathrm{C}$ and air cooled; and heat treatment to simulate material conditions of safe-end welds, i.e., $8 \mathrm{~h}$ at $620^{\circ} \mathrm{C}$ and furnace cooled $+200 \mathrm{~h}$ at $400^{\circ} \mathrm{C}$ and air cooled. Jenssen et al. 58 observed a beneficial effect of a postweld heat treatment of $8 \mathrm{~h}$ at $620^{\circ} \mathrm{C}+200 \mathrm{~h}$ at $400^{\circ} \mathrm{C}$, on SCC susceptibility of Alloy 182 welds; see Fig. 28. The benefit of heat treatment was related to possible transformation of $\mathrm{M}_{23} \mathrm{C}_{6}$ carbides to $\mathrm{M}_{7} \mathrm{C}_{3}$ carbides or to relaxation of weld stresses. Andresen ${ }^{44}$ reported an increase in cracking susceptibility of Alloy 182 weld heat treated for $24 \mathrm{~h}$ at $620^{\circ} \mathrm{C}+200 \mathrm{~h}$ at $400^{\circ} \mathrm{C}$. 


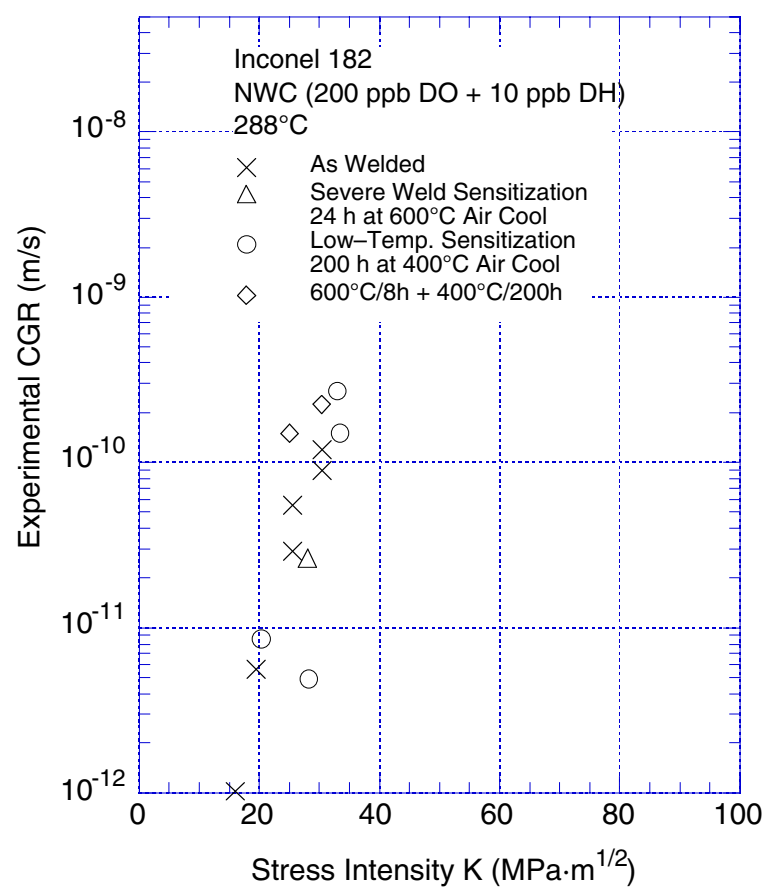

(a)

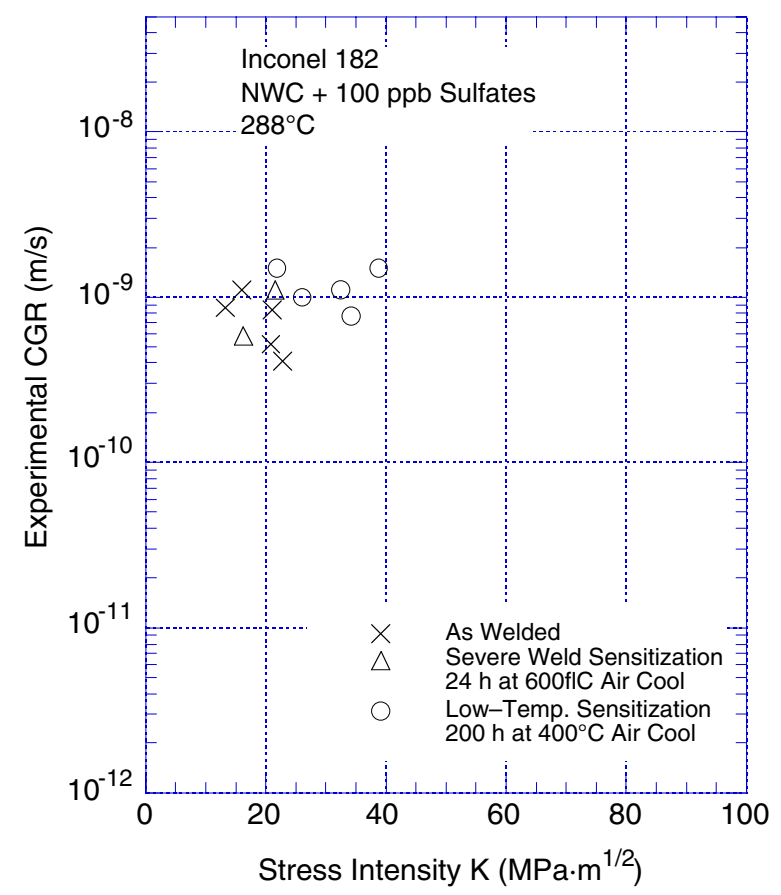

(b)

Figure 27. Effect of thermal treatment on SCC CGRs in Alloy 182 welds at $288^{\circ} \mathrm{C}$ in (a) NWC and (b) NWC with $0.1 \mathrm{ppm}$ sulfates. Data obtained by Ljungberg et al. (Ref. 50).

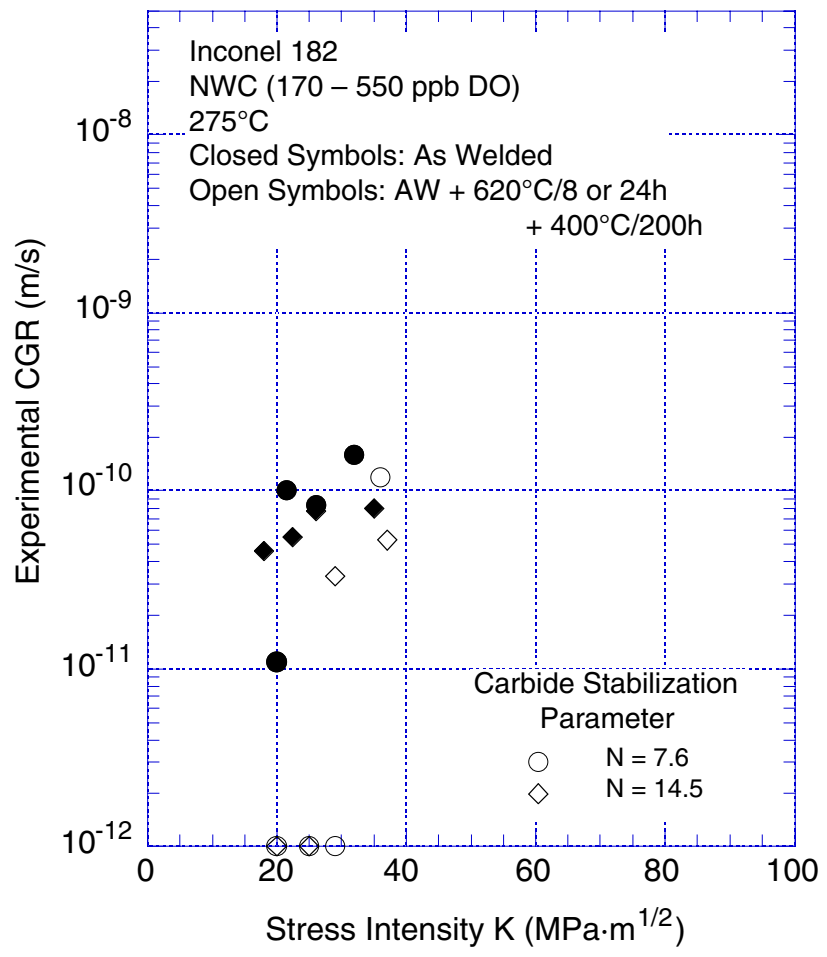

Figure 28.

Effect of thermal treatment on SCC CGRs in Alloy 182 welds at $275^{\circ} \mathrm{C}$ in NWC. Data obtained by Jenssen et al. (Ref. 58). 
The SCC crack growth data on Alloy 82 and 52 welds are very limited. The CGRs of Alloy 82 welds in a PWR environment with relatively high dissolved $\mathrm{H}\left(150 \mathrm{~cm}^{3} / \mathrm{kg}\right.$ of water $)$ at $360^{\circ} \mathrm{C}^{55}$ are shown in Fig. 29a; the CGRs of Alloy 82 in PWR water with $30 \mathrm{~cm}^{3} / \mathrm{kg}$ dissolved $\mathrm{H}$ at $345^{\circ} \mathrm{C}^{29}$ are also shown in the figure for comparison. The results for Alloy 82 show significant scatter, possibly associated with local variations in microstructure, cold work, and residual stresses in the welds. In PWR water, fracture mode in these welds is predominantly intergranular cracking with a very uneven crack front; unbroken ligaments are often observed far behind the advancing crack front. The results also indicate no influence of the direction of crack propagation, e.g., growth rates in a direction longitudinal to the welding direction are comparable to those in a transverse direction. However, both of these orientations shared a common crack plane.

In the same study on SCC susceptibility of Alloy 82 and 52 welds in PWR water with $150 \mathrm{~cm}^{3} / \mathrm{kg}$ dissolved $\mathrm{H}$, SCC was not observed in any of the ten Alloy 52 weld specimens. ${ }^{55}$ These results suggest that the resistance of Alloy 52 to SCC in PWR water is superior to that of Alloy 82.

The SCC susceptibility of Alloy 82 and 182 welds at $275^{\circ} \mathrm{C}$ in BWR environment with NWC is shown in Fig 29b.

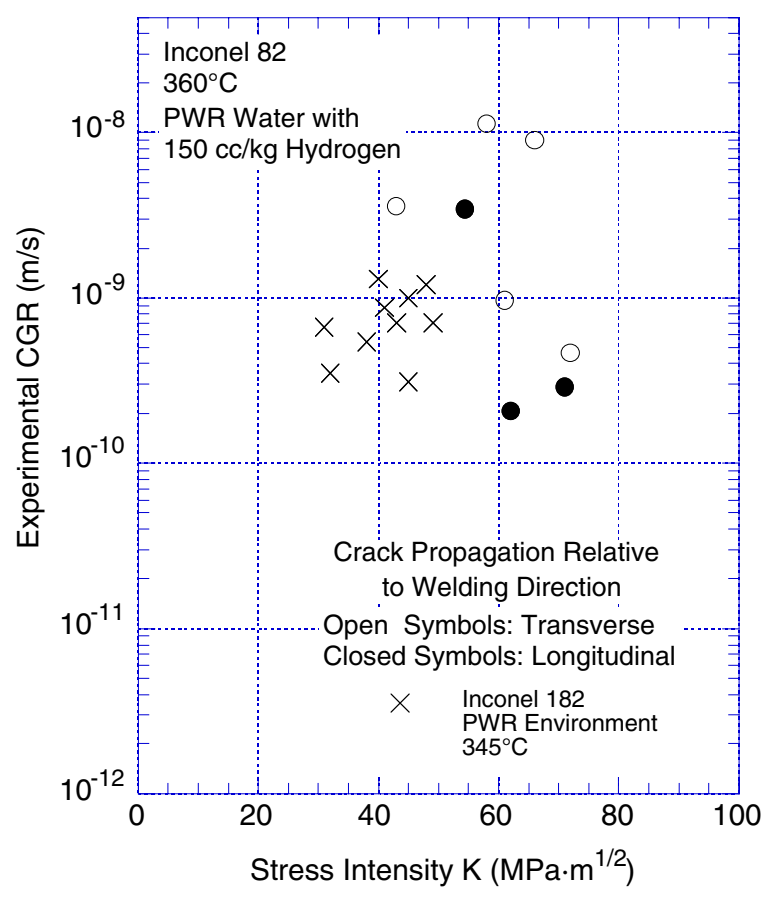

(a)

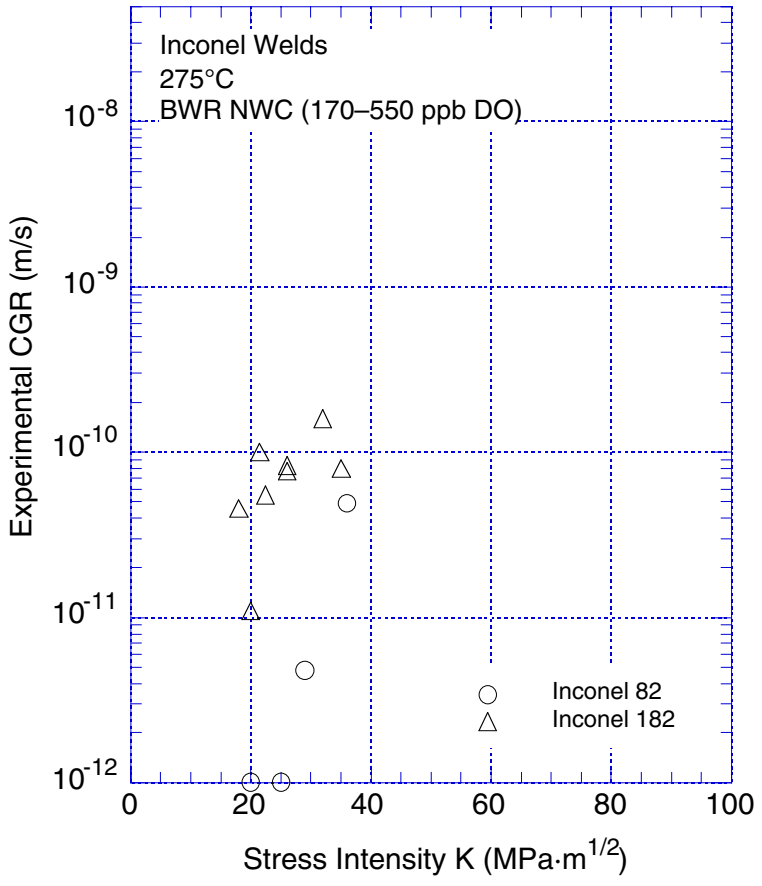

(b)

Figure 29. SCC susceptibility of Alloy 82 welds in (a) PWR environment at $360^{\circ} \mathrm{C}$ and (b) BWR NWC with 170-550 ppb DO. Data obtained by Brown and Mills (Ref. 55), Lindstrom et al. (Ref. 29), and Jenssen et al. (Ref. 58). 
The fracture resistance of Alloy 82 and 52 welds have been investigated by conducting fracture toughness $\mathrm{J}-\mathrm{R}$ curve tests at $24-338^{\circ} \mathrm{C}$ in deionized water with $<20 \mathrm{ppb}$ DO and dissolved $\mathrm{H}$ levels of $125-200 \mathrm{~cm}^{3} / \mathrm{kg}$ of water. ${ }^{55,56}$ The results indicate that these welds exhibit high fracture toughness in air and high-temperature water $\left(>93^{\circ} \mathrm{C}\right)$. However, the apparent fracture toughness of both materials is dramatically reduced at temperatures below $149^{\circ} \mathrm{C}$, particularly in $54^{\circ} \mathrm{C}$ water, under slow rising loads. The apparent fracture toughness $\mathrm{J}_{\mathrm{IC}}$ and tearing modulus are reduced by one to two orders of magnitude. The reduction has been attributed to a $\mathrm{H}$-induced intergranular cracking mechanism. Hydrogen from the water reduces grain boundary cohesive strength and promotes planar slip, which localizes strain concentrations along the grain boundaries. As noted previously, in other systems such decreases in apparent fracture toughness in slow rising load tests have been associated with susceptibility to SCC. 


\section{Crack Growth Rate Correlations}

\subsection{Scott Model}

$\mathrm{Scott}^{63}$ has developed a model for primary-water SCC growth rates of Alloy 600 at $330^{\circ} \mathrm{C}$ as a function of the applied stress intensity factor in PWR environments. The model is based on the SCC data reported by Mcllree and Smialowska ${ }^{64}$ for steam generator tubes. The data at $330^{\circ} \mathrm{C}$ are represented by

$$
\mathrm{da} / \mathrm{dt}=2.8 \times 10^{-11}(\mathrm{~K}-9)^{1.16} \text {, }
$$

where crack growth da/dt is in $\mathrm{m} / \mathrm{s}$ and stress intensity $\mathrm{K}$ is in $\mathrm{MPa} \cdot \mathrm{m}^{1 / 2}$. Equation 10 implies a $\mathrm{K}$ threshold for SCC susceptibility of $9 \mathrm{MPa} \cdot \mathrm{m}^{1 / 2}$. The existing data reviewed in Section 5 suggest that the preexponent in Eq. 10 is influenced by temperature; material parameters such as microstructure, cold work, and yield strength; and possibly the $\mathrm{H}$ content in water. The preexponent can be adjusted for temperature dependence between $290-360^{\circ} \mathrm{C}$ with an activation energy of $130 \mathrm{~kJ} /$ mole. For applications other than steam generator tubing, Scott's model is usually adjusted for the effects of cold work. Based on the studies by Cassagne and Delpi, ${ }^{47}$ a factor of 5 or 10 has been proposed to account for cold-work effects, i.e., the preexponent in Eq. 10 is divided by 5 or 10 to predict the CGRs for noncold-worked Alloy 600 at $330^{\circ} \mathrm{C}$. Rigorous expressions for estimating the effects of mateerial yield strength and cold work on CGRs of Alloy 600 in PWR environments have een presented by Vaillant et al. ${ }^{49}$

\subsection{Film Rupture/Slip Oxidation Model}

Ford and Andresen 40,41 have proposed that the CGR can be correlated with the oxidation that occurs when the protective film at the crack tip is ruptured. ${ }^{40}$ Faraday's law can be used to relate the oxidation charge density (Q) per film rupture event to the amount of metal dissolved or transformed from the metallic to the oxidized state. In reactor systems, a protective oxide re-forms rapidly at the bared surface, and crack advance can be maintained only if the crack tip is being strained so that the film rupture process can be repeated. The frequency of rupture is $\dot{\varepsilon}_{C T} / \varepsilon_{\mathrm{f}}$, where $\varepsilon_{\mathrm{f}}$ is the fracture strain of the oxide and $\dot{\varepsilon}_{\mathrm{ct}}$ is the crack-tip strain rate. The average CGR is then

$$
\mathrm{v}=\frac{\mathrm{M}}{\mathrm{z \rho F}} \frac{\mathrm{Q}}{\varepsilon_{\mathrm{f}}} \dot{\varepsilon}_{\mathrm{CT}},
$$

where $\mathrm{M}$ and $\rho$ are the atomic weight and density of the crack-tip metal, $\mathrm{F}$ is Faraday's constant, and $z$ is the number of electrons involved in the overall oxidation of an atom of metal. The oxidation charge can be obtained by integrating, over time, the oxidation current that occurs after the rupture event, which is assumed to follow a power law relationship of the form

$$
i=i_{o}\left[\frac{t}{t_{o}}\right]^{-n},
$$

where $\mathrm{n}$ is the slope of the repassivation response and $\mathrm{i}_{\mathrm{O}}$ and $\mathrm{t}_{\mathrm{O}}$ are constants that depend on the material, potential, and environment. Thus, 


$$
\mathrm{v}=\frac{\mathrm{M}}{\mathrm{z \rho F}} \frac{\dot{\mathrm{i}}_{\mathrm{o}} \mathrm{t}_{\mathrm{o}}^{\mathrm{n}}}{(1-\mathrm{n})\left(\varepsilon_{\mathrm{f}}\right)^{\mathrm{n}}}\left(\dot{\varepsilon}_{\mathrm{CT}}\right)^{\mathrm{n}}=\mathrm{f}(\mathrm{n})\left(\dot{\varepsilon}_{\mathrm{CT}}\right)^{\mathrm{n}}
$$

To use Eq. 13 to obtain quantitative predictions of CGR, Ford and Andresen ${ }^{40,41}$ have addressed two primary parameters: the crack-tip strain rate $\dot{\varepsilon}_{C T}$, which represents mechanical aspects such as load, frequency, $\mathrm{R}$, crack depth, and crack geometry, etc.; and $\mathrm{n}$, which characterizes the relationship between the crack-tip water chemistry and material chemistry and their effect on repassivation rates. For SS tested under constant load or near constant load, the crack-tip strain rate is expressed as

$$
\dot{\varepsilon}_{\mathrm{CT}}=4.1 \times 10^{-14}(\mathrm{~K})^{4} \text {, }
$$

where $\mathrm{K}$ is in $\mathrm{MPa} \cdot \mathrm{m}^{1 / 2}$. The function $\mathrm{f}(\mathrm{n})$ and $\mathrm{n}$ depend on material and water chemistry. For austenitic SSs,

$$
f(n)=7.8 \times 10^{-3}(n)^{3.6}
$$

Thus, the average CGR is given as

$$
\mathrm{v}=\left[7.8 \times 10^{-3}(\mathrm{n})^{3.6}\right]\left[4.1 \times 10^{-14}(\mathrm{~K})^{4}\right]^{\mathrm{n}} \text {. }
$$

For SSs, Ford/Andresen give values for $\mathrm{n}$ in terms of environmental conditions and material sensitization. ${ }^{40,41}$ In applications to $\mathrm{Ni}$ alloys, $\mathrm{n}$ has simply been used as a fitting parameter and the numerical coefficient for $\mathrm{f}(\mathrm{n})$ is assumed to be temperature dependent, with an activation energy of $130 \mathrm{~kJ} / \mathrm{mole}$.

\subsection{Hydrogen-Assisted Cracking}

A thermodynamic model for $\mathrm{H}$ assisted cracking has been proposed for EAC of Alloy 600 in PWR water. ${ }^{39}$ The model is based on the assumption that the crack tip environment consists of steam $\mathrm{H}$ bubbles; i.e., similar to the environment for tests in $\mathrm{H}$-doped superheated steam. Hydrogen is produced by anodic dissolution and hydrolysis reactions inside the crack. The nascent $\mathrm{H}$ atoms adsorbed on the metal surface can either diffuse into the bulk material or recombine to form molecular $\mathrm{H}$. Within the metal, $\mathrm{H}$ can react with $\mathrm{C}$ to form methane, leading to intergranular $\mathrm{H}$-assisted cracking postulated by Shen and Shewmon. ${ }^{65}$ Hydrogen may also lead to intergranular cracking by fracture mechanisms such as $\mathrm{H}$-related phase change, $\mathrm{H}$-assisted local plasticity, or effects of $\mathrm{H}$ on the cohesive energy.

According to the model, the CGR of Alloy 600 is assumed to depend on $\mathrm{H}$ diffusion into the metal ahead of the crack tip along the grain boundaries. This process is influenced by the formation of steam $\mathrm{H}$ bubbles at the crack tip and by the partial pressure of gaseous $\mathrm{H}$ at the crack tip. The existence of gaseous $\mathrm{H}$ and water vapor have been demonstrated by thermodynamic calculations, experimental results, and field data. ${ }^{39}$ The prerequisites for the process are: the potential difference between the metal and solution at the crack tip must be low for formation of hydrogen; a corresponding positive current must pass, due to an anodic reaction (metal oxidation), to account for the charge balance in the system; $\mathrm{H}$ evolution must be extensive to exceed the solubility limit in water; and diffusion of molecular $\mathrm{H}$ away from the crack tip must be slow to maintain $\mathrm{H}$ concentrations at the crack tip at the solubility limit. 
Examples of experimental observations that provide support for this model are presented below.

The significant result in support of this model is that the CGRs of Ni alloys in PWR environment often depend on loading history. For example, a fatigue test on Alloy 600 in PWR water at $320^{\circ} \mathrm{C}$, load ratio $\mathrm{R}=0.9$, and frequency $\mathrm{f}=0.05 \mathrm{~Hz}$, yielded a CGR of $0.5 \times 10^{-10} \mathrm{~m} / \mathrm{s}$. CGR under the same conditions was significantly higher, $3.5 \times 10^{-10} \mathrm{~m} / \mathrm{s}$, after the load ratio was decreased to 0.5 and then increased to 0.75 , and back to 0.9 . The fracture mode was transgranular during the initial stage and intergranular during the final stage. The difference in the growth rates has been explained on the basis of $\mathrm{H}$ production. If there is not enough new bare fracture surface to enable sufficient $\mathrm{H}$ production, the CGR will remain slow, thus retaining slow $\mathrm{H}$ production. Whereas, in the final stage, enough new bare fracture surface had been produced in the test periods with $\mathrm{R}=0.5$ or 0.75 to form a crack tip environment with high $\mathrm{H}$ production.

Another example is the increase in CGRs of Alloy 600 in PWR water with a decrease in the $\mathrm{H}$ content of the water. As discussed above, a decrease in the bulk $\mathrm{H}$ content leads to an increase in corrosion potential of the bulk material and thus in increased anodic reaction, i.e., oxidation of the metal. This in turn must be compensated by $\mathrm{H}$ evolution at the crack front.

\subsection{Comparisons with Experimental Data}

\subsubsection{Alloys 600 and 690}

The existing SCC data on Alloy 600 in PWR environments have been compared with the Scott ${ }^{63}$ and Ford/Andresen ${ }^{40,41}$ models. For PWR environments, the crack rate data at $330^{\circ} \mathrm{C}$ were initially fit to the models and the values at other temperatures were determined by using an activation energy of $130 \mathrm{~kJ} / \mathrm{mole}$. The effect of applied stress intensity on CGRs (da/dt) for various heats and heat treatment conditions of Alloy 600 tested in simulated PWR water or low-DO high-purity water at temperatures between 290 and $360^{\circ} \mathrm{C}$ are shown in Fig. 30 . The predicted curves, based on the Scott model ${ }^{63}$ for steam generator tubes and noncold-worked material, and those based on the Ford/Andresen model for $n$ values of 0.5 and 0.7 are also shown in the plots. For noncold-worked material, the predictions of Scott's model for steam generator tubes were lowered by a factor of 10. The upper and lower curves provide estimates of the range of CGRs that could occur, depending on material conditions. The conditions that lead to high SCC susceptibility in low-DO water include cold work, low grain boundary coverage of carbides, and high tensile strength.

The upper curves for either the Scott or Ford/Andresen models bound most of the data, even for materials with high susceptibility. The Ford/Andresen curve may be overly conservative for stress intensities $>50 \mathrm{MPa} \cdot \mathrm{m}^{1 / 2}$; for high $\mathrm{K}$ values, the Ford/Andresen curve may be replaced by a plateau that represents a constant growth rate. The lower curve for the Scott model may be nonconservative for $\mathrm{K}$ values $>50 \mathrm{MPa} \cdot \mathrm{m}^{1 / 2}$, e.g., at $330^{\circ} \mathrm{C}$, the data (shown as open circles in Fig. 30) for solution-annealed material fall above the predicted curve at high stress intensities.

The effect of applied stress intensity on CGRs of several heats of Alloy 600 tested in high-DO (200 ppb or higher DO) high-purity water at 290 and $320^{\circ} \mathrm{C}$ are shown in Fig. 31 . Although the Scott model was developed for PWR conditions, it is included in the figures for 

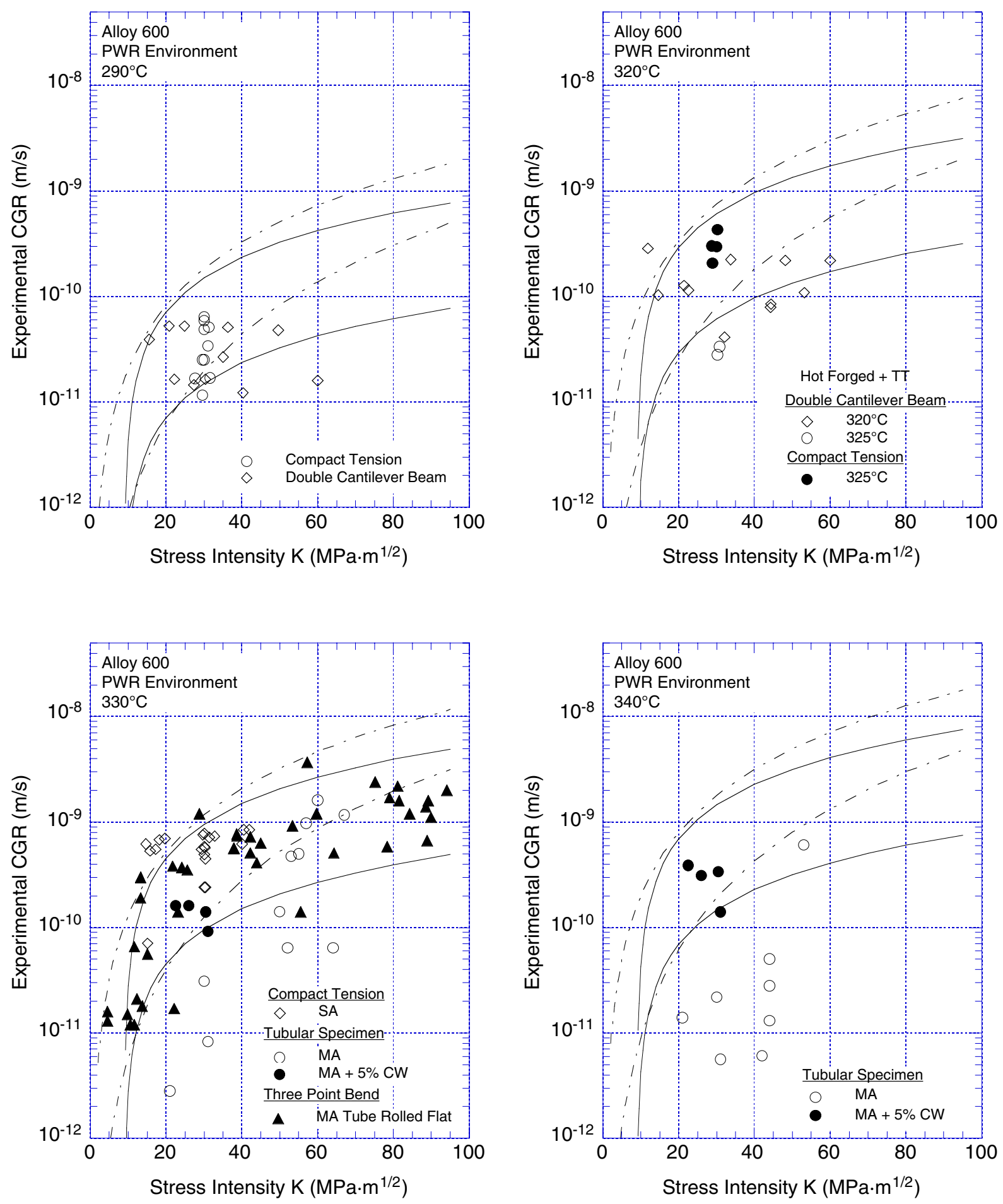

Figure 30. Effect of applied stress intensity on CGRs in Alloy 600 in simulated PWR or low-DO water at $290-360^{\circ} \mathrm{C}$. Two sets of upper and lower curves represent CGRs predicted from Scott model, shown as solid lines for cold-worked and noncold-worked material; and Ford/Andresen model, shown as chain dot line for $n=0.5$ and 0.7 . 

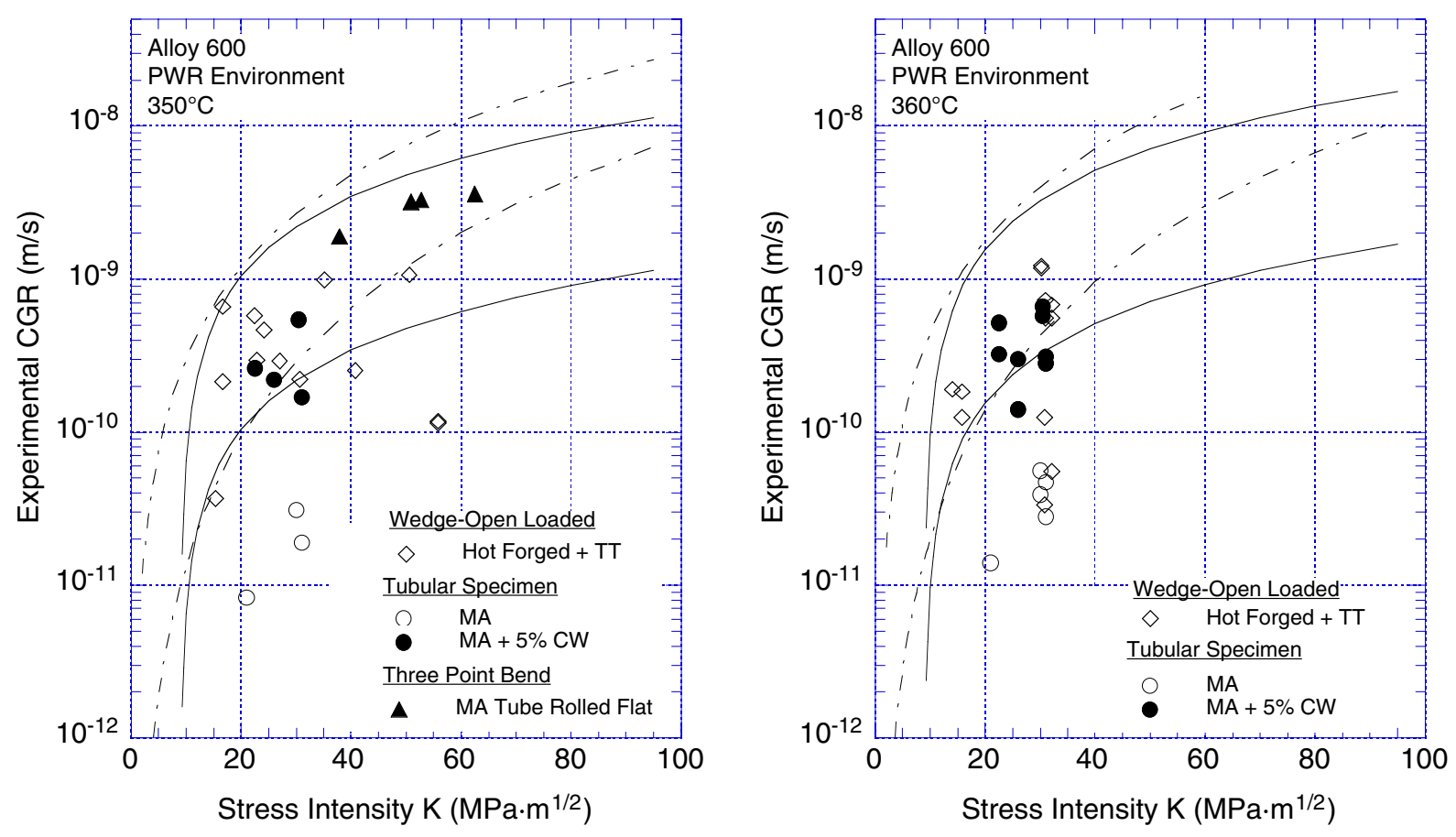

Figure $30 \quad$ (Continued)
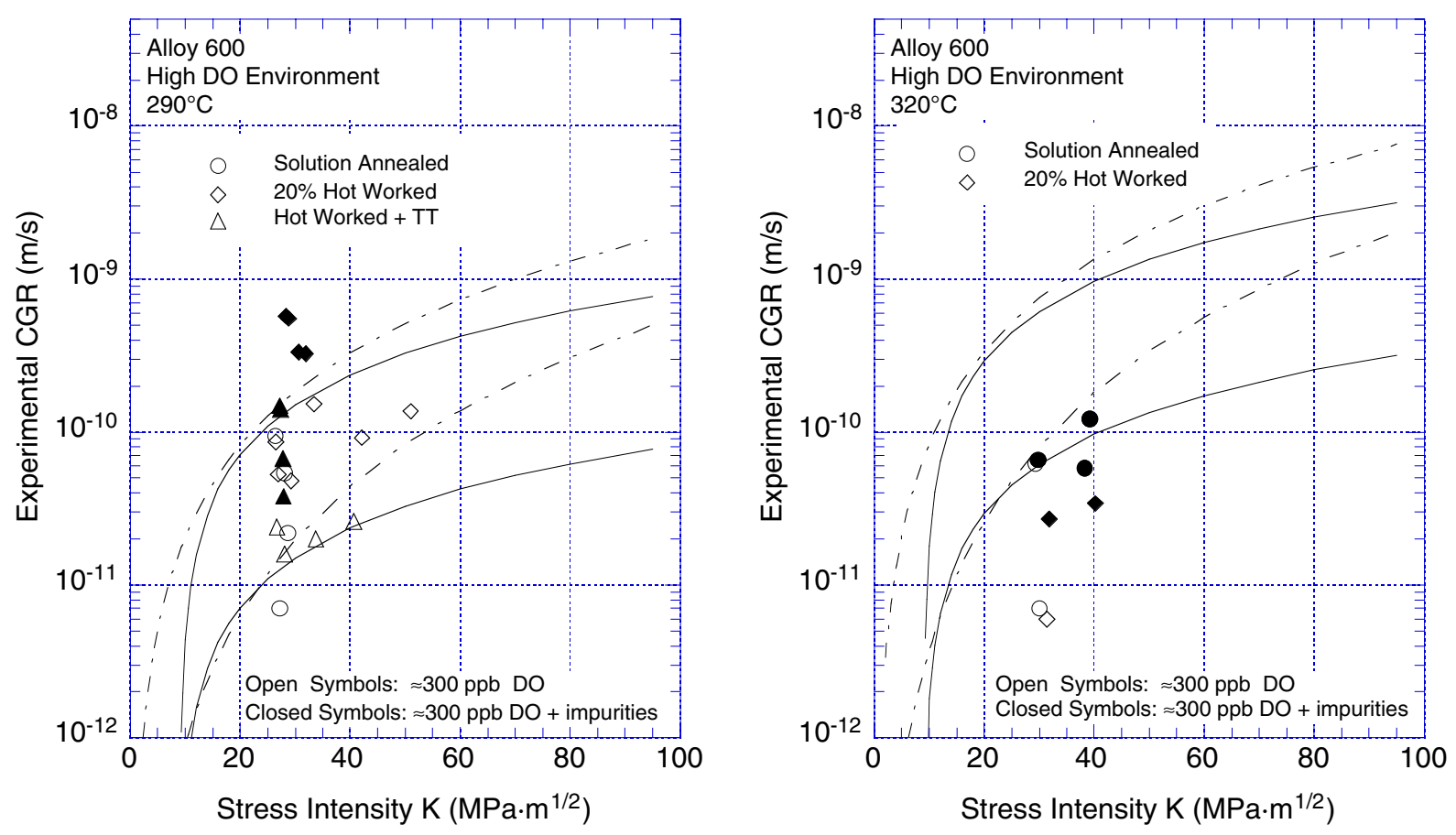

Figure 31. Effect of applied stress intensity on CGRs in Alloy 600 in high-purity water with $\approx 300 \mathrm{ppb}$ DO at 290 and $320^{\circ} \mathrm{C}$. Two sets of upper and lower curves represent CGRs predicted from Scott model, shown as solid lines for cold-worked and noncold-worked material; and Ford/Andresen model, shown as chain dot line for $n=0.5$ and 0.7 . 
comparison purposes. Agreement with the data at $290^{\circ} \mathrm{C}$ is reasonable. Using the value of the activation energy developed for PWR environments, the models predict a much stronger dependence on temperature than is observed in the data, although the data are limited.

\subsubsection{Ni Alloy Welds}

The existing SCC data on Ni alloy welds in BWR and PWR environments have been compared with the Scott ${ }^{63}$ and Ford/Andresen ${ }^{40,41}$ models. The effect of applied stress intensity on CGRs (da/dt) of Alloy 182 welds at $288^{\circ} \mathrm{C}$ in BWR water (i.e., $50 \mathrm{ppb}$ or higher DO) with or without sulfate additions are shown in Fig. 32. The predicted curves at $290^{\circ} \mathrm{C}$, based on the Scott model for cold-worked Alloy 600 and Ford/Andresen model with $n=0.5$, do not adequately represent the results for Alloy 182 welds in BWR environments. The experimental data for high-DO water without sulfate additions are up to a factor of 5 higher than the predicted curve, and those with sulfate additions are up to a factor 10 higher.

The effect of applied stress intensity on CGRs of Alloy 182 welds in simulated PWR water water at temperatures between 290 and $345^{\circ} \mathrm{C}$ are shown in Fig. 33. In PWR environment, nearly all of the limited data for Alloy 182 welds are bounded by the Scott model for cold-worked material and the Ford/Andresen model for $n=0.5$.
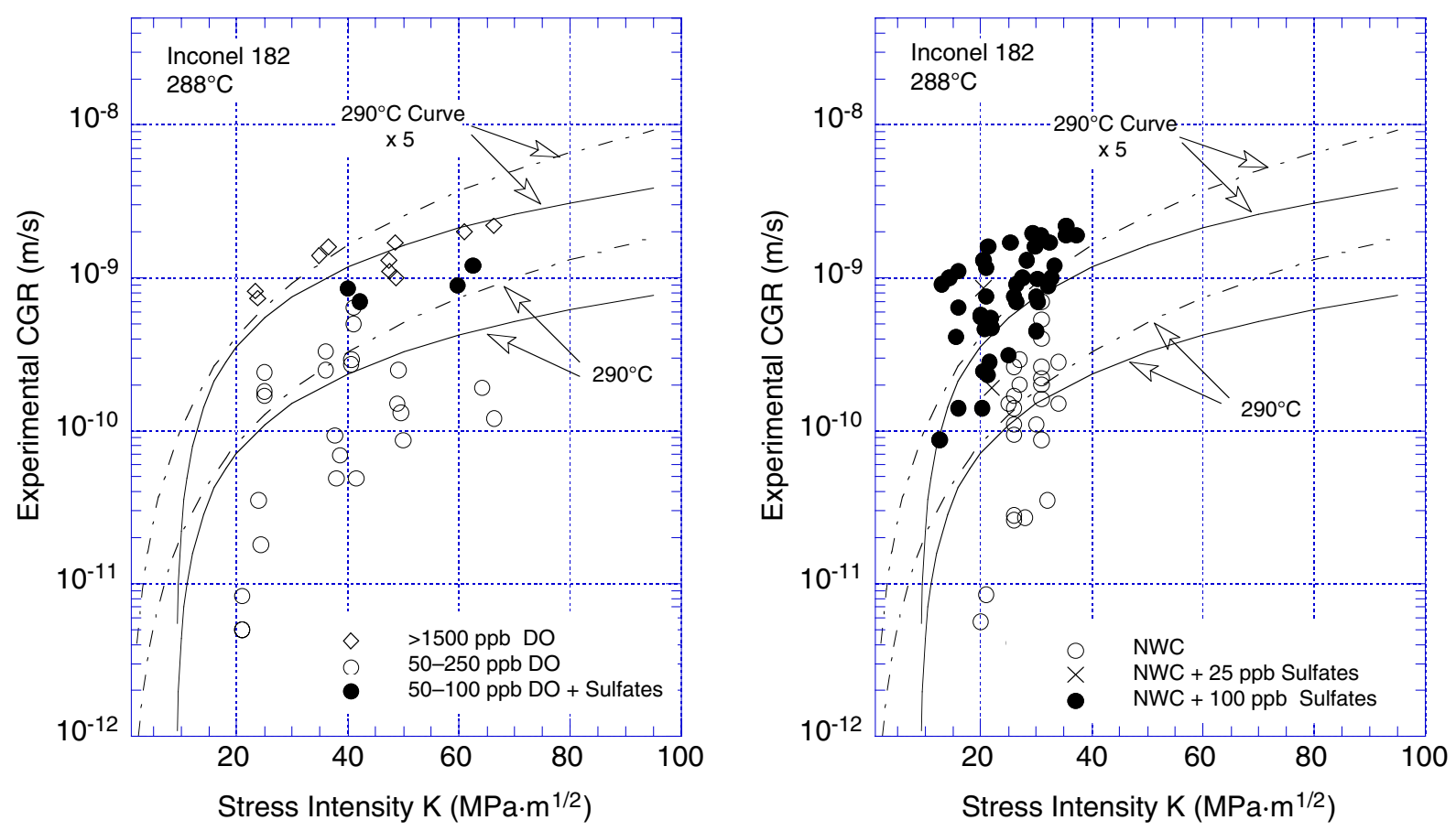

Figure 32. Effect of applied stress intensity on CGRs in Alloy 182 weld in high-purity water with $50 \mathrm{ppb}$ or higher DO at $288^{\circ} \mathrm{C}$. Predicted CGRs from Scott model for cold-worked material are shown as solid lines and from Ford/Andresen model, as chain dot line. Data obtained by Itow et al. (Refs. 59 and 60) and Ljungberg et al. (Ref. 50). 

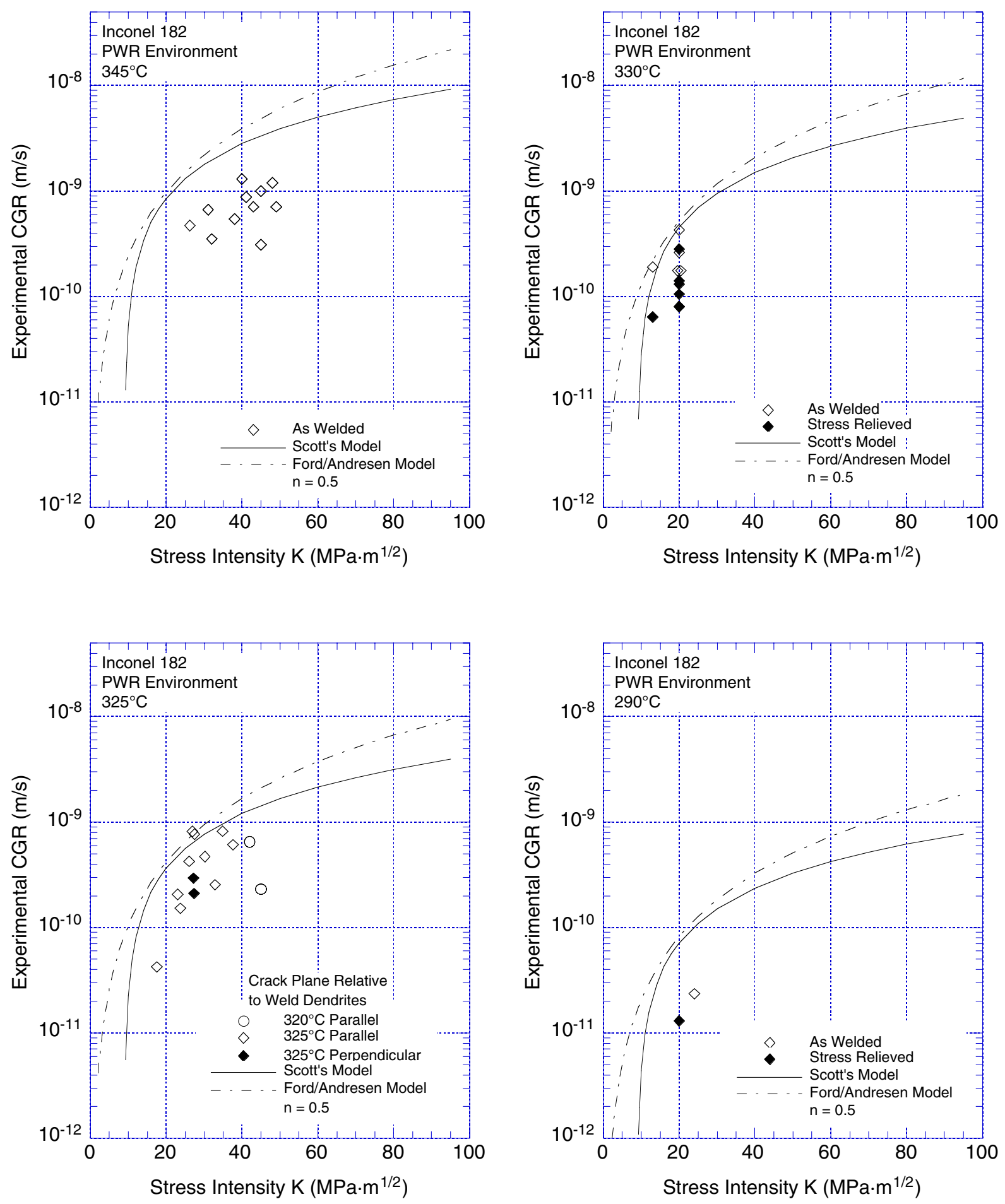

Figure 33. Effect of applied stress intensity on CGRs in Alloy 182 weld in simulated PWR water at 290-345 ${ }^{\circ}$ C. Predicted CGRs from Scott model for cold-worked material are shown as solid lines, and from Ford/Andresen model as chain dot line. 


\section{Summary}

The resistance of Alloys 600 and 690 and their welds, i.e., Alloys 82, 812, 52, and 152, to EAC in simulated LWR environments has been evaluated. Existing CGR data for these materials under cyclic and constant loads have been analyzed to establish the effects of alloy chemistry, material heat treatment, cold work, temperature, load ratio R, stress intensity K, and DO level. The fatigue crack growth data in air have been analyzed to develop correlations for estimating the fatigue CGRs of Alloys 600 and 690 as a function of stress intensity range $\Delta \mathrm{K}$, load ratio $\mathrm{R}$, and temperature. The results indicate that in air, the CGRs of these materials are relatively insensitive to changes in frequency.

For cyclic loads, the experimental CGRs in high-temperature, high-purity water are compared with CGRs that would be expected in air under the same mechanical loading conditions to obtain a qualitative understanding of the degree and range of conditions for significant environmental enhancement in growth rates. The fatigue CGRs of Alloy 600 are enhanced in high-DO water; the environmental enhancement of growth rates does not appear to depend on either the $\mathrm{C}$ content or heat treatment of the material. Also, in high-DO water, the CGRs at $320^{\circ} \mathrm{C}$ are comparable to those at $289^{\circ} \mathrm{C}$. In contrast to the behavior in high-DO water, environmental enhancement of CGRs of Alloy 600 in low-DO water seems to depend on material conditions such as yield strength and grain boundary coverage of carbides. Material with high yield strength and/or low grain boundary coverage of carbides exhibit enhanced CGRs. Correlations have been developed for estimating the enhancement of CGRs of Alloy 600 in LWR environments relative to the CGRs in air under the same loading conditions.

For Alloy 690, the data suggest some enhancement of CGRs in high-DO water, i.e., $\approx 300 \mathrm{ppb}$ DO. Limited data indicate no environmental effects on CGRs in low-DO water, i.e., water with $<10 \mathrm{ppb}$ DO. However, the existing database for Alloy 690 is small, and additional tests are needed to verify these results.

The enhancement of fatigue CGRs of Alloy 182 welds in LWR environments has been determined relative to the CGRs of Alloy 600 in air. Fatigue CGRs of Alloy 82 and 182 welds are enhanced in PWR water. The results show significant scatter; growth rates of welds may be up to a factor of 10 higher than the predicted CGRs of Alloy 600 in air. Baseline CGRs of Ni alloy welds in an air environment are not available; CGRs of Alloy 82 are a factor of 2 higher than those of Alloy 600. The data in a PWR environment indicate little or no effect of frequency on the CGRs of Alloy 82. The lack of frequency dependence suggests only minor influence of environment on growth rates. Also, most of the data have been obtained under loading conditions that correspond to $>1 \times 10^{-9} \mathrm{~m} / \mathrm{s}$ CGRs in air; under these conditions, environmental enhancement of growth rates is expected to be moderate. The existing data for Alloy 52 weld indicate little or no enhancement of CGRs in a PWR environment.

In a BWR environment with NWC, the CGRs of Alloy 182 weld are enhanced relative to those of Alloy 600 in air. The results show good agreement with the predicted curve for Alloy 600. Hydrogen water chemistry has a beneficial effect on growth rates; CGRs are decreased by a factor of 5-10 when DO level is decreased from 200 to $10 \mathrm{ppb}$.

The existing SCC data on Alloys 600 and 690 and Alloy 82, 182, and 52 welds have been reviewed to determine the effects of critical parameters such as stress intensity, temperature, 
material heat treatment, cold work, and water chemistry on CGRs. In general, the SCC susceptibility of Alloy 82 and 182 welds is greater than that of Alloy 600. However, limited data suggest that the temperature dependence of growth rates is similar to that for Alloy 600; CGRs of both can be represented by an activation energy of $130 \mathrm{~kJ} / \mathrm{mole}$. The SCC growth rates of welds exhibit significant scatter because of irregularities of the crack front. Most investigations have reported the maximum CGRs obtained from the maximum crack length masured anywhere along the crack front. The average CGRs are a factor of $\approx 2$ lower than the maximum values.

The SCC data have been compared with correlations developed from the Scott or Ford/Andresen models. Although the conceptual bases underlying the two models differ significantly, by appropriately choosing the constants in the models, the predicted CGRs from the correlations are reasonably consistent with the available data for SCC in LWR environments. 


\section{References}

1. USNRC Information Notice No. 90-10, Primary Water Stress Corrosion Cracking (PWSCC) of Inconel 600, Feb. 1990.

2. USNRC Generic Letter 97-01, Degradation of Control Rod Drive Mechanism and Other Vessel Closure Head Penetrations, Apr. 1, 1997; USNRC Information Notice No. 96-11, Ingress of Demineralizer Resins Increases Potential for Stress Corrosion Cracking of Control Rod Drive Mechanism Penetrations, Feb. 1996; INPO Document SER 20-93, Intergranular Stress Corrosion Cracking of Control Rod Drive Mechanism Penetrations, Sept. 1993.

3. USNRC Information Notice 93-101, Jet Pump Hold-Down Beam Failure, Dec. 1993.

4. USNRC Information Notice 92-57, Radial Cracking of Shroud Support Access Hole Cover Welds, Aug. 1992.

5. USNRC Information Notice No. 90-49, Stress Corrosion Cracking in PWR Steam Generator Tubes, Aug. 1990; Notice No. 91-43, Recent Incidents Involving Rapid Increases in Primary-to-Secondary Leak Rate, July 1991; Notice No. 92-80, Operation with Steam Generator Tubes Seriously Degraded, Dec. 1992; Notice No. 94-05, Potential Failure of Steam Generator Tubes with Kinetically Welded Sleeves, Jan. 1994.

6. USNRC Information Notice No. 89-33, Potential Failure of Westinghouse Steam Generator Tube Mechanical Plugs, March 1989; Notice No. 89-65, Potential for Stress Corrosion Cracking in Steam Generator Tube Plugs Supplied by Babcock and Wilcox, Sept. 1989; Notice No. 94-87, Unanticipated Crack in a Particular Heat of Alloy 600 Used for Westinghouse Mechanical Plugs for Steam Generator Tubes, Dec. 1994.

7. USNRC Information Notice No. 91-67, Problems with the Reliable Detection of Intergranular Attack (IGA) of Steam Generator Tubing, Oct. 1991.

8. W. E. Ruther, W. K. Soppet, and T. F. Kassner, Corrosion Fatigue of Alloys 600 and 690 in simulated LWR Environments, NUREG/CR-6383, ANL-95/37 (April 1996).

9. W. E. Ruther, W. K. Soppet, and T. F. Kassner, Environmentally Assisted Cracking of Alloys 600 and 690 in Simulated LWR Water, in Environmentally Assisted Cracking in Light Water Reactors, Semiannual Report, July 1997-December 1997, NUREG/CR-4667 Vol. 25, ANL-98/18, pp. 42-75 (Sept. 1998).

10. W. E. Ruther, W. K. Soppet, T. F. Kassner, and W. J. Shack, Environmentally Assisted Cracking of Alloys 600 and 690 in Simulated LWR Water, in Environmentally Assisted Cracking in Light Water Reactors, Semiannual Report, January 1998-July 1998, NUREG/CR-4667 Vol. 26, ANL-98/18, pp. 25-32 (March 1999).

11. W. E. Ruther, W. K. Soppet, T. F. Kassner, and W. J. Shack, Environmentally Assisted Cracking of Alloys 600 and 690 in Simulated LWR Water, in Environmentally Assisted Cracking in Light Water Reactors, Semiannual Report, July 1998-December 1998, NUREG/CR-4667 Vol. 27, ANL-99/11, pp. 45-54 (October 1999). 
12. W. K. Soppet, O. K. Chopra, and W. J. Shack, Environmentally Assisted Cracking of Alloys 600 and 690 in Simulated LWR Water, in Environmentally Assisted Cracking in Light Water Reactors, Semiannual Report, July 1999-December 1999, NUREG/CR-4667 Vol. 29, ANL-00/23, pp. 39-45 (November 2000).

13. G. L. Webb and M. G. Burke, Stress Corrosion Cracking Behavior of Ally 600 in High-Temperature Water, in Proc. of the 7th Intl. Symp. on Environmental Degradation of Materials in Nuclear Power Systems-Water Reactors, NACE International, Houston, TX, pp. 41-55 (1995).

14. J. M. Server, J. R. Crum, and W. L. Mankins, Carbide Precipitation and the Effect of Thermal Treatments on the SCC Behavior of Inconel Alloy 690, in Proc. of the Third Intl. Symp. on Environmental Degradation of Materials in Nuclear Power Systems-Water Reactors, The Metallurgical Society, Warrendale, PA, pp. 581-586 (1987).

15. D. A. Mertz, P. T. Duda, P. N. Pica, and G. L. Spahr, Role of Microstructure in Caustic Stress Corrosion Cracking of Alloy 690, in Proc. of the 7th Intl. Symp. on Environmental Degradation of Materials in Nuclear Power Systems-Water Reactors, NACE International, Houston, TX, pp. 477-494 (1995).

16. C. L. Briant and E. L. Hall, The Microstructural Causes of Intergranular Corrosion of Alloys 82 and 182, Corrosion, 43, pp. 539-548 (1987).

17. G. Kharshafdjian, and A. H. Park, PVRC Alloy 600 Fatigue Growth Rate Module, CD-ROM File DADN600.XLS (September 1999).

18. L. A. James, Fatigue Crack Propagation Behavior of Inconel 600, Int. J. Pres. Vessels and Piping, Vol. 5, pp. 241-259 (1977).

19. R. G. Ballinger, R. M. Latanision, W. C. Moshier, and R. M. Pelloux, The Effects of Heat Treatment and Environment on Corrosion Fatigue, Volume 2: Alloy 600, EPRI TR-102436 (May 1993).

20. C. Amzallag, G. Baudry, and J. L. Bernard, Effects of PWR Environment on the Fatigue Crack Growth of Different Stainless Steels and Inconel Type Alloy, Proc. IAEA-Specialists Meeting on Subcritical Crack Growth, NUREG/CP-0044, Vol. 1, pp. 263-294 (1983).

21. H. Nagano, K. Tokimasa, K. Tanaka, and H. Tsuge, Evaluation of SCC Resistance of Alloy 600 in High Temperature Pressurized Water Environments by the High-Stress-Ratio Cyclic Crack Growth Tests, ISIJ Intl., 28, p. 338 (1988).

22. G. S. Was and R. G. Ballinger, Hydrogen Induced Cracking under Cyclic Loading of Nickel Base Alloys Used for PWR Steam Generator Tubing, Third Semi-Annual Progress Report, NP4613, Research Project 1166-3, EPRI (1980).

23. L. A. James and D. P. Jones, Fatigue Crack Growth Rates for Austenitic Stainless Steel in Air, in Predictive Capabilities in Environmentally Assisted Cracking, PVP Vol. 99, The American Society of Mechanical Engineers, New York, pp. 363-414 (1985). 
24. W. H. Bamford, P. K. Liaw, and E. D. Eason, A Review of Corrosion Fatigue Crack Growth Behavior for Pressure Vessel Steels in Light Water Environments, in Fatigue, Degradation, and Fracture - 1990, W. H. Bamford, et al., eds., PVP Vol. 195, MPC Vol. 30, The American Society of Mechanical Engineers, pp. 1-12 (1990).

25. E. K. Walker, The Effect of Stress Ratio during Crack Propagation and Fatigue for 2024-T3 and 7075-T6, in The Effects of Environments and Complex Load History on Fatigue Life, STP 462, American Society for Testing and Materials, Philadelphia, pp. 1-14 (1970).

26. E. K. Walker, An Effective Strain Concept for Crack Propagation and Fatigue Life with Specific Applications to Biaxial Stress Fatigue, in Proc. Air Force Conference on Fatigue and Fracture of Aircraft Structures and Materials, H. A. Wood, et al., eds., Report AAFFDL-TR-70-144, Air Force Flight Dynamics Laboratory, pp. 25-233 (Sept. 1970).

27. J. L. Bernard and G. S. Slama, Fatigue Crack Growth in Air Environment at $300^{\circ} \mathrm{C}$ for Stainless Steels, Nucl. Technol., 59 (1), 136-147 (1982).

28. P. Rabbe and H. P. Lieurade, Etude a l'Aide de la Mecanique de la Rupture de la Vitesse Fissuration en Fatigue d'une Gamme Etendue d'Aciers, Memoires Scientificiques Revue Metallurgie, 69 (9), 606-621 (1972).

29. R. Lindstrom, P. Lidar, and J. Lagerstrom, Crack Growth of Alloy 182 in Simulated Primary Side PWR Environment, in Proc. of the 8th Intl. Symp. on Environmental Degradation of Materials in Nuclear Power Systems-Water Reactors, S. M. Bruemmer, ed., American Nuclear Society, La Grange Park, IL, pp. 422-429 (1997).

30. L. A. James and W. J. Mills, Fatigue-Crack Propagation Behavior of Wrought Alloy 600 and Weld-Deposited EN82H in an Elevated Temperature Aqueous Environment, in Service Experience, Structural Integrity, Severe Accident, and Erosion in Nuclear and Fossil Plants, PVP Vol. 303, The American Society of Mechanical Engineers, pp. 21-36 (1995).

31. C. K. Sheeks, W. C. Moshier, R. G. Ballinger, R. M. Latanision, and R. M. N. Pelloux, Fatigue Crack Growth of Alloys X-750 and 600 In Simulated PWR and BWR Environments, in Intl. Symp. on Environmental Degradation of Materials in Nuclear Power SystemsWater Reactors, NACE, pp. 701-726 (1984).

32. N. Konda, K. Toyama, K. Yamanaka, and K. Tokimasa, Environmental Effects on the Crack Growth Properties of Alloy 600, Sumitomo Metal Industries, Ltd. R \& D Division, 1-3 Fusocho, Amagasaki 660, Japan (October 1991).

33. H. Nagano, K. Tokimasa, K. Tanaka, and H. Tsuge, Evaluation of SCC Resistance of Alloy 600 in High Temperature Pressurized Water Environments by the High Stress Ratio Cyclic Crack Growth Tests, ISIJ Intl. (1988).

34. P. L. Andresen, Fracture Mechanics Data and Monitoring of Environmental Cracking of Nickel-Base Alloys in High-Temperature Water, Corrosion, 47, pp. 917-938 (1991).

35. G. Nakao, H. Yamasaki, and S. Kimura, Fatigue Crack Growth Behavior of Inconel 600 Alloys in Oxygenated High Temperature Pure Water, cited in Ref. 34 (1985). 
36. H. D. Solomon, Summary of In 600 Metallurgical Studies, Report SRD-81-034, GE CRD, Schenectady, NY (April 1981).

37. R. Magdowski, F. Vaillant, C. Amzallag, and M. O. Speidel, Stress Corrosion Crack Growth Rates of Alloy 600 in Simulated PWR Coolant, in Proc. of the 8th Intl. Symp. on Environmental Degradation of Materials in Nuclear Power Systems-Water Reactors, S. M. Bruemmer, ed., American Nuclear Society, La Grange Park, IL, pp. 333-338 (1997).

38. T. Cassagne, D. Caron, J. Daret, and Y. Lefevre, Stress Corrosion Crack Growth Rate Measurements in Alloys 600 and 182 in Primary Loops Under Constant Load, in Proc. of the Ninth Intl. Symp. on Environmental Degradation of Materials in Nuclear Power Systems-Water Reactors, F. P. Ford, S. M. Bruemmer, and G. S. Was, eds., The Minerals, Metals, and Materials Society, Warrendale, PA, pp. 217-224 (1999).

39. J. Lagerstrom, U. Ehrnsten, T. Saario, and H. Hanninen, Model for Environmentally Asisted Cracking of Alloy 600 in PWR Primary Water, in Proc. of the 8th Intl. Symp. on Environmental Degradation of Materials in Nuclear Power Systems-Water Reactors, S. M. Bruemmer, ed., American Nuclear Society, La Grange Park, IL, pp. 349-356 (1997).

40. F. P. Ford, Quantitative Prediction of Environmentally Assisted Cracking, Corrosion, 52 , pp. 375-395 (1997).

41. F. P. Ford, D. F. Taylor, P. L. Andresen, and R. Ballinger, Corrosion-Assisted Cracking of Stainless and Low-alloy Steels, EPRI NP-5064, Electric Power Research Institute, Palo Alto, CA (Feb. 1987).

42. T. Shoji, Quantitative Prediction of Environmentally Assisted Cracking Based on Crack Tip Strain Rate, Proc. Conf. on Predictive Capabilities in Environmentally-Assisted Cracking, R. Rungta, ed., PVP Vol. 99, American Society of Mechanical Engineers, New York, pp. 127-142 (1985).

43. M. J. Psaila-Dombrowski, C. S. Wade, J. M. Sarver, W. A. Van Der Sluys, and P. E. Doherty, Evaluation of Weld Metals 82, 152, 52, and Alloy 690 Stress Corrosion Cracking and Corrosion Fatigue Susceptibility, in Proc. of the 8th Intl. Symp. on Environmental Degradation of Materials in Nuclear Power Systems-Water Reactors, S. M. Bruemmer, ed., American Nuclear Society, La Grange Park, IL, pp. 412-42 1 (1997).

44. P. L. Andresen, Observation and Prediction of the Effects of Water Chemistry and Mechanics on Environmentally Assisted Cracking of Inconels 182 Weld Metal and 600, Corrosion, 44, 376-385 (1988).

45. R. G. Lott, R. J. Jacko, and R. E. Gold, Primary Water Stress Corrosion Crack Growth Rates in Alloy 600 Steam Generator Tubing, in Proc. of the 5th Intl. Symp. on Environmental Degradation of Materials in Nuclear Power Systems-Water Reactors, American Nuclear Society, La Grange Park, IL, pp. 525-532 (1991). 
46. R. B. Rebak., A. R. McIlree, and Szklarska-Smialowska, Effects of $p H$ and Stress Intensity on Crack Growth Rate in Alloy 600 in Lithiated + Borated Water at High Temperatures, in Proc. of the 5th Intl. Symp. on Environmental Degradation of Materials in Nuclear Power Systems-Water Reactors, American Nuclear Society, La Grange Park, IL, pp. 511-517 (1991).

47. T. Cassagne, and A. Gelpi, Crack Growth Rate Measurements on Alloy 600 Steam Generator Tubing in Primary and Hydrogenated AVT Water, in Proc. of the Sixth Intl. Symp. on Environmental Degradation of Materials in Nuclear Power Systems-Water Reactors, R. E. Gold and E. P. Simonen, eds., The Minerals, Metals, and Materials Society, Warrendale, PA, pp. 679-685 (1993).

48. C. Pichon, D. Buisine, C. Faidy, A. Gelpi, and M. Vaindirlis, Phenimenon Analysis of Stress Corrosion Cracking in the Vessel Head Penetrations of French PWR's, in Proc. of the 7th Intl. Symp. on Environmental Degradation of Materials in Nuclear Power SystemsWater Reactors, NACE International, Houston, TX, pp. 1-10 (1995).

49. F. Vaillant, C. Amzallag, and J. Champredonde, Crack Growth Rate Measurements of Alloy 600 Vessel Head Penetrations, in Proc. of the 8th Intl. Symp. on Environmental Degradation of Materials in Nuclear Power Systems-Water Reactors, S. M. Bruemmer, ed., American Nuclear Society, La Grange Park, IL, pp. 357-365 (1997).

50. L. G. Ljungberg and M. Stigenberg, Stress Corrosion Cracking propagation in Low-Strength Nickel-Base Alloys in Simulated BWR Environments, in Proc. of the 8th Intl. Symp. on Environmental Degradation of Materials in Nuclear Power Systems-Water Reactors, S. M. Bruemmer, ed., American Nuclear Society, La Grange Park, IL, pp. 704-711 (1997).

51. R. M. Latanision and R. W. Staehle, Stress Corrosion Cracking of Iron-Nickel-Chromium Alloys, in Proc. of Conf. on Fundamental Aspects of Stress Corrosion Cracking, R. W. Staehle, A. J. Forty, and D. Van Rooyen, eds., NACE, Houston, TX (1969).

52. S. M. Bruemmer, L. A. Charlot, and C. H. Henager, Microstructure and Microdeformation Effects on IGSCC of Alloy 600, Corrosion, 44, 782 (1988).

53. Foster, J. P., Bamford, W. H., and Pathania, R. S., 1997, Effect of Materials Variables on Alloy 600 Crack Growth Rates, in Proc. of the 8th Intl. Symp. on Environmental Degradation of Materials in Nuclear Power Systems-Water Reactors, S. M. Bruemmer, ed., American Nuclear Society, La Grange Park, IL, pp. 340-348.

54. G. Economy, R. J. Jacko, and F. W. Pement, IGSCC Behavior of Alloy 600 in Water or Steam Tests above $360^{\circ} \mathrm{C}$, Corrosion, 43, 727-734 (1987).

55. C. M. Brown and W. J. Mills, Effect of Water on Mechanical Properties and Stress Corrosion Behavior of Alloy 600, Alloy 690, EN82H Welds, and EN52 Welds, Corrosion, 55 (2), 173-186 (1999).

56. C. M. Brown and W. J. Mills, Fracture Behavior of Nickel-Based Alloys in Water, in Proc. of the Ninth Intl. Symp. on Environmental Degradation of Materials in Nuclear Power Systems-Water Reactors, F. P. Ford, S. M. Bruemmer, and G. S. Was, eds., The Minerals, Metals, and Materials Society, Warrendale, PA, pp. 1-8 (1999). 
57. W. H. Bamford, J. P. Foster, and R. S. Pathania, An Investigation of Alloy 182 Stress Corrosion Cracking in Simulated PWR Environment, in Proc. of the Ninth Intl. Symp. on Environmental Degradation of Materials in Nuclear Power Systems-Water Reactors, F. P. Ford, S. M. Bruemmer, and G. S. Was, eds., The Minerals, Metals, and Materials Society, Warrendale, PA, pp. 279-294 (1999).

58. A. Jenssen, U. Morin, B. Bengtsson, and C. Jansson, Crack Propagation in Stainless Steels and Nickel Base Alloys in a Commercial Operating BWR, in Proc. of the 7th Intl. Symp. on Environmental Degradation of Materials in Nuclear Power Systems-Water Reactors, NACE International, Houston, TX, pp. 553-562 (1995).

59. M. Itow, Y. Abe, A. Sudo, and T. Kaneko, Crack Growth Rates of Alloy 182 in High Temperature Water, in Proc. of the 7th Intl. Symp. on Environmental Degradation of Materials in Nuclear Power Systems-Water Reactors, NACE International, Houston, TX, pp. 541-552 (1995).

60. M. Itow, Y. Abe, S. Hida, H. Sakamoto, K. Takamori, and S. Suzuki, The Effect of Corrosion Potential on Alloy 182 Crack Growth Rate in High Temperature Water, in Proc. of the 8th Intl. Symp. on Environmental Degradation of Materials in Nuclear Power Systems-Water Reactors, S. M. Bruemmer, ed., American Nuclear Society, La Grange Park, IL, pp. 712-721 (1997).

61. L. G. Ljungberg, Stress Corrosion Cracking of Alloys 600 and 182 in BWR Environments Interim Report, EPRI TR-100658, Electric Power Research Institute (1992).

62. L. G. Ljungberg, M. Stigenberg, K. Gott, U. Morin, J. L. Nelson, B. Bengtsson, and C. Jansson, Propagation of Stress Corrosion Cracking in Weld Structures of the Nickel-Base Alloy 182, in Proc. of the Intl. Symp. on Plant Aging and Life Predictions of Corrodible Structures, pp. 911-920 (1995).

63. P. Scott, An Analysis of Primary Water Stress Corrosion Cracking in PWR Steam Generators, Proc. of the Specialists Meeting on Operating Experience with Steam Generators, Brussels, Belgium, pp. 5-6 (1991).

64. A. R. McIlree, R. B. Rebak, and S. Smialowska, Relationship of Stress Intensity to Crack Growth Rate of Alloy 600 in Primary Water, in Proc. Intl. Symp. Fontevraud II, Vol. 1, 261 (1990).

65. C. H. Shen and P. G. Shewmon, IGSCC A Mechanism for Hydrogen-Induced Intergranular Stress Corrosion Cracking in Alloy 600, Met. Trans., 21A, 1261-1271 (1990). 
NRC FORM 335

(2-89)

NRCM 1102,

3201, 3202
U. S. NUCLEAR REGULATORY COMMISSION

BIBLIOGRAPHIC DATA SHEET

(See instructions on the reverse)

2. TITLE AND SUBTITLE

Effects of Alloy Chemistry, Cold Work and Water Chemistry on Corrosion Fatigue and Stress

Corrosion Cracking of Nickel Alloys and Welds

5. AUTHOR(S)

O. K. Chopra, W. K. Soppet,, and W. J. Shack

1. REPORT NUMBER

(Assigned by NRC. Add Vol., Supp., Rev., and Addendum Numbers, if any.)

NUREG/CR-6721

ANL-01/07

3. DATE REPORT PUBLISHED

\begin{tabular}{l|l} 
MONTH & YEAR
\end{tabular}

March 2001

4. FIN OR GRANT NUMBER

W6610

6. TYPE OF REPORT

Technical

7. PERIOD COVERED (Inclusive Dates)

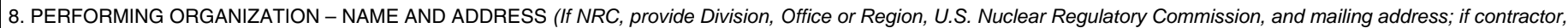
provide name and mailing address.)

Argonne National Laboratory

9700 South Cass Avenue

Argonne, IL 60439

9. SPONSORING ORGANIZATION - NAME AND ADDRESS (If NRC, type "Same as above": if contractor, provide NRC Division, Office or Region, U.S. Nuclear Regulatory Commission, and mailing address.)

Division of Engineering Technology

Office of Nuclear Regulatory Research

U.S. Nuclear Regulatory Commission

Washington, DC 20555-0001

10. SUPPLEMENTARY NOTES

M. B. McNeil, NRC Project Manager

11. ABSTRACT (200 words or less)

Reactor vessel internal components made of nickel-base alloys are susceptible to environmentally assisted cracking (EAC). A better understanding of the causes and mechanisms of this cracking may permit less conservative estimates of damage

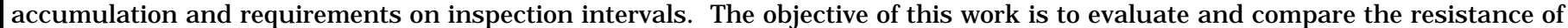

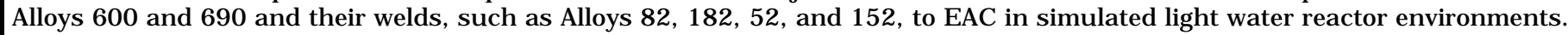

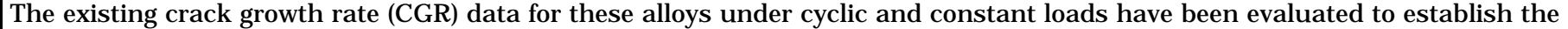

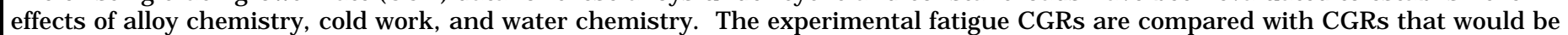
expected in air under the same mechanical loading conditions to obtain a qualitative understanding of the degree and range of

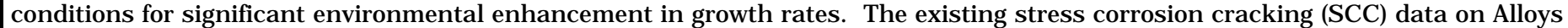

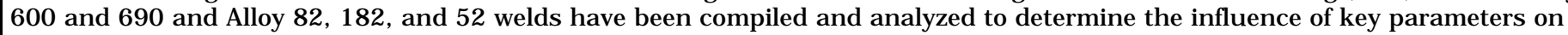
growth rates in simulated PWR and BWR environments. The SCC data for these alloys have been evaluated with correlations developed by Scott and by Ford and Andresen.

12. KEY WORDS/DESCRIPTORS (List words or phrases that will assist researchers in locating this report.)

Stress Corrosion Cracking

Corrosion Fatigue

Crack Growth

Alloy 600

Alloy 690

Alloy 82

Alloy 182

Alloy 52

LWR Environment

\begin{tabular}{|l|}
$\begin{array}{l}\text { 13. AVAILABILITY STATEMENT } \\
\text { Unlimited }\end{array}$ \\
\hline $\begin{array}{l}\text { 14. SECURITY CLASSIFICATION } \\
\text { (This Page) } \\
\text { Unclassified }\end{array}$ \\
$\begin{array}{l}\text { (This Report) } \\
\text { Unclassified }\end{array}$ \\
\hline $\begin{array}{l}\text { 15. NUMBER OF PAGES } \\
\text { 16. PRICE }\end{array}$ \\
\hline
\end{tabular}

NRC FORM 335 (2-89) 